University of Louisville

ThinkIR: The University of Louisville's Institutional Repository

Electronic Theses and Dissertations

$12-2013$

\title{
Resilience in late-life bereavement : disentangling the relationship between resilience and cumulative lifetime loss.
}

Shruti N. Shah

University of Louisville

Follow this and additional works at: https://ir.library.louisville.edu/etd

\section{Recommended Citation}

Shah, Shruti N., "Resilience in late-life bereavement : disentangling the relationship between resilience and cumulative lifetime loss." (2013). Electronic Theses and Dissertations. Paper 1307.

https://doi.org/10.18297/etd/1307

This Doctoral Dissertation is brought to you for free and open access by ThinkIR: The University of Louisville's Institutional Repository. It has been accepted for inclusion in Electronic Theses and Dissertations by an authorized administrator of ThinkIR: The University of Louisville's Institutional Repository. This title appears here courtesy of the author, who has retained all other copyrights. For more information, please contact thinkir@louisville.edu. 
RESILIENCE IN LATE-LIFE BEREAVEMENT: DISENTANGLING THE RELATIONSHIP BETWEEN RESLIENCE AND CUMULATIVE LIFETIME LOSS

\author{
By \\ Shruti N. Shah \\ B.A., University of Louisville, 2006 \\ M.A., University of Louisville, 2010

\begin{abstract}
A Dissertation
Submitted to the Faculty of the

College of Arts and Sciences of the University of Louisville

In Partial Fulfillment of the Requirements

For the Degree of
\end{abstract}

Doctor of Philosophy

Department of Psychological and Brain Sciences

University of Louisville

Louisville, KY

December 2013 

RESILIENCE IN LATE-LIFE BEREAVEMENT: DISENTANGLING THE RELATIONSHIP BETWEEN RESLIENCE AND CUMULATIVE LIFETIME LOSS

By

Shruti N. Shah

B.A., University of Louisville, 2006

M.A., University of Louisville, 2010

A Dissertation Approved on July 24, 2013

by the following Dissertation Committee:

Suzanne Meeks, Ph.D.

Dissertation Director

Benjamin T. Mast, Ph.D.

Barbara Burns, Ph.D.

Jay Irby, Ph.D.

Barbara Head, Ph.D., RN 


\section{DEDICATION}

This dissertation is dedicated to

my parents, Navinchandra and Renuka Shah, for their unconditional support, and my mentor, Suzanne Meeks, Ph.D., for the opportunity to pursue my dream. 


\section{ACKNOWLEDGEMENTS}

I would like to thank my mentors, Drs. Suzanne Meeks and Benjamin Mast, for their endless support, patience and guidance throughout my undergraduate and graduate careers. Both have been sources of motivation and inspiration, and challenged me to grow as a clinician, researcher and professional in ways for which I will always be

grateful. I would also like to convey appreciation to my clinical supervisors, faculty in the Department of Psychological and Brain Sciences and dissertation committee, for your time, support, and willingness to share your knowledge and expertise. This project could not have been conducted without the help of study participants, community leaders and organizations, and the effort put forth by Janna Imel, who went above and beyond her undergraduate research duties to diligently recruit participants and manage the data. I would like to thank all my family, friends, and colleagues, whose unyielding support carried me through each hurdle of graduate school. Finally, I want to express a special shout-out to my cat, Stinky, who kept me company through every draft and grounded me in moments of celebration and uncertainty. I am eternally grateful for you all. 


\begin{abstract}
RESILIENCE IN LATE-LIFE BEREAVEMENT: DISENTANGLING THE RELATIONSHIP BETWEEN RESLIENCE AND CUMULATIVE LIFETIME LOSS
\end{abstract}

Shruti N. Shah

July 24, 2013

Though much of the recent focus in bereavement literature has been examining the nature and correlates of complicated grief, it is important to recognize that many older adults endure bereavements without major disruptions in emotional and daily functioning, despite the likelihood of having experienced numerous losses over a lifetime. This suggests an adaptive or resilient coping style within the context of late-life bereavement. However, much less is known about the underlying mechanisms and correlates that contribute to different bereavement outcomes. Broadly, the aim of this project was to expand our current knowledge of varying bereavement-related outcomes in an effort to enrich the current conceptualization of late-life bereavement. The current study investigated the relationships between cumulative lifetime loss, engagement in resilience-related coping/emotions-regulation strategies (affective complexity, positive emotions, and repressive coping), and resilient and non-resilient bereavement outcomes. A total of 74 recently bereaved, community-dwelling older adults completed study questionnaires assessing a variety of bereavement-related variables, including depression history; history of loss; retrospective affect; current experiences of grief, depression, 
anxiety, and well-being; and social and emotional functioning. Results revealed that cumulative lifetime loss was largely unrelated to bereavement-related outcomes. However, engagement in positive affect one month post-loss and the absence of a depression history were strongly associated with the following resilient bereavement outcomes: lower post-loss depression and grief and unimpaired social and emotional functioning. Although considering an individual's prior experience in coping with loss is an important aspect of the broader conceptualization of his/her current bereavement experience, the results suggest that other factors, such as psychiatric history and emotional engagement, may be more strongly related to resilient outcomes, provide implications for grief-related assessment and help discern who may benefit from grief interventions. In light of some of the methodological issues of this project (i.e. reliance on participants' retrospective report of affect), suggestions for future research involve using a prospective and longitudinal study designs that allows researchers to capture grief reactions as they unfold in an effort to minimize biased recall and examine the effects of co-occurring stressors on the grief process. Future research can also examine the relationships between cumulative impact of having experienced multiple bereavements, lessons learned/wisdom gained in the context of coping with multiple losses, and bereavement outcome. 
TABLE OF CONTENTS

\begin{tabular}{|c|c|}
\hline \multirow{2}{*}{\multicolumn{2}{|c|}{ DEDICATION }} \\
\hline & iii \\
\hline ACKNOWLEDGEMENTS & iv \\
\hline ABSTRACT & $\mathrm{v}$ \\
\hline 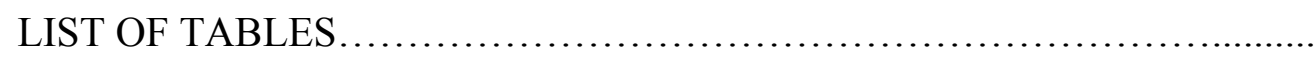 & viii \\
\hline LIST OF FIGURES... & $\mathrm{x}$ \\
\hline 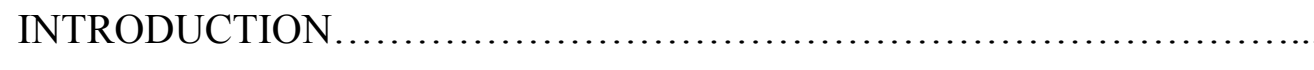 & 1 \\
\hline METHODS............ & 43 \\
\hline RESULTS......... & 60 \\
\hline DISCUSSION... & 80 \\
\hline REFERENCES....... & 100 \\
\hline TABLES....... & 122 \\
\hline FIGURES.............. & 150 \\
\hline … & 151 \\
\hline URRICULUM VITAE... & \\
\hline
\end{tabular}




\section{LIST OF TABLES}

TABLE

Page

1. Recruitment Resources for Study Participants........................ 122

2. Characteristics of Study Participants............................... 123

3. Bereavement Characteristics of Study Participants..................... 124

4. Descriptive Statistics for Key Study Variables for the Whole Sample........ 125

5. Descriptive Statistics for Key Variables for the Target Subsample.......... 126

6. Missing Data for Key Study Variables: Target Subsample................. 127

7. Descriptive Statistics for Imputed Variables: Target Subsample............ 128

8. Missing Data for Key Study Variables: Whole Sample.................... 129

9. Descriptive Statistics for Imputed Variables: Whole Sample.............. 130

10. Kolmogorov-Smirnov Test of Normality: Target Subsample.............. 131

11. Kolmogorov-Smirnov Test of Normality: Whole Sample................ 132

12. Bivariate Correlations between Age and Bereavement Outcomes and

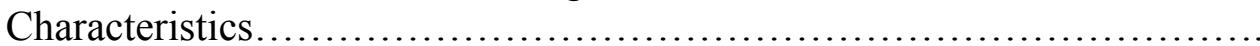

13. Bereavement-Related Variable Means for Males and Females............... 134

14. Bereavement-Related Variable Means for Caucasian and AfricanAmerican Participants...........................................

15. Pearson Correlational Matrix of Outcome Variables: Target Subsample and Whole Sample 
16. Cross Tabulations of Number of Reported Bereavements (Too Little, Moderate, Too Much) and Bereavement Outcome (Resilient and NonResilient) for the Target Subsample...

17. Cross Tabulations of Number of Reported Bereavements (Too Little, Moderate, Too Much) and Bereavement Outcome (Resilient and NonResilient) for the Whole Sample.

18. Correlational Matrix of Emotion Regulation Variables: Target Subsample and Whole Sample...

19. Means of Emotional Regulation and Coping Variables between Resilient and Non-Resilient Grievers for the Target Subsample.

20. Means of Emotional Regulation and Coping Variables between Resilient and Non-Resilient Grievers for the Whole Sample.

21. Logistic Regression Predicting Likelihood of Bereavement Outcome (Resilient or Non-Resilient): Target Subsample...

22. Logistic Regression Predicting Likelihood of Bereavement Outcome (Resilient or Non-Resilient: Whole Sample...

23. Pearson Correlations between Emotion Regulation and Outcome Variables: Target Subsample.

24. Bivariate Correlations between Emotion Regulation and Outcome Variables: Whole Sample...

25. Cross Tabulations of Depression History and Bereavement Outcome (Resilient and Non-Resilient) for the Whole Sample.

26. Means of Emotional Regulation and Coping Variables between Resilient and Non-Resilient Grievers for the Whole Sample....

27. Logistic Regression Predicting Likelihood of Bereavement Outcome (Resilient or Non-Resilient) based on Affective Complexity: Whole Sample.

28. Logistic Regression Predicting Likelihood of Bereavement Outcome (Resilient or Non-Resilient) based on Positive and Negative Affect: Whole Sample. 


\section{LIST OF FIGURES}

FIGURE

1. Proposed Late-Life Comprehensive Bereavement Outcome Framework
Page

156 


\section{CHAPTER 1 \\ INTRODUCTION}

\section{Overview and Aim}

Just as the aging process is often associated with the experience of desirable life events (Norris \& Murrell, 1990) such as grandparenthood and retirement, it is also associated with the experience of less desirable life events, such as the loss of a loved one (Hansson, Hayslip \& Stroebe, 2007). Death rate statistics show that older adults are not only experiencing the greatest number of deaths within their age group compared to their younger counterparts, but also have the opportunity to experience the widest variety of bereavements in terms of type of relationship to the deceased (U.S. Department of Health and Human Services, 2010). Bereavement is defined as the objective condition of having experienced a significant loss (M.S. Stroebe, Hansson, Schut, \& Stroebe, 2008). Late-life bereavements may include death of a spouse, child, peer, sibling, grandchild, etc. depending on the breadth of one's social and familial network.

The death of a spouse may be deemed as one of the most stressful events a married older adult can endure (Whitbourne \& Meeks, 2010), and highly undesirable compared to other adverse life events (Murrell, Norris \& Hutchins, 1984). Prevalence statistics indicate that in 2007 , approximately $29.7 \%$ of U.S. community-dwelling individuals over age 65 were considered to be conjugally bereaved. The percentage of widowed older adults also rises with increasing age, and the trend, according to cohort, is as follows: $17.7 \%$ between ages $65-75 ; 37.5 \%$ between ages $75-84$, and $62.1 \%$ over age 
85. Widowhood occurs more frequently in older women than older men, with estimates nearing $42.2 \%$ for widows and $13.1 \%$ for widowers among U.S. community-dwelling older adults (Federal Intragency on Age-Related Statistics, 2008).

In addition to being a highly probable event, bereavement in older adulthood may result in negative consequences in the areas of emotional, physical, social, and cognitive functioning (Hansson et al., 2007; Parkes \& Prigerson, 2010; M. Stroebe, Schut \& W. Stroebe, 2007). The following is a list of possible negative consequences that have been associated with late-life bereavement: exacerbation of preexisting levels of depression (Gilewski, Farberow, Gallagher, \& Thompson, 1991), increased risk for mortality (Impens, 2005; c.f. M. Stroebe et al., 2007), impairment in physical functioning (Lee \& Carr, 2007), higher levels of financial and global stress (Norris \& Murrell, 1990), emotional and social loneliness (van Baarsen, van Duijn, Smit, Snijders \& Knipscheer, 2001-2002), decline in memory functioning (Aartsen, Van Tilburg, Smits, Comijs, \& Knipscheer, 2005), increased suicide risk (Erlangsen, Jeune, Bille-Brahe \& Vaupel, 2004), higher levels of anxiety if the widowed individual was dependent on the deceased spouse (Carr et al., 2000), and an overall risk for developing a mood disorder (Onrust \& Cuijpers, 2006). Thus, late-life bereavement, an unfortunate and inevitable condition one must endure with age, can be considered a costly condition for an older adults and special attention to this topic is therefore warranted.

One negative consequence that has recently sparked increased interest in the bereavement literature is grief reactions that demonstrate a more complicated or atypical course. Grief has been commonly defined as the complex set of emotional responses to a loss. In a large prospective study including 205 bereaved spouses who were tested prior 
to the death of their spouse, then at 6- and 18-months post-loss, Bonanno and his colleagues (2002) demonstrated that nearly $16 \%$ of their sample showed a pattern of "chronic grief" in which bereaved participants experienced low levels of depression prior to the loss and elevated levels of depression and grief at 6 months post-loss. The chronic grievers also showed elevated grief symptoms at 18 months post-loss. A more difficult grief course was demonstrated by nearly 8 percent of their sample, in which individuals exhibited high levels of depression both pre-and post-loss (Bonanno et al., 2002). Likewise, Ott, Lueger, Kelber, \& Prigerson (2007) found that 17\% of their sample of older bereaved spouses $(\mathrm{N}=141)$ could be classified as chronic grievers if scores on grief and depression measures remained elevated 18 months after the death of their spouses. These studies suggest that patterns of either exacerbation or development of prolonged depressive symptoms following the death of a spouse characterize abnormal bereavement processes, and that these processes are sufficiently prevalent to be of concern. The bereavement literature has referred to these patterns as "complicated grief," broadly defined as an atypical grief reaction associated with persistent and atypical psychological, behavioral and/or functional disturbances following a bereavement event.

Despite the negative consequences associated with bereavement and its possible emotional complications, it has also been empirically verified that the majority of older widows effectively cope with loss. For example, in the same study described above, Bonanno and colleagues (2002) demonstrated that nearly $46 \%$ of their sample endured a pattern of "resilient" grief characterized by minimal levels of emotional and functional distress both prior and following a bereavement. Moreover, nearly $10 \%$ of the sample endured a "common grief" pattern characterized by the absence of or low pre-loss 
depression, an initial peak in depressive symptoms following the loss, and an eventual return to baseline. A decline in depressive symptoms following a loss was demonstrated in about $5 \%$ of the participants who displayed high levels of pre-loss depression. These individuals were considered to follow a "depressed-improved" grief trajectory.

Together, the findings from Bonanno and colleagues (2002) and Ott and colleagues (2007) represent two important conceptual advances in the grief and bereavement literature. First, these studies support the view that grief reactions are heterogeneous and idiosyncratic in terms of intensity, duration, and adaptation to loss (Hansson et al., 2007; Hansson, \& Stroebe, 2007; van Baarsen et al., 2001-2002), as illustrated by the various grief trajectories. As will be discussed in greater detail in the following section, this view calls into question the long-held belief that the process of grief, although considered a universal phenomenon, follows a stage-like, predictable pattern that all bereaved individuals must follow in order to successfully adjust to life after loss. Second, the findings highlight the importance of considering the pre-loss context, such as preexisting depression, in the prediction of varying grief trajectories characterized by resilient or complicated patterns. Differentiating the various grief trajectories has clinical relevance, as it may help identify those at risk for having complications in their grief or individuals who may benefit from professional support. What these studies do not emphasize are the underlying mechanisms that contribute to the differentiation of grief trajectories. More attention within the bereavement literature has been given to enhancing our understanding of the relationships between risk and protective factors, coping mechanisms, and bereavement outcomes through the use of conceptual frameworks and theory. Broadly, the aim of this study was to expand our 
current knowledge of varying grief courses and their underlying mechanisms by drawing upon conceptual ideas and theoretical models within the resilience and bereavement literature. In particular, this study focused on how these concepts contribute to our knowledge of late-life bereavement

\section{Historical and Current Perspectives of Grief and Bereavement}

Grief has long been recognized as a universal phenomenon inherent in the lifedeath cycle of the human experience (Bonanno, Goorin \& Coifman, 2008; Breen \& O'Connor, 2007; Walter \& McCoyd, 2009). The terms grief and mourning, although often used interchangeably, represent two distinct aspects of bereavement. Grief refers to the complex affective response to a loss that is highly individualized in regards to which, to what degree, and for how long affective responses are expressed (Hansson \& Stroebe, 2007). Typical grief reactions are not perceived as static or as having an abrupt ending; instead, grief reactions are viewed as adaptive responses to loss that vary in time and course (Elder, 1995). Mourning, on the other hand, refers to the outward expression of grief that is highly influenced by cultural, societal, and/or religious beliefs and practices (Averill, 1968; M.S. Stroebe et al., 2008). Sigmund Freud's article Mourning and Melancholia (1917/1963; as discussed in Granek, 2010) has been frequently cited in the bereavement literature as being one of the first to discuss possible pathological aspects of

grief. He suggested that the bereaved must endure proper "work of mourning" (Freud, 1917/1963, pp. 166) in order to successfully cope with the loss of a loved one.

Deviations from prescribed patterns or tasks left incomplete were hypothesized to suggest the development of pathological grief. Several years later, other theorists adopted the 
idea of grief work and stage- or task- based models of grief (e.g. Kubler Ross's (1969) Five Stages of Grief and Worden (2009)'s Task Model of Mourning) as a method of tracking grief patterns and determining when intervention may be necessary.

Although the concepts of grief work and stage- and task-models of grief are commonly used methods of conceptualizing grief patterns, several reviews have recognized the dearth of empirical evidence supporting them (Bonanno \& Kaltman, 1999; Breen \& Connor, 2007; Lindstrom, 2002; W. Stroebe, Schut \& Stroebe, 2005; Wortman $\&$ Silver, 1989). Only a few studies found in the literature have explicitly examined the validity supporting stage theory of grief (Holland \& Neimeyer, 2010; Maciejewski, Zhang, Block, \& Prigerson, 2007). For example, Maciejewksi and colleagues (2007) examined grief stage theory based on Jacob's (1993) hypothesis that a typical response to a natural bereavement occurs through a timely progression through the following five stages: disbelief, yearning, anger, depression, and acceptance. Each stage was hypothesized to have separate symptom trajectories, in which the symptoms peak in the aforementioned sequence then gradually subside over time, with the exception of acceptance which gradually increases over time. Disbelief was hypothesized to be the first and dominant grief stage. The sample of 233 individuals (mean age $=62.9, S D=$ 13.1 years; $97.0 \%$ European American; $71.2 \%$ female), from the larger longitudinal Yale Bereavement Study, was tracked in 6-month intervals from 1 to 24 months post-loss. Each participant was administered single items from the Inventory of Complicated Grief - Revised (ICG-R; Prigerson \& Jacobs, 2001), measuring indicators of disbelief, yearning, anger, and acceptance, at each 6-month post-loss interval. Depression was measured using the single-item "depressed mood" from the Hamilton Rating Scale for 
Depression (HRSD; Hamilton, 1960). Frequency of endorsement for each grief indicator was tracked across each assessment interval. The results of the study supported the assumption that typical grief reactions progressed in order of the aforementioned stages, in that the 5 grief indicators reached their respective peaks in sequence as predicted by Jacob's grief stage theory. However, the time each indictor reached its peak did not match the temporal course posited by stage theory, in that the indicators of yearning, anger, and depression peaked closer together between months $4-7$ than was originally hypothesized. Acceptance was found to be the most frequently endorsed grief indicator, followed by yearning. This finding countered the assumption that disbelief is the first and most dominant grief indicator.

Although the study by Maciejewski and colleagues(2007) supports the assumption that typical grief reactions progress via a stage-like process to some degree, solely adopting the stage theory of grief as a method of conceptualizing typical grieving patterns results in several limitations. First, the findings demonstrated that the stages of grief are not as clean and precise, in terms of frequency and duration of symptoms, as stage theory posits. The results showed symptoms of yearning, anger, and depression peak between months $4-7$, and that there was some overlap in symptom endorsement during these months. This counters the assumption that a single grief indictor can define each stage. Second, assuming that most bereaved people adhere to the stage-like progression of grief in a timely, ordered fashion contradicts the widely accepted recognition that grief is heterogeneous and idiosyncratic (Hansson et al., 2007; Hansson, $\&$ Stroebe, 2007). Moreover, the manner in which the grief indicators were measured, using single items from the ICG-R and HRSD, provides a limited scope into 
understanding the grieving process. The perspective is even more limited by the fact that stage theory fails to consider how interpersonal and intrapersonal factors contribute to the progression through the various grief stages. Lastly, stage theory provides limited information regarding grief outcome. For example, can stage theory predict long-term bereavement outcomes based on how successfully a bereaved individual progresses through the various grief stages? Although stage theory is a simple concept and can provide general information regarding what is expected through the grieving process, these limitations call into question the validity and clinical utility of adopting a stagebased model of grief.

\section{Dual-Process Model of Coping with Bereavement}

Recognition of the limitations of task- and stage-based and models of grief and the lack of supportive evidence for these models has resulted in the drive to propose bereavement models with stronger theoretical and empirical bases. For example, Stroebe \& Schut (1999) proposed the Dual-Process Model of Coping with Bereavement. The model was proposed in response to the following limitations of the grief work hypothesis:

(a) it is ill defined; (b) it does not effectively address the psychodynamic (e.g. denial, avoidance, and suppression) and interpersonal (e.g. social support) processes inherent in the grieving process; (c) it is overly focused on health outcomes and neglects the positive outcomes of bereavement; (d) it lacks convincing supporting empirical evidence, and (e) it has questionable generalizability across cultures and between genders (Stroebe \& Schut, 1999). Instead, the Dual-Process Model (DPM) of bereavement focuses on the adaptive challenges and array of emotions bereaved individuals experience while 
grieving. The model considers two types of bereavement-related coping processes: lossorientation (LO) and restoration-orientation (RO). LO processes concern the bereaved person's internal experience of having lost a loved one; they focus on the attachment to the deceased and myriad emotional and behavioral responses such as yearning, rumination, pleasurable reminiscing, despair, and loneliness. In contrast, RO processes are the challenges bereaved persons face secondary to the loss, such as defining new social roles/identities, addressing changes in living arrangements and finances, and acquiring new skills to adapt to life without the loved one. Over time, it is hypothesized that the bereaved individual will spend less time on LO processes and more time engaged in RO (M. Stroebe \& Schut, 2010). DPM also addresses individual differences in bereavement outcome. For example, optimal post-loss adjustment is posited to occur if the bereaved person smoothly oscillates, in terms of avoiding and confronting, between LO and RO processes. Here, the individual can effectively fluctuate between experiencing the affective aspects of grief while addressing the practical challenges associated with bereavement. Difficulties in the grieving process are posited to arise if the bereaved individual has trouble smoothly oscillating between the two coping processes (Stroebe \& Schut, 1999).

Empirical examination of the Dual-Process Model has shown some limited yet promising results. For example, Richardson \& Balaswamy (2001) examined the LO and RO processes of conjugally bereaved older men $(\mathrm{N}=200$; mostly Caucasian) within their second year of bereavement. The sample was divided into two groups: those who were bereaved $<500$ days ("Early Bereaved"; $\mathrm{n}=100$ ), and those who were bereaved $>500$ days ("Later Bereaved"; $\mathrm{n}=100$ ). LO was measured by collecting information about 
circumstances surrounding the loss (e.g. where the wife had died, whether or not she suffered, if she required medical attention, and if he had been warned about her death). Assessment of RO variables focused on the widower's level of social engagement following the loss (e.g. whether or not he was dating, number of friends he had, and degree of interaction with neighbors). Positive and negative affect, assessed by the Affect Balance Scale (Bradburn, 1969), were used to measure psychological well-being. Using two tailed t-tests, the authors found that the Early Bereaved widowers demonstrated significantly more negative and less positive affect compared to the Later Bereaved. Linear multiple regression analyses revealed that (a) certain circumstances, such as losing a wife in a medical setting, predicted higher levels of negative affect in the Early Bereaved group; (b) certain restoration variables, such as level of involvement with neighbors, predicted less negative affect; and (c) restoration variables predicted positive affect in the Later Bereaved group. The findings from Richardson \& Balaswamy (2001) suggest that loss- and restoration-orientation processes occur throughout bereavement, and that these processes influence overall psychological well-being. The results also suggest that loss-oriented processes, such as thinking about the circumstances of the loss, are more salient in the early part of bereavement, whereas restoration-orientation processes gradually become more prevalent over time. Although the study was crosssectional by design and included a homogenous sample in terms of race and gender, the findings suggest that loss- and restoration-orientation processes during bereavement may influence psychological well-being. These findings appear to lend some support to the DPM despite questionable generalizability to widows and bereaved individuals of other cultures and age groups. 


\section{Cognitive Stress Theory}

Another theoretically driven conceptualization of bereavement outcome derives from Lazarus and Folkman's (1984)'s Cognitive Stress Theory (CST). CST addresses an individual's cognitive appraisal of and coping with a stressor. Cognitive appraisal refers to the evaluation of a stressor, usually in terms of personal significance (e.g. harmfulness of the situation to the individual) and emotional demands required to handle the stressor. Stress is posited to emerge when stressors (a) are personally salient; (b) demand emotional resources that are limited or taxing, and (c) are limiting in terms of allowing the opportunity to engage in alternative coping methods. When applied in the context of a bereavement, the loss itself is considered to be the stressor and the bereaved individuals' cognitive appraisals (negative and positive) and coping ability, in terms of handling the emotional tax of enduring a bereavement event, are posited to influence bereavement outcome (Stroebe \& Schut, 1999; M. Stroebe \& Schut, 2010).

Integrative Bereavement Outcome Framework

Together, DPM and CST have contributed to the development of the most comprehensive and theoretically integrative bereavement framework to date (Stroebe, Folkman, Hansson \& Schut, 2006; Hansson \& Stroebe, 2007). The framework considers the relationships between the nature of the bereavement, in terms of loss-orientation and restoration-orientation variables, interpersonal risks factors (e.g. quality of social support, culture and family dynamics), intrapersonal risk factors (e.g. attachment style, intellectual ability and socioeconomic status), and appraisal and coping (e.g. 
positive/negative cognitive appraisals and emotion regulation), in the prediction of shortterm and long-term bereavement outcome (e.g. grief intensity, social reintegration and psychological well-being). Unlike past models of grief (e.g. stage theory or grief work hypothesis) that provide limited information about individual outcome and fail to consider the broader context in which a bereavement occurs, the integrative model proposed by Stroebe and her colleagues allows for a more personalized and comprehensive conceptualization of bereavement outcome. A particular strength of this framework is its attempt to integrate the objective context in which the bereavement event occurred with the behavioral, affective, and cognitive coping processes inherent in the grief experience.

In line with the framework's emphasis on risk factors, van der Houwen and colleagues (2010) examined an extensive pool of risk factors and bereavement-related outcome variables using a longitudinal design. Their sample, the control group for a larger email-based grief intervention study, included 195 bereaved participants who had lost a first-degree relative. The sample was mostly female $(n=180)$, had a mean age of 41.50 years $(S D=10.96)$, and was bereaved for an average of one year. Data were collected via online questionnaires immediately, 3 months, and 6 months after the loss occurred. Risk factors included in the study were based on the following commonly researched predictors: bereavement-related (e.g. cause of death or time since loss), intrapersonal (e.g. age, gender, and religiosity), social/environmental (e.g. social support, professional help seeking, financial circumstances, and medication use). Outcome variables included grief symptoms, depressive symptoms, positive emotions, and emotional loneliness. They measured these variables using the proposed criteria for 
Complicated Grief (Prigerson et al., 2009), Center for Epidemiological StudiesDepression Scale (CES-D; Radloff, 1977), Positive Affect Negative Affect Schedule (PANAS; Watson, Clark, \& Tellegan, 1988), and two questions addressing emotional loneliness rated on a 7-point scale. Overall, using a multilevel modeling strategy, the results indicated that certain risk factors differentially predicted certain outcome measures. For example, an unexpected death of a loved one predicted elevated grief and depressive symptoms, but not emotional loneliness or positive mood. Financial deterioration following the loss predicted grief but not depressive symptoms. Moreover, the findings demonstrated that $24-27 \%$ of the variance across the outcome measures was explained by the bereavement-related, intrapersonal, and social/environmental predictors when analyzed simultaneously (van der Houwen et al., 2010). Together, these findings suggest that the relationship between various risk factors and bereavement outcome is multi-factorial, and that examining risk factors in isolation may mask the effects of possible moderating or mediating variables on various bereavement outcomes.

\section{Pre-loss Conditions}

The value of comprehensively examining how risk factors predict bereavement outcome is demonstrated strongly by van der Houwen et al. (2010), and appears to lend some initial support to Stroebe \& Schut's (1999)'s integrative bereavement framework that emphasizes the various predictive relationships between bereavement-related risk factors and outcome. Underemphasized, however, are the pre-loss conditions that may influence bereavement outcome. In line with the framework's primary aim to identify who may be most vulnerable to experiencing atypical post-loss difficulties, consideration 
of pre-loss conditions (e.g. preexisting psychopathology) has shown to be a strong predictor of post-loss psychological functioning (Bonanno et al., 2002 and 2004).

The prospective study briefly described in the introduction of this paper, Bonanno et al. (2002), highlights the importance of considering pre-loss conditions in the prediction of bereavement outcome. The authors presented data from a larger prospective, multidimensional, multi-wave project: the Changing Lives of Older Couples study of bereavement (CLOC; as described in Carr, Nesse, \& Wortman, 2006), in which a large sample of older adult couples $(\mathrm{N}=1,532)$ residing in the Detroit Metropolitan area were assessed at baseline (pre-loss), then at six, eighteen, and forty-eight months post-loss. The data they analyzed included 205 older widowed individuals (180 widows and 25 widowers) enrolled in the CLOC study. The average age of the sample was 72 years $(S D=6.5)$. Grief symptoms were measured using items derived from three grief measures: the Bereavement Index (Jacobs, et al., 1986), the Present Feelings About Loss Scale (Singh \& Raphael, 1981), and the Texas Revised Inventory of Grief (TRIG; Zisook, Devaul \& Click, 1982). Level of depression, measured by the CES-D, was collected at baseline and each post-loss assessment interval.

Based on the depression and grief measures obtained at baseline and 6- and 18months post-loss, five trajectories of grieving were captured: resilient, common, chronic, depressed-improved, and chronic depression. In particular, those who endured a more difficult grief course demonstrated chronic depression or chronic grief trajectories, in which depression and grief scores remained elevated across the two post-loss assessment waves. The chronic depressed group endorsed elevated scores of depression prior to the bereavement event, whereas the chronic grief group did not endorse high levels of 
baseline depression. Approximately $46 \%$ demonstrated a resilient grief trajectory denoted by low depressive symptoms both pre- and post-loss as well as low grief symptoms 6and 18-months post-loss.

The findings from Bonanno et al. (2002) suggest that consideration of pre-loss depressive symptoms helps discriminate between two particular bereavement outcomes: bereavement-related depression (chronic depression) and CG (chronic grief). Failure to consider baseline depressive symptoms in different grief trajectories may result in the false assumption that the chronically depressed and chronic grievers are the same given their similar post-loss depressive and grief symptomatologies. Individuals with preexisting depression may be at heightened risk for the exacerbation of depressive symptoms following a significant loss, as these individuals may be less emotionally equipped for coping and adjusting to stressful life circumstances. For individuals who did not display pre-loss depressive symptoms, but then experienced elevated grief and depressive symptoms 6- and 18- months post-loss, the bereavement event may have been the trigger for the onset of elevated depressive symptoms. Further examination of preloss factors, such as the quality of the relationship/marriage with the deceased, coping resources (religious affiliations and personality traits), one's world view, and the support system in which the loss occurs has also allowed for better discrimination between chronic grievers and the chronically depressed. Bonanno and colleagues (2002) showed, via one-way ANOVAs and pairwise comparisons, that both chronic grievers and chronically depressed individuals could be linked to higher levels of dependency on the deceased spouse and general interpersonal dependency. Those who were chronically depressed perceived themselves as having poor coping ability, were more neurotic, and 
exhibited a negative world view. Chi-square analyses indicated that chronic grievers were more likely to have had a healthy spouse die and report less instrumental support compared to other individuals. Although these comparisons do not fully explain the specific etiology of CG, they attest to the importance of accounting for pre-loss context, especially in terms of existing depressive symptoms, when distinguishing between bereavement-related depression and CG.

\section{Post-loss Mechanisms}

To further explore the distinctions between the various grief trajectories, Bonanno et al. (2004) examined differences in how they reacted to and processed the loss of a spouse using a prospective design and sample pooled from the CLOC study. Using MANOVA and pairwise comparisons, the authors found that chronic grievers were more likely to search for meaning in their loss, endorse experiences of yearning and emotional pangs, and talk and think about the loss 6-months post-loss. At 18-months post-loss, chronic grievers demonstrated a reduction in how often they thought and discussed their loss, and were more likely to find meaning in the loss. In contrast, chronically depressed individuals did not find meaning in their loss, endorsed experiences of significant yearning and/or emotional pangs, and were less likely to discuss/think about the loss at any time during the assessment intervals. Resilient grievers, on the other hand, were less likely to think/talk about or search for meaning in the loss. They also scored lower on measures of distraction/avoidance following the loss, which is posited to be a sign of better post-loss adjustment rather than deliberate denial. Resilient grievers also were 
shown to experience more comfort from positive memories associated with the deceased spouse.

In line with Hansson \& Stroebe (2007)'s integrative bereavement framework, the findings from Bonanno et al.'s 2002 and 2004 prospective studies demonstrate that consideration of several interpersonal and intrapersonal contextual factors and pre-loss conditions allow for clearer prediction of bereavement outcome. In other words, the process of grief and various late-life bereavement outcomes can best be understood within the affective, cognitive, and supportive context in which the loss occurred. In particular, the pre-loss affective context has been a valuable predictive variable in distinguishing between those who endure a more pathological grief course from those who have a more resilient, healthy form of grief. Recently, most attention has been focused on understanding the risk factors associated with the development of complicated grief since the push to include it as a diagnostic entity in the next edition of the DSM. However, a thorough understanding of resilience in bereavement is also warranted as a way to expand our knowledge of how a large number of bereaved individuals effectively cope with and adjusts to loss. The following section will discuss the concept of resilience within a bereavement context

\section{Resilience in Bereavement}

The construct of resilience has been present in the trauma and developmental literature for decades, but gained increased attention after Werner's (1993) longitudinal study contradicted the common belief that children growing up in adverse environments were doomed to have negative physical and mental health outcomes later in life. Instead, 
Werner found that many at-risk children developed into healthy adults. Given their exposure to negative environments as children, positive outcomes were signs of overcoming negative environmental stressors. These children were described as resilient.

Depending on area of study, the concept of resilience has been defined as a personality trait, an outcome or a process (Greve \& Staundinger, 2006). Within the literature reviewed, resilience consists of "adaptive responses to adversity," (Zautra, Arewaskiporn, \& Davis, 2010, pp. 222). For the purpose of this study, resilience is operationally defined and will be measured as an outcome rather than a manner of describing or measuring inherent personality traits (e.g. Ong, Bergman, \& Boker, 2009) or process. Resilience is argued to be conceptually different from the process of recovery from a traumatic event. The process of recovery "connotes a trajectory in which normal functioning temporarily gives way to threshold or subthreshold psychopathology ...usually for a period of at least several months, and then gradually returns to pre-event levels,” (Bonanno, 2004, pp. 20). In contrast, resilience suggests a rapid and effective return to baseline functioning and ability to sustain normal functioning in the midst of a stressor (Zautra et al., 2010). For example, resilient individuals may experience a slight and transient spike in stress-related psychological symptoms, but are able to quickly resume normal functioning, compared to those who endure a longer recovery process following a stressful event. In other words, resilience is not the mere absence of psychopathology, but is reflective of "the ability to maintain a stable equilibrium ... as well as the capacity for generative experiences and positive emotion" (Bonanno, 2004, pp. 20-22) within the context of a significant risk or an adverse event. 
As previously discussed, the long-held belief that bereaved individuals must actively work through a prescribed mourning process in order to successfully cope with a significant loss has been argued to be limited and weakly validated in the literature. Counter to the concept of stage- or task-based models of grief, Bonanno (2004) argued that experiencing only minimal levels of overt and/or stereotyped characteristics of grief, such as feeling shocked, stunned, or deeply sad or troubled by the loss almost to the point of functional impairment, is more common than is realized. While some have argued that the absence of grief symptoms is indicative of pathological or disordered grief and has been associated with psychological defenses such as denial or inhibition (c.f. Bonanno, 2004), Bonanno suggests grief reactions with absent or minimal emotional and functional distress maybe more reflective of a healthy and stable form of loss-related coping. He posits such reactions can be conceptualized in terms of resilience given the emotional upheaval of having lost a loved one. Beyond describing resilience during bereavement as the absence of post-loss psychological symptoms, the recent literature has also examined possible bereavement-related processes related to a resilient grief reaction. Three possible mechanisms are discussed below.

\section{Affective Dynamics}

In an effort to explain the affective mechanisms involved in a resilient grief reaction, Coifman, Bonanno, \& Rafaeli (2007) studied the affect of 54 bereaved individuals (conjugally bereaved $=44)$ with an average age of 49.8 years $(S D=8.2$ years). The sample was comprised of 33 females, 21 males, and was mostly Caucasian. The premise of the study was based on the Dynamic Model of Affect (DMA; Zautra, 
2003 as cited in Coifman et al. (2007). The DMA posits that the relationship between positive and negative affect is dynamic and complex. During stressful times, when cognitive resources are narrowed, affective complexity between experiencing positive and negative emotions is diminished; the relationship between positive and negative affect has been shown to demonstrate a bipolar, inversely correlated relationship, suggesting less affective complexity (e.g. a person may experience more negative and less positive emotions). In contrast, this relationship has been demonstrated to be bivariate and less inversely correlated during less stressful times, suggesting an increase in affective complexity (e.g. an individual may be experiencing both positive and negative emotions simultaneously) (Zautra, Berkhof \& Nicolson, 2002). Participants in the Coifman et al. (2007) study were interviewed 4 months post-loss. Measures of psychological distress and perceived health were administered to each participant. Physiological arousal (heart rate and skin conductance response rate) was measured using EEG sensors. The researchers also conducted semi-structured interviews in which participants were asked to discuss specified topics related to (a) relationship with the deceased; (b) how they are coping with the loss; (c) a recent negative event; and (d) a recent positive event. The participants were also asked to rate the frequency of experiencing negative affect (guilt, distress and sadness) and positive affect (enjoyment, amusement, and happiness) during each interview segment as a measure of their subjective emotional state. As hypothesized by the DMA, the results indicated that those whose responses indicated resilient coping (e.g. low levels of psychological distress and physiological arousal) showed a significantly weaker inter-affect correlation than those exhibiting more loss-related psychological distress, suggesting that they experienced 
greater affective complexity than the symptomatically bereaved group. Multivariate analyses of variance also revealed that the resilient individuals exhibited more affective complexity than symptomatically bereaved individuals, regardless of their level of coexisting distress. Together, the findings suggest that the affective complexity demonstrated by the resilient bereaved group may be related to participants' ability to regulate their emotional experience and flexibly suppress or express their emotional display within the context of a stressful event. The authors assert that affective complexity moderates the negative effects of stress, allowing these individuals to maintain stable and healthy functioning during bereavement. Thus, affective complexity may be considered a self-regulatory and adaptive process (Labouvie-Vief \& Medler, 2002).

\section{Positive Emotions}

Although much of the bereavement literature has focused on negative bereavement-related consequences and experiences, a growing body of literature has turned its focus to understanding the positive aspects of loss, such as positive emotional experience during bereavement. Despite the gravity of having lost a loved one, the role

of positive emotions during bereavement has been hypothesized to be a beneficial process associated with adaptive coping in the face of bereavement-related stress (Folkman \& Moskowitz, 2000; Ong, Bergeman, \& Bisconti, 2004). For example, laughter and smiling during bereavement (6-months post-loss) has been associated with self-reported reduced anger, increased pleasure and stronger social support (Keltner \& Bonanno, 1997). The authors suggest that positive affect during a stressful event allows the person 
to emotionally distance himself from feeling negative emotion and distress. Others have examined the benefits of humor during bereavement. Similar to the role of positive emotions during stress, humor has been hypothesized to be an adaptive coping mechanism that operates as a buffer against the negative effects of stress, allowing for better adjustment following a stressful event (Kuiper, Martin \& Olinger, 1993). To illustrate, Ong et al. (2004) examined the daily role of positive emotion and humor coping for 34 conjugally bereaved women (mean age $=71.94, S D=6.11$ ) for 98 days, starting approximately 1-month post-loss. Participants completed questionnaires assessing the degree to which they engaged in humor coping to deal with stressful situations and the degree to which they perceive their life as stressed. Ratings of positive emotions and symptoms of depression and anxiety were tracked daily using a diary. The results showed that self-reported symptoms of stress and depression were significantly reduced on days in which there were higher reports of positive emotion. The results also demonstrated that participants who engaged in more humor coping were less likely to endorse daily depressive symptoms and more likely to report daily positive emotions. The authors suggested that humor coping and the experience of daily positive emotion during bereavement may buffer against the negative effects of loss-related stress and help facilitate resilience throughout the bereavement process.

\section{Repressive Coping}

Another mechanism proposed to be involved in a resilient grief reaction is the concept of repressive coping, a type of coping style in which a person, when presented with a threat (e.g. self-evaluation), reports minimal symptoms of distress but 
demonstrates elevated reactivity on physiological responses, such as heart rate or skin conductance (Barger, Kircher, \& Croyle, 1997; Bonanno, Keltner, Holen, \& Horowitz, 1995). Repressive coping has been demonstrated to be an automatic and self-deceptive process that is qualitatively different from deliberate emotional avoidance (Bonanno et al, 1995), and can also be distinguished from a non-repressive coping style by differential responding on measures of trait anxiety and defensiveness. For example, Weinberger, Schwartz, \& Davidson (1979) operationally defined repressive coping as the combination of scoring low on measures of trait anxiety and high on measures of defensiveness.

While some may argue that repressive coping during bereavement may be maladaptive (e.g. Freud, 1915/1957), research has examined the adaptive and resilient qualities of bereavement-related repressive coping. For example, Coifman, Bonanno, Ray, \& Gross (2007) examined the discrepancy between (a) self-reported grief processing and deliberate grief avoidance symptoms, psychopathology, health problems, and somatic complaints and (b) skin conductance response between bereaved individuals $(\mathrm{N}=66)$ and a matched nonbereaved sample $(\mathrm{N}=52)$. The combined sample was mostly female $(\mathrm{n}=$ $75)$, of European American descent $(\mathrm{n}=91)$ and was an average age of 47.3 years $(S D=$ 9.4 years). Participants were asked to engage in a semi-structured interview that addressed topics related to (1) the relationship with the deceased individual for bereaved participants, or the relationship with the spouse for nonbereaved individuals; and (2) the self, or their current coping style and future outlook for bereaved participants or current perspective on their life and future outlook for nonbereaved participants. Participants were also asked to rate how often they felt negative affect during each segment of the semi-structured interview. In addition to participant self-report data, three close friends 
of the participant were recruited to provide information regarding the participant's level of post-loss adjustment. Data were collected 4-months post-loss for the bereaved group, and immediately following enrollment for the nonbereaved group. Longitudinal followup data was collected for bereaved participants 18-months post-loss.

Using the affective-autonomic response discrepancy (AARD), or the measurable difference between minimal self-reported negative affect and elevated physiological arousal indicative of repressive coping, the authors hypothesized repressive AARD scores would be consistent with a more resilient grief reaction as indicated by better postloss adjustment and less endorsement of grief and psychopathologic symptomatology. Separate AARD scores were calculated for each semi-structured interview segment (self and relationship). Regression analyses showed that AARD-self scores significantly and positively predicted concurrent psychopathologic symptoms at 4-months and 18-months post-loss across both bereaved and nonbereaved groups, suggesting that AARD scores consistent with repressive coping were found regardless of bereavement status, and that this remained consistent for the bereaved group over time. Follow-up ratings from close friends showed that bereaved individuals whose AARD scores suggested repressive coping were better adjusted than participants whose AARD scores did not suggest repressive coping. In addition, regression analyses showed that repressive AARD-self scores significantly predicted fewer somatic complaints and a lower likelihood of having a history of respiratory or cardiovascular problems. Lastly, regression analyses did not reveal significant associations between repressive coping behavior and grief avoidance; however a trend towards a positive association between AARD scores and grief 
processing was found, suggesting that repressed bereaved individuals think/talk about the loss less frequently than other bereaved individuals.

In sum, the findings from this study suggest that bereaved individuals whose AARD-self scores suggest repressive coping demonstrated relatively healthy post-loss adjustment according to informant information. They also demonstrated low levels of self-reported negative affect and fewer psychological symptoms. Their findings were also consistent with past research indicating that repressive coping is an autonomic process and does not involve deliberate affective avoidance. Despite increases in physiological arousal, Coifman et al. (2007) suggest that repressive coping may be a protective mechanism involved in a resilient bereavement reaction due to the low levels of reported negative affect and high ratings of post-loss adjustment. Thus, engagement in repressive coping during bereavement, like positive emotions and affective complexity, may allow the individual to remain emotional stable and better apt to handling bereavement-related stress.

\section{Contextual Resilience and Individual Differences}

Although the mechanisms discussed above do not represent an exhaustive list of factors involved in a resilient grief reaction, they are the ones that have received recent attention and demonstrated impressive findings in the bereavement literature. It is important to keep in mind that grief is idiosyncratic and complex and that there may be multiple pathways leading to and various risk/protective factors involved in the prediction of grief reactions (Bonanno, 2004). Specific to resilience, Sandler, Wolchik, and Ayers (2008) adopted a "contextual resilience" (Sandler et al., 2008, pp. 60) 
perspective, which places emphasis on the broader context in which losses occur. This perspective emphasizes the complex relationship between individual differences (e.g. coping efficacy, self esteem, or threat appraisal) and environmental factors (e.g. family dynamics or post-loss stressful events) as determining one's ability to adapt resiliently after a significant loss. The contextual resilience perspective recognizes that resilient outcomes should be predicted from the cumulative effect of multiple pre-and post-loss risk and protective factors, which may represent or influence possible moderating or mediating variables underlying a resilient outcome.

Similar to Hansson \& Stroebe's (2007) integrative bereavement outcome framework previously discussed, Mancini \& Bonanno (2009) have recently proposed a model of resilience during loss that focuses on multiple empirically supported relationships between various individual difference factors and resilience. The model considers the relationships between intrapersonal differences (e.g. personality, capacity for and comfort in positive emotions, identity complexity, and a priori beliefs) and exogenous resources (e.g. financial resources, physical health and cultural beliefs/practices), and their impact on the following individual difference factors: social support (emotional and instrumental), appraisal processes (whether the bereaved individual perceives the loss as threatening or an opportunity for growth), and differences in emotional, behavioral and cognitive coping styles. The authors theorized that cognitive appraisals and social systems operate as indirect moderating processes. Together, both the contextual resilience perspective and resilience during loss model emphasize the importance of considering the broader context of bereavement in the prediction of loss-related outcome. 


\section{Resilience in Late-Life}

While much of the developmental literature has examined the relationships between risk/protective factors and resilient/negative outcomes in children and adolescents, a growing body of literature has turned its focus to understanding how psychological resilience manifests and operates in later adulthood and late-life (e.g. Davis, Zautra, Johnson, Murry, \& Okvat, 2007; Greve \& Staundinger, 2006; Ryff \& Singer, 2003). Contrary to the popular belief that older adulthood is plagued by diminished abilities, loss of friends/family and depression, it has been well documented that the majority of older adults are able to maintain an active and engaged lifestyle despite increased susceptibility to medical problems or decreased cognitive ability (Greve \& Stauginger, 2006; Hildon, Montgomery, Blane, Wiggins, \& Netuveli, 2009).

To illustrate, Hardy, Concato, \& Gill (2004) assessed 546 nondisabled and community dwelling older adults who had experienced a stressful life event (personal illness, death of a friend or family member, illness of a family member or friend or nonmedical event) within the past 5 years. Participants were asked to rate the stressfulness of the event and the stressful event's positive and negative consequences regarding their recovery using an adapted resilience module from a larger study (Asset and Health Dynamics, Soldo et al., 1997 as cited in Hardy et al., 2004). Demographic, medical, functional, and psychosocial information was also gathered for each participant, in addition to scores on the Folstein Mini-Mental Status Examination (Folstein M., Folstein, S., \& McHugh, 1975) and Center for Epidemiological Studies- Depression Scale (CES-D; Kohout, Berkman, Evans, et al., 1993). The results indicated that 212 
subjects were identified as having high resilience, as they scored within the highest tertile on the resilience measure. Bivariate analyses revealed that the following factors were significantly associated with high resilience: male sex, living with others, having few depressive symptoms, high grip strength, good self-rated health status, and independent functional ability. Other indicators associated with resilience in older age included having a wide range of quality social relationships, practical support from and frequent contact with family and friends, and being integrated within the community (Hildon et al., 2009).

\section{Social Support, Emotion, and Coping in Late-Life}

Together, the findings from Hildon and colleagues (2009) and Hardy and colleagues (2004) suggest that resilience may be strongly tied with having a supportive interpersonal context, an area of research that has been extensively studied in the aging population. Work by Carstensen and colleagues have demonstrated that older persons tend to narrow their social networks in order to focus on meaningful, closely knit relationships (Carstensen, Gross, \& Fung, 1997; Charles \& Carstensen, 2010). These researchers argue that proactive selection of one's social network promotes positive emotions and well being in older age (Lang \& Carstensen, 1994).

In a related area of study, research on the emotional processes in older adults suggests that despite age-related changes in emotional and cognitive functioning, coupled with the co-occurrence of stressful life events such as the loss of a loved one, many older adults are able to effectively regulate their emotions (Lawton, Kelban, Rajagopal, \& Dean, 1992), especially when instructed to do so (Phillips, Henry, Hosie, \& Miline, 
2008). They are also able to experience emotional heterogeneity (Charles, 2005), and sustain positive emotions during times of stress (Ong et al., 2004). Gross and colleagues (1997) found that older adults reported fewer negative emotional experiences and were less emotionally expressive compared to their younger counterparts. Carstensen, Pasupathi, Mayr, and Nesselroade's (2000) widely cited study of the daily emotional experience of both younger and older adults provides additional support for the findings cited above. A sample of 184 subjects whose ages ranged from 18 to 94 years was asked to complete an emotion rating for one week. Each participant was given an emotion sampling booklet and instructed to rate the degree to which they were feeling 19 designated emotions, such as anger, joy, happiness, sadness, or guilt, at five randomly chosen times throughout the day. Self-reported measures of general health and personality were also administered to each subject. The older participants demonstrated stability in positive states of emotion $(r=.17, p<0.5)$, and were more likely to sustain the absence of negative emotional states compared to their younger counterparts. However, there were no age differences in frequency or intensity of positive emotional experience. Eigenvalues of emotional ratings across all measurement occasions were calculated to measure the affective complexity for each subject. Age-related differences in emotional poignancy, or the degree to which subjects experienced both positive and negative emotions within one measurement occasion, were found, in that older age was significantly correlated with greater poignancy $(r=.26, p<0.1)$. The authors concluded that emotional functioning is an important facet of life in older adulthood, older adults can simultaneously experience a variety of positive and negative emotions, and negative emotions are better controlled and positive emotions are better sustained with age. 
Age-related differences in emotion regulation and changes in social functioning have been explained by Socioemotional Selectivity Theory (SEST; Carstensen, 1995). SEST posits that older adults tend to optimize positive emotions and dampen negative affect as they age, despite the frequency and breadth of negative experiences. The theory takes into consideration the motivational consequences of perceived time left to live; it can be hypothesized that older adults tend to pursue goals that promote emotional satisfaction and meaning (e.g. fostering meaningful relationships) when death seems near. In contrast, younger individuals focus on acquiring new knowledge (e.g. educational attainment) that will help them in future endeavors, such as securing a job. Within this theoretical framework, the motivational shift from meeting future-orientated goals in younger adulthood to seeking meaningful relationships and sustaining positive emotion in older adulthood may be related to age-related differences in coping style (Lockenhoff \& Carstensen, 2005).

Relationships between emotion regulation and coping behavior are tightly interwoven (Lazarus \& Folkman, 1984), and there is evidence that coping style mediates the emotional experience following a stressful event (Folkman \& Lazarus, 1988). Studies examining differences in coping across various age groups have yielded mixed results, perhaps due to differences in population studied and methodology used to assess coping ability (Amirkan \& Auyeung, 2007; Hamarat, Thompson, Steele, Matheny, \& Simmons, 2002). Consistent with SEST, there is some evidence that older adults utilize emotionfocused coping strategies more frequently than problem-focus coping (e.g. Aldwin, 1991). However, there appears to be general consensus among researchers that absolute shifts in coping strategies, such as total abandonment of certain coping strategies and 
development of others across different developmental stages do not occur as one ages. Instead, evidence suggests that there are relative shifts in how often certain coping strategies are employed across different age groups (Aldwin, Sutton, Chiara, \& Spriro, 1996; Martin, Kliegel, Rott, Poon, \& Johnson, 2008; Amrikan \& Auyeung, 2007; Meeks, Carstensen, Tamsky, Wright, \& Pelligrini, 1989). For example, in a systematic review of the coping literature, Amirkahn \& Auryeung (2007) found that avoidant, support-seeking, and problem-solving strategies were most frequently identified in studies examining coping behavior in children and adult populations. However, in their own examination of coping types across five age groups ( $9-70$ years), the authors found that while all age groups utilize similar coping styles, differences in preference of coping type emerged as a factor of age. For example, preference to use problem-solving strategies increased with age, while avoidant strategies were preferred less with age. Although it has been documented that older adults use fewer coping strategies than younger adults (Meeks et al., 1989), older adults are able to utilize similar external and internal coping resources, such as social support or physical health status compared to younger adults. Older adults also perceive themselves as coping effectively with various stressors compared to their younger counterparts (Hamarat et al., 2002; Meeks et al., 1989). Effective use of coping strategies and resources following a stressful event may be a sign of resilience, especially in the face of co-occurring age-related changes, which may negatively impact daily functioning (Davis et al., 2007; Hansson \& Stroebe, 2007).

\section{Stressful Life Events \& Cumulative Lifetime Adversity}


Older adults face stressful situations spanning a variety of life domains, including physical and mental health, interpersonal, financial, or occupational (Aldwin, 1991; Murrell et al., 1984). In a survey of 603 community-dwelling older adults, Hardy, Concato, and Gill (2002) found that the loss of a family member or friend was the most frequently reported stressful event $(n=254)$, followed by other's illness $(n=138)$, personal illness $(n=108)$, and other nonmedical event $(n=101)$. There was no significant difference in perceived stressfulness across categories, suggesting that participants rated their events as highly stressful, regardless of what type of event they reported (Hardy et al., 2002). Despite perceiving events as highly stressful, a large number of older adults appear to remain resilient when dealing with adverse life events (Bonanno, 2004), especially when they utilize strong and supportive social resources (Hardy et al., 2004; Hildon et al., 2008). They also appear to be consistent in how they cope with stressful events across different life domains (R. Moos, Brennan, Schutte, \& Moos, 2006).

Lazarus (1996) pointed out that the content of the stressor and context in which it occurs may vary greatly across age groups, thereby influencing how different age groups react to the same stressful event (Lazarus, 1996, as referenced in Hansson \& Stroebe, 2007). For example, it is well-documented that younger persons endure more intense grief reactions following conjugal bereavement compared to their older counterparts, and that this age difference may be attributable to the subjective appraisal that death is untimely and unexpected in younger years, and timely and expected in later years (see W. Stroebe \& Schut, 2001 for a review). Aldwin (1991) posited that age-related differences in coping with stressful life events may be the result of differences in the amount of 
experience in enduring adverse events, assuming that increased age indicates increased experience; such knowledge gained from handling past stressful events may help one effectively cope with future stressors. To illustrate, Norris and Murrell (1988) interviewed 234 older adults residing in Kentucky before and after the occurrence of a serious flood. The interview focused on assessing for trait anxiety and weather-specific distress. They demonstrated that prior experience in dealing with a stressor (serious flooding) protected against increased anxiety or weather-related distress following the flood; those without prior experience in dealing with floods showed elevations on both trait anxiety and weather-specific distress that were not present in those who had weathered a prior flood. This finding appears to counter conventional thinking and empirical evidence that multiple adversities, especially those occurring in childhood and/or adolescence, puts individuals at higher risk for having negative outcomes, such as psychopathology (e.g. Turner \& Lloyd, 1995) or alcohol dependence (e.g. Lloyd \& Turner, 2008). Rather than focusing solely on negative outcomes, this line of thinking suggests that there may be advantages to experiencing and managing stressful life events. Advantageous outcomes may include resilience or psychological toughness following future life stressors (Seery, Holman \& Silver, 2010).

While the majority of the studies examining the relationship between adversity and negative outcome focus on the impact of enduring one adverse event, a concept that is starting to receive more attention within the resilience literature is cumulative lifetime adversity, defined as the total number of adverse events experienced by an individual over a defined time period, such as a lifetime. Once again, conventional thinking posits that a positive linear relationship exists between amount of adversity experienced over a 
lifetime and risk for negative outcome. However, as discussed above, prior experience with stressors appears to play a protective role in facilitating more favorable post-stressor outcomes. The concept of cumulative lifetime adversity begs the question of how many adverse events one must experience to predict favorable versus negative outcomes. A study by Seery et al. (2010) is the first to differentiate mental health and well-being outcomes based on individuals with varying amounts of cumulative lifetime adversity. The sample $(\mathrm{N}=2,398$; mean age $=49.3$ years, $S D=16.1)$ was drawn from an internetbased research panel (Knowledge Networks, Inc.), and data were collected longitudinally across five measurement intervals between 2001 and 2004. Each participant completed surveys about their demographic background, mental health history, and personality. Cumulative lifetime adversity was measured using a modified version of the Diagnostic Interview Schedule trauma section (Robins, Helzer, Croughan, Williams, \& Spitzer, 1981, as cited in Seery et al., 2010). The schedule included a list of 37 adverse events (e.g. spouse's death, major fire and physical assault). Participants were asked to report if the each adverse occurred and if so, at what age(s) it took place. Data included measures of global distress, functional impairment, life satisfaction, and post-traumatic stress. The sample reported a mean of 7.69 cumulative adverse events, $S D=6.024$, with totals ranging from 0-71 events. Results showed that greater cumulative lifetime adversity significantly predicted negative outcomes of increased global distress, functional impairment, post-traumatic stress symptoms, and lower life satisfaction. However, when the sample was split between those who endured no adverse events, low lifetime adversity and high lifetime adversity, better outcomes were found for those with a low number of lifetime adversities, compared to those who reported either no adversity 
history or a high number of negative life events. Group assignment was based on the quadratic Lifetime Adversity X Lifetime Adversity interaction, in which no adversity was represented as " 0 " and high lifetime adversity was represented as $\mathrm{M}+1 \mathrm{SD}$ on a standardized adversity scale. Because the low adversity group appeared to have better outcomes overall, the authors suggested that a moderate amount of lifetime adversity may foster resilience in the face of adversity, compared to those without a history of adversity or an extensive adversity history, both of whom reported worse outcomes.

To date, there are no empirical studies that have explored the relationship between the cumulative effect of multiple losses experienced over the lifetime and bereavementrelated outcomes, although the concept of "bereavement overload" (Kastenbaum, 1969, as cited in Hansson \& Stroebe, 2007) is frequently referenced in the bereavement literature. Some speculate that older adults, because of their increased lilkihood of having endured more bereavements over their lifetimes compared to younger adults, will have had more experience in employing various adaptive bereavement-related coping strategies (Hansson \& Stroebe, 2007). Thus, experience with multiple losses over the course of a lifetime may be an important variable in distinguishing age-related differences in bereavement outcome.

\section{Bereavement-Related Psychosocial and Functional Outcomes}

While a significant loss can result in several outcomes spanning a variety of life domains, such as changes in economic status, living arrangements and physical health, this section will focus on outcome variables that have been studied most frequently within the recent bereavement literature. 


\section{Depression}

Aside from grief, post-loss depressive symptomatology has been the most extensively examined bereavement-related outcome due to its overlap with complicated grief (e.g. Boelen, van den Bout \& de Keijser, 2003; Bonanno, 2006; Horowitz et al., 1993; Prigerson et al., 1995a; Prigerson et al., 1996; Prigerson \& Maciejewski, 20052006, Stroebe et al., 2008; Thompson, Tang, di Mario, Cusing, \& Gallagher-Thompson, 2007). For example, Hansson and Stroebe (2007) provide a list of affective, cognitive, behavioral and physiological-somatic reactions to bereavement, including the following symptoms that are also found in depression: sadness, fear, guilt, anhedonia, rumination, helplessness/hopelessness, fatigue, restlessness, crying, withdrawal, appetite loss, and sleep disturbance. Despite the overlap in symptomology, some have argued that complicated grief should be considered a unique construct compared to Major Depressive Disorder, Post-Traumatic Stress Disorder (PTSD), and Adjustment Disorder as outlined by the DSM-IV-TR (Lichtenthal, Cruess \& Prigerson, 2004; Gray, Prigerson \& Litz, 2004). To illustrate, Boelen and van den Bout (2005) administered the Dutch version of the Inventory of Traumatic Grief and the depression and anxiety subscales of the Dutch Symptom Checklist-90 (SCL-90; Arrindell \& Etterma, 2003, as cited in Boelen \& van den Bout, 2005) to a sample of 1,321 self-selected Dutch mourners (mean age $=43$ years; $82 \%$ female). Using confirmatory factor analysis, the authors found three distinct clusters of complicated grief, bereavement-related depression, and anxiety in their model. A moderate correlation was found between factors of complicated grief and depression ( $r$ $=0.78$ ), providing evidence that the symptom clusters represented distinct but related 
constructs. These correlations were similar to those found in other studies examining the overlap of symptoms between depression and complicated grief (Boelen \& Prigerson, 2007; Bonanno et al., 2007; Langer \& Maercker, 2005; Prigerson et al., 2009), suggesting that aspects of depression are very similar, yet distinct from complicated grief. While the discrete boundary between these two constructs is still under empirical scrutiny, symptoms of bereavement-related depression appear to be linked to complicated grief reactions, and thus warrant measurement in examining post-loss outcomes.

\section{Global Functioning}

Level of global functioning has also been a popular outcome in recent bereavement studies, especially those attempting to validate complicated grief as a unique and distinguishable construct from depression and anxiety (e.g. Bonanno et al., 2007;

Prigerson et al., 2009). Global functioning refers to one's ability to maintain functioning across various life domains, including social, occupational, psychological, and physical. Impairment in at least two domains, coupled with elevated symptoms of psychological distress, is usually indicative of psychopathology according to the diagnostic criteria for a mental disorder put forth by the DSM (APA, 2000). Inherent in the distinction between resilient and complicated grief trajectories is the level of functional ability following a significant loss, in which resilient individuals appear to experience minimal functional disruption following a loss and those who endure a more complicated grief course show greater difficulty carrying out everyday activities (Bonanno, 2004; Mancini \& Bonanno, 2009). Thus, level of global functioning following a significant loss may be a critical 
variable in distinguishing between resilient and non-resilient grief courses (Boelen \& van den Bout, 2008; Prigerson \& Maciejewski, 2005-2006; Ott, 2003).

\section{Quality of Life/Well-being}

The concept of quality of life is a frequently discussed variable in both the psychopathology and resilience literatures, and refers to a general sense of well-being or satisfaction with one's life. Within the bereavement literature, differential outcomes in well-being/quality of life have been demonstrated between those with and without complications in their grief (e.g. Prigerson et al., 2009; Ott, 2003). For example, in a study examining the grief patterns of 141 older adults, those who were considered to be resilient grievers reported significantly higher levels of quality of life compared to those who endured a path of elevated grief and depressive symptoms (Ott et al., 2007); generally, a better sense of psychological well-being, especially in the face of a stressful event, may be indicative of resilience (Zautra et al., 2010).

\section{Late-Life Bereavement: A Comprehensive Outcome Framework}

This paper has reviewed the literatures on the theoretical aspects and implications of late-life grief, with most focus on the mechanisms and outcomes differentiating complicated and resilient grief. Unlike other discussions of late-life bereavement that mostly focus on the negative consequences of bereavement, this paper has attempted to broaden our understanding of late-life grief by incorporating a phenomenon that has started to become a popular topic of discourse in the aging literature: resilience. While there may be multiple pathways to resilience in the face of a traumatic event (Bonanno, 
2004), the theoretical models discussed in this paper (e.g. Dual Process Model, Contextual Resilience Model), fail to emphasize the importance of considering pre-loss conditions in the conceptualization of various bereavement-related outcomes. The longitudinal studies by Bonanno et al., 2002, 2004 demonstrate that the presence or absence of pre-bereavement depression can help differentiate between different grief trajectories. In addition, the findings from Seery et al. (2010) suggest that considering number of cumulative lifetime adversities is an important variable in differentiating between who will have positive vs. negative post-event outcomes. Hansson \& Stroebe's (2007) Integrative Bereavement Outcome Framework, which considers the relationships between the nature of the bereavement, interpersonal risks, intrapersonal risk factors and appraisal and coping in the prediction of short-term and long-term bereavement outcome, appears to be the most comprehensive framework that attempts to capture the complexity and multidimensionality of bereavement to date. However, it fails to explicitly emphasize the importance of considering certain pre-loss conditions, such as preexisting depression, in the prediction of late-life bereavement outcome. Building upon Hansson \& Stroebe's (2007) Integrative Bereavement Outcome Framework, a revised framework (See Figure 1) that explicitly considers such important pre-loss variables has been proposed for a more accurate prediction of late-life bereavement outcome (Shah \& Meeks, 2012).

\section{Summary}

This paper has reviewed the bereavement literature, with special emphasis on latelife bereavement and various grief outcomes. This paper has also attempted to integrate 
the concept of resilience, an area of study that focuses on positive outcomes, with an otherwise somber topic. Although the topic of grief has been present in the literature for several decades, its empirical study appears to still be in its infancy. A clear boundary between pathological grief and other outcomes, such as bereavement-related depression, is still undergoing empirical scrutiny. Additionally, and perhaps more alarming, the boundary between uncomplicated and complicated grief still remains quite fuzzy (Hogan, Worden \& Schmidt, 2003-2004); thus research delineating this boundary is greatly needed, especially in the event complicated grief becomes a diagnosable entity.

The research reviewed in this paper suggests that uncomplicated grief may consist largely of individuals whose grief course is resilient. The purpose of this paper is to expand our knowledge of resilient grief. Although the study of complicated grief is vital, it is argued that the bereavement literature is in need of a better understanding of successful grief as well.

The comprehensive late-life bereavement outcome framework proposed by Shah \& Meeks (2012) emphasizes the consideration of pre-loss context, such as prebereavement depression, in the broader conceptualization of bereavement outcome. In line with the framework's emphasis on pre-bereavement context, this study focused on the role of one's history of experiencing loss over the lifetime. Like preexisting depression, can one's breadth of experience in dealing with loss over a lifetime be an important factor in predicting late-life bereavement outcome? While the experience of any loss at any age is a source of sadness, perhaps it can also be a source of growth and sustainability when experienced in moderation. Together, the findings from Seery et al. (2010) regarding cumulative lifetime adversity and the comprehensive late-life 
bereavement framework proposed by Shah and Meeks (2012) served to guide the following research questions and hypotheses:

\section{Research Questions and Hypotheses:}

1) What is the relationship between number of prior bereavements and resilient and non-resilient bereavement outcome following a recent loss?

Hypothesis 1: The number of prior losses will predict resilient versus nonresilient bereavement outcomes. Recently bereaved individuals who have experienced "little" and "too much" loss will have non-resilient post-loss outcomes measured at 6-12 months post-loss, as evidenced by greater depression and anxiety symptoms, lower quality of life/well-being, lower social and emotional functioning, and more intense grief symptoms, compared to those with a "moderate" amount of loss. It is also hypothesized that, in addition to a moderate amount loss, the absence of pre-bereavement depression will improve prediction of resilient versus nonresilient outcomes compared to prediction based on either predictors (history of depression and history of loss) alone.

2) What is the relationship between bereavement-related psychosocial and functioning outcomes and coping and emotion regulation of a recent loss?

Hypothesis 2: Bereavement-related psychosocial and functioning outcomes measured at 6-12 months post-loss will be associated with affective complexity, engagement in repressive coping, and maintenance of positive emotions during the grieving process. Participants' retrospective reports of affective complexity, 
repressive coping, and amount of positive emotion will be associated with a resilient bereavement outcome, as indicated by the following: lower depression and anxiety, higher quality of life/well-being, maintained social/emotional functioning, and lowered grief symptoms.

3) What are the relationships between number of prior losses, resilient and non-resilient bereavement outcomes, and coping/emotion regulation during the most recent bereavement?

Hypothesis 3: The relationship between number of prior losses and bereavement outcomes (resilient and non-resilient) measured at 6-12 months post-loss will be mediated by the following coping/emotion regulation variables during the most recent bereavement: affective complexity, engagement in repressive coping, and amount of positive emotion experience. That is, the benefit of experiencing prior losses is hypothesized to be related to the development of better emotional coping skills. 


\section{CHAPTER 2}

\section{METHODS}

\section{Study Design \& Sample}

This study was retrospective and cross-sectional in design, using a questionnaire and/or interview format. It was approved by the University of Louisville's Institutional Review Board and remained in compliance with approval procedures required by the Human Subjects Protection Program. Recruitment occurred through a variety of community-based resources in and around the Louisville Metropolitan area, including senior housing units, senior centers, an outpatient geriatric clinic, non-profit hospice organizations, aging service companies and government organizations, and local churches, social clubs (i.e. Women's Club), funeral homes, festivals and YMCAs. Trained researchers posted flyers on community bulletin boards frequently viewed by older adults. The researchers also liaised with community organizations to present brief in-services to potential participants to help educate them on grief and bereavement, and increase interest in participating in the project. Inclusion criteria included the following: at least 65 years old, English-speaking and able to provide accurate personal historical information. Each participant must have had a significant bereavement (e.g. loss of a spouse, close family member or close friend) within the past 6-12 months for eligibility. Participants were excluded from the study if they demonstrated evidence of cognitive 
impairment or active psychosis. Questionnaires were administered in an interview format to participants with vision impairments or reading difficulties.

\section{Measures}

Background Information:

Socio-demographic data were collected through self-report, and included the following information: gender, age, racial/ethnic group, marital status, religious affiliation, current living arrangement, education level, employment status, and household income. Information related to the participant's most recent bereavement was also requested, including relationship to the deceased, mode of death, and time since death. The background information sheet is located in Appendix A.

\section{Pre-Bereavement Predictive Variables:}

\section{History of Loss}

Information regarding the participant's history of loss, prior to the most recent bereavement was gathered via self-report using questions from Section 2 "Before the Death of Your Loved One" of the Grief Evaluation Questionnaire (GEM). The GEM is a 9 page self-report questionnaire designed to comprehensively measure grief severity and has a specific aim for detecting individuals at higher risk for having complications in their grief. It is comprised of 7 sections, each designed to assess a specific aspect of one's bereavement. Only two sections (the "Experiences" and "Problems" sections, which measure grief distress and post-loss physical and psychological symptoms) were analyzed in the GEM's initial validation study, both of which demonstrated sound psychometric properties. Currently, the GEM is the only published measure to include 
detailed questions regarding the respondent's history of loss. More specifically, within Section 2, respondents are asked to list all the loved ones in their life who have passed away and include the relationship category (e.g. parent, child, sibling) and year of death. Respondents are also instructed to provide subjective ratings of the impact of the death. Ratings are made along a 6 -point scale $(1=$ none to $6=$ very great $)($ Jordan, Baker, Matteis, Rosenthal, \& Ware, 2005). Participants in this study will be asked questions regarding their bereavement history using similar language and chart-response format from Section 2 (see Appendix B). Number of losses noted by each participant were counted by tallying how many losses were listed.

\section{History of Depression}

History and treatment of depression prior to the participant's most recent bereavement was screened using questions similar to those used by Vahia et al. (2010), in a study examining the relationship between subthreshold depression and perceived successful aging. They used four screening questions with a sample of communitydwelling older adult women. The questions were presented in a yes/no format, and participants were asked if they had ever been (1) "diagnosed with a mental or emotional problem" (2) "in treatment with a mental health professional" (3) "prescribed medication for a mental or emotional problem" and (4) "hospitalized for such a problem" (Vahia et al., 2010, pp. 215). Results showed the questions helped to distinguish between those with clinical depression, subthreshold depression, and no depression as measured by the

CES-D. In particular, participants with clinically significant depression were more likely to report positively across all four questions than those classified as having subthreshold 
or no depression. Those with subthreshold depression were more likely to report a history of diagnosis and medication use than those without a depression diagnosis. Thus, such screening questions may be useful in distinguishing between participants with and without a history of depression. For the purpose of this study, participants were instructed to answer the questions using the preceding statement, "Prior to your most recent bereavement, have you ever been..."

Additional information regarding history of depression prior to the most recent bereavement was also assessed using a modified version the Mood Episodes section of the Structured Clinical Interview for DSM-IV-TR Axis I Disorders, Non-Patient Research Version (SCID-I/NP; First, Gibbon, Spitzer, \& Williams, 2002). The SCID is a well-established structured interview designed to help clinicians and researchers accurately diagnose mental disorders based on DSM diagnostic criteria. The Past Major Depressive Episode section within the Mood Episodes module was modified in order to screen for pre-bereavement depression, and was administered using a self-report format. The standardized language used in the SCID was preserved, following a similar yes/no and follow-up question response style (see Appendix C).

\section{Coping \& Emotion Regulation Variables:}

\section{Repressive Coping}

Based on the operational definition put forth by Weinberger et al. (1979), those with a repressive coping style demonstrate the combination of low levels of subjective trait anxiety and high levels of subjective defensiveness. An inverse relationship between trait anxiety and defensiveness has been shown to predict a repressive coping style, measured by avoidance or denial of threatening/disturbing cognitions and elevations in 
physiological measures of anxiety (e.g. heart rate and sweat gland activity) despite low levels of self-reported anxiety following a stressful experiment. The discrepancy between the subjective report of emotion and cardiovascular arousal has been labeled as the verbal-autonomic response dissociation (Newton \& Contrada, 1992), and has shown to be related to a repressive coping style under a variety of experimental conditions (e.g. Asendorpf \& Scherer, 1983; Coifman et al., 2007; Derakshan \& Eysenck, 2001; Newton \& Contrada, 1992). For example, Weinberger et al.'s participants engaged in phraseassociation task in which they were instructed to complete sentences, some of which contained sexual or aggressive content. They then filled out self-report measures of trait anxiety and defensiveness. Measures of behavioral (reaction time and verbal interference) and physiological (heart rate and skin conductance) arousal were assessed throughout various points in the experiment. The results indicated that those identified as having a repressive coping style (self-report of low trait anxiety and high defensiveness) demonstrated significantly greater physiological arousal than those identified as lowanxious subjects (self-report of low trait anxiety and low defensiveness). Repressive copers were also more likely to have more speech interferences, which the authors suggested was a behavioral sign of emotional arousal. Together, the findings suggest that level of defensiveness may be able to distinguish between individuals with low levels of self-reported anxiety reflective of a repressive coping style from those who are just low in trait anxiety.

In the absence of physiological data, researchers have identified repressive copers from non-repressive copers based on score discrepancies on self-report measures of trait anxiety and defensiveness (e.g. Erskine, Kvavilashvili, Conway \& Myers, 2007; 
Weinberger et al., 1979). The Speilberger State-Trait Anxiety Inventory (STAI; Speilberger, Gorusch, Luschene, Vagg, \& Jacobs, 1983) and Marlowe Crowne Social Desirability Scale (MC; Crowne \& Marlowe, 1960) are two of the most widely administered scales used to identify repressors. Classification between repressors and non-repressors (e.g. low anxious and low defensive individuals) has been measured using either the sample's median or quartile splits between the scores on a trait anxiety measure and the MC. Weinberger et al. (1979) used the quartile split method, in which they classified repressors as those who scored above the upper quartile on the $\mathrm{MC}$ and below the lower quartile on anxiety. The quartile-split technique was also employed in a study comparing repressive coping in younger and older adults, in which those who scored below a 36 on the STAI and above a 19 on the MC were identified as repressors (Erskine et al., 2007). While different identification techniques may lead to more lenient or stringent classification criteria, thus leading to identifying different people in each group (Myers, 2000), similar results have been found regardless of which identification method was employed (Boden \& Baumeister, 1997; Erskine et al., 2007). For the purpose of this study, the typological method of using the sample's quartile splits suggested by Weinberger et al. (1979) and used in subsequent studies was used to identify individuals with a repressive coping style.

\section{Speilberger State-Trait Anxiety Inventory, Trait Form}

The State-Trait Anxiety Inventory, Form Y-2 (Trait Anxiety scale) is a commonly administered tool designed to measure enduring, trait-like anxious symptomatology. This scale is part of a larger measure that assesses for both state and trait levels of anxiety 
(STAI, Form Y-). The Trait-Anxiety scale is comprised of 20 items, and ratings for each item are made along a 4-point scale, ranging from "not at all" to very much so." Scores range from 20-80, and higher scores suggest greater symptom endorsement (Speilberger et al., 1983). The measure has demonstrated excellent internal consistency and test-retest reliability over a period of 2-4 weeks (Coefficient $\alpha$ 's $=.79$ and .84 , respectively) in a control sample of community-dwelling older adults (Stanley, Beck \& Zebb, 1996). Similar coefficients have been found in older adult psychiatric patients (Himmelfarb \& Murrell, 1983; Kabacoff, Segal, Hersen \& Van Hasselt, 1997; Stanley, Novy, Bourland, Beck, \& Averill, 2001). The Trait-Anxiety scale demonstrates convergent validity through significant correlations with the State form (S-Anxiety) of the STAI-Y $(r=.74)$, and other scales measuring worry $(r=.57)$, obsessions and compulsions $(r=.57)$, and fear $(r=.43)$ (Stanley et al., 1996).

\section{Marlow Crowne Social Desirability Scale}

The Marlowe Crowne Social Desirability Scale (MC) is a measure used to assess affect inhibition and defensiveness related to social desirability, independent of psychopathology. It is comprised of 33 items, and each item is answered using a true/false format. Items are designed to measure behaviors that are "culturally sanctioned or approved but which are improbable in occurrence," (Crowne \& Marlowe, 1960, pp. 350). Examples include "I never deliberately said something that hurt someone's feeling" or "I sometimes I try to get even rather than forgive and forget." Internal consistency in the measure's initial validation study was excellent (coefficient $\alpha=.83$ ), as was test-test reliability (coefficient $\alpha=.89$ ). The $\mathrm{MC}$ also demonstrated convergent 
validity with significantly high correlations with scales from other measures of

personality and social desirability (Crowne \& Marlowe, 1960). Although the MC is still awaiting validation in a geriatric population, older adults have been shown to score higher on the MC, indicating increased social desirability with age (Erkskine et al., 2007; Soubelet \& Salthouse, 2011).

Affective Complexity \& Positive Emotions:

Positive and Negative Affect Schedule

Retrospective recall of positive and negative emotions during each participant's most recent bereavement was assessed using the Positive and Negative Affect Schedule (PANAS). The scale consists of two 10-item mood scales, one measuring positive affect (PA; interested, excited, strong, enthusiastic, proud, alert, inspired, determined, attentive, and active) and the other measuring negative affect (NA; distressed, upset, guilty, scared, hostile, irritable, ashamed, nervous, jittery, and afraid). Respondents are to estimate the extent to which a certain mood is felt during an indicated time frame using a 5-point rating scale ranging from $1=$ very slightly or not at all to $5=$ extremely. Indicated time frames include the following: this moment, today, past few days, week, past few weeks, year, and in general. Higher scores on each scale suggest higher levels of positive or negative affect (Watson, et al., 1988). For the purpose of this study, participants will be instructed to estimate their positive and negative affect for two time frames: one-month post-loss and at the time the measure is completed. Both scales have demonstrated excellent internal consistencies for all times frames, with Cronbach alpha's ranging from .86-.90 for PA, and .84-.87 for NA. Test-retest reliability correlations (over an 8-week 
interval) revealed that both scales are relatively stable across all time frames, ranging from .47-.68 for PA and .39-.71 for NA. The general time frame demonstrated the highest test-retest correlations, with .68 for PA and .71 for NA (Watson et al., 1988). The PA scale demonstrated divergent validity with significant negative correlations with measures of depression and trait anxiety $(r=-.44$ and $r=-.49$, respectively $)$ in a sample of older adults with generalized anxiety disorder. The NA scale showed significantly negative correlations with measures of depression and trait anxiety $(r=-.39$ and $r=.45$, respectively) in the same sample, suggesting adequate convergent validity (Beck et al., 2003). Affective complexity was determined based on the degree of association between the PA and NA scales, in which lower interaffect correlations suggest greater affective complexity (Coifman et al., 2007). Positive emotions were measured using only the PA scale, in which higher PA scores suggest greater positive emotions.

Outcome Measures: For the purpose of this study, resilience is operationally defined as an outcome to experiencing an adverse event, and was assessed based on a combination of various outcomes that have been demonstrated to be related to post-loss psychosocial functioning: lower grief and depression and maintained well-being and social and emotional functioning. The following measures were used to assess these bereavementrelated outcomes:

Inventory of Traumatic Grief

The Inventory of Complicated Grief (ICG) is a questionnaire designed to assess for maladaptive symptoms of grief that are "clearly distinguishable from the symptoms of depression and anxiety" (Prigerson et al., 1995b, pp. 66). In its original version 
containing19 items in which respondents are to rate the degree to which each statement represents their grief experience along a 5-point scale ("almost never" to "always"), the ICG demonstrated excellent internal consistency (Cronbach's $\alpha=0.94$ ), and test-retest reliability of 0.80 over six months of bereavement. Validity was demonstrated with significant and slightly high correlations with a measure of depression $(r=0.67)$, grief $(r$ $=0.87)$, and another measure of maladaptive grief $(r=0.70)$. It has also shown adequate predictive validity with sensitivity of .93 and specificity of .93 (Prigerson et al., 1999). Inventory of Traumatic Grief (ITG), also called the Inventory of Complicated Grief- Revised, is the expanded and revised version of the ICG. It is commonly used as diagnostic tool based on the consensus criteria for complicated grief (Prigerson \& Jacbos, 2001). The ITG consists of 34 declarative statements in which responses are made along a 5-point Likert-type scale. As a whole, the ITG assesses grief along the following five criteria for complicated grief:

Criterion A1: Whether the individual has experienced a significant death.

Criterion A2: Measures the frequency of 5 symptoms of separation distress (e.g. "I feel drawn to places associated with " or "I feel myself longing and yearning for ." These items are measured along a 5 -point scale $(1=$ "Almost never" and $5=$ "Always"). In order to meet criteria for complicated grief, the respondent must obtain a score of 4 or greater on at least 3 symptoms of separation distress. These items are noted by an asterisk in the measure.

Criterion B: Measures the intensity or frequency 12 symptoms of traumatic distress (e.g. "I feel stunned, dazed, or shocked over ___'s death" or "I hear the voice of speak to me." These items are also measured along a 5-point rating scale, with higher scores indicating greater frequency or intensity. In order to meet criteria for complicated grief, the respondent must obtain a score of 4 or 
higher on at least 6 symptoms of traumatic distress. These items will be noted by an asterisk in the measure.

Criterion C: Duration of symptoms (in months)

Criterion D: Level of functional impairment associated with grief symptoms, rated using a 5 -point scale $(1=$ "No functional impairment" and $5=$ "Extreme"

The ITG uses symptoms of grief that are similar to those measured in its original version. It has also been shown to be internally consistent (Cronbach's alpha $=94)$ and stable across test-retest intervals of 9-28 days (test-retest correlation $=.92$ for total score). Predictive validity with diagnosing complicated grief has also been adequate with a sensitivity of $86 \%$ and specificity of $76 \%$ (Boelen, van den Bout, de Keijser \& Hoijtink, 2003). For the purpose of this study, level of grief was measured using the sum items 130, with higher scores indicating greater grief symptomatology. Participants who met the requirements outlined in Criteria A2 and B were considered to have elevated grief symptomatology.

Geriatric Depression Scale - 15

The Geriatric Depression Scale (GDS) is a well-established and widely administered self-report tool for detecting depressive symptomatology in older adults. It assesses for 30 symptoms of depression, and respondents are required to answer each item using a yes/no, forced-choice format (Brink, et al., 1982). The 30-item version of the GDS has demonstrated excellent internal consistency (Cronbach's $\alpha=.94$ ) and has been shown to be very reliable (split-half $=.94$; Yesavage et al., 1982). In a systematic review of criterion validity, Wancata, Alexandrowicz, Marquart, Weiss, \& Friedrich (2006) found the GDS-30 to have a sensitivity of 0.753 and specificity of 0.770 across 
variety of settings and populations. The 15-item version of the GDS was used in this study (Sheihk \& Yesavage, 1986). It has been shown to correlate highly with the full version ( $r=.89$; Lesher \& Berryhill, 1994). The sensitivity, specificity, positive predictive value and negative predictive value for detecting depression according to DSM criteria are as follows: $90.9 \%, 64.5 \%, 73.2 \%$, and $86.9 \%$, respectively. These values were found using a 5/6 cut-off score, in which scores below 6 indicate the absence of clinically significant depression and scores above 5 suggest the presence of clinical depression (Almeida \& Almeida, 1999).

\section{Ryff's Scales of Psychological Well-Being}

Based on a multidimensional model of well-being, Ryff \& Keyes (1995) devised a scale to assess 6 theoretically derived constructs of psychological well-being: self acceptance, personal growth, positive relations with others, purpose in life, environmental mastery, and autonomy. Respondents are prompted to rate statements indicating their degree of agreement, ranging from $1=$ strong disagreement and $6=$ strong agreement Responses are summed for each category; a higher score within a category suggests that the respondent has increased mastery or well-being that that domain. Internal consistency coefficients for the six scales have ranged from $.33-.56$, indicating low to modest correlations. Predictive validity has been demonstrated through negative associations with measures of psychological distress (Abbott et al., 2006) and depression $(r=.22-.70)$ in addition to positive correlations with happiness $(r=.16-.54)$, life satisfaction $(r=.21-.64)$ (Ryff, Lee, Essex, \& Schmutte, 1994). To minimize the burden on the elderly participants in this study, a shortened version of the parent scale 
consisting of 3 items from each scale (total of 18 items across scales), will be used in this study. It has been significantly correlated with the 20 -item original scales $(r=.70-.89)$ (Ryff \& Keyes, 1995), and has been used in various large-scale international and national surveys. Cut-points for discriminating between high and low well-being has not been established. For the purpose of this study, those with high-well being were defined as scores that are one standard deviation above the sample's mean on at least one out of 6 domains.

\section{Dartmouth COOP Scales of Functioning}

The Dartmouth COOP Scales of Functioning is a tool used to quickly assess functional status across 8 life domains, including daily activities, emotional status/feeling, overall condition, pain, physical fitness, social activities/social support, quality of life, and change in health status. Respondents are presented with 8 domainspecific charts. Each chart includes a descriptive title representing the domain being assessed (e.g. "Emotional Status"), a question regarding the domain, and a chart that pictorially and verbally depict responses to the question along a 5-point scale. Higher scores indicate worse functional status within the domain being assessed (Nelson et al., 1987). Due to its ease of use and brevity, the COOP charts are frequently administered to assess functional status in older adults. Specific to elderly patients, the charts have evidenced Cronbach alphas ranging from $.42-.90$, and test-retest correlation of .93 (Haywood, Garratt, \& Fitzpatrick, 2005), indicated adequate reliability. Validity of the charts has been demonstrated through adequate comparison to other measures of functional status, with overall inter-correlations ranging from .60-.70 (Beaufait et al., 
1992). For the purpose of this study, only the emotional status and social activities/social support charts were used to assess social and emotional post-loss functioning. Scores of 1-2 on both scales were interpreted as unimpaired post-loss social and emotional functioning.

Based on the findings discussed in the background section, a resilient outcome was described as having the following bereavement-related characteristics: absence of post-loss depression, maintained post-loss social and emotional functioning, non-elevated grief scores, and maintained post-loss quality of life/well-being. Each study hypotheses required the sample be categorized into "resilient" and "non-resilient" grieves to allow the proposed comparisons between these two groups. In order to be coded as "resilient," the case must have met the four following criteria: GDS scores at or below 5, scores of at least 1 SD's above the sample's mean for 1 out of 6 Ryff scales, and scores of 1-2 on both COOP charts (Criteria A, C, and D, respectively). The case also could not meet Criteria A2 and B on the ITG, indicating an uncomplicated level of grief. All cases that did not meet the criteria A - D were coded as "non-resilient." The coding rubric is presented below:

\begin{tabular}{|ll|l|}
\hline \multicolumn{2}{|l|}{ Criteria for Resilient Grief: } & \\
\hline A. & Post-Loss Depression & $\leq 5$ on the GDS \\
\hline B. & Grief & $\begin{array}{l}\text { Does not meet Criteria A2 and B on the } \\
\text { ITG }\end{array}$ \\
\hline C. & Well-being & $\begin{array}{l}\text { Scores of at least 1 SD above the sample's } \\
\text { mean for 1 out of 6 Ryff scales }\end{array}$ \\
\hline D. & Functional Status & Scores of 1-2 on both COOP charts \\
\hline
\end{tabular}




\section{Procedures}

Persons recruited from advertisements or referrals were given a description of the study via telephone. Those interested in participating who also met inclusion criteria were provided information regarding the consent form, either in person or over the phone. In the event recruitment occurred on-site, such as at a congregate housing facility or senior center, an investigator explained the consent form in person. Most study packets were completed independently, in which case the questionnaire packet was usually mailed to the participant (if not recruited on-site), along with a self-addressed, stamped envelope ready for return or collected at a mutually determined location (i.e. recruitment site). Participants were encouraged to call the researchers to assist them in answering any study questions. Approximately fifteen study packets were completed at a mutually determined time and location if the participant preferred to complete the packet alongside a trained researcher. Completion of the study packet took approximately $60-90$ minutes.

\section{Power Analyses \& Sample Size}

\section{Hypotheses 1 \& 3:}

The relationship between number of bereavements experienced over the lifetime and mental health outcomes and coping processes has been understudied. Prior research relating amount of cumulative lifetime adversity with global distress, depression, anxiety, well-being, and functional status has revealed a small-to-medium effect size $\mathrm{f}^{2}=.252$ using multiple regression. G*Power analyses revealed that a sample size of 57 was needed to detect this effect size with a power of .80 and an error rate of .05 for a two- 
tailed multiple regression analysis (G*Power; Faul, Erdfelder, Lang, \& Buchner, 2007). Hypothesis 1 involved examining the relationship between two categorical variables: resilient vs. non-resilient grief, and number of prior losses. G*Power analyses determined that a sample size of 108 would be necessary to detect a medium effect $(\mathbf{w}=$ $.30)($ Power $=.80$, alpha $=.05)$ for a $3 \times 2$ chi-square analysis $($ degrees of freedom $=2)$. Hypothesis 1 also involved examining the relationship of history of depression and loss with bereavement outcome. G*Power analyses determined that a sample size of 88 was needed to detect a medium effect $(\mathrm{w}=.3)($ Power $=.80$, alpha $=.05)$ for a $2 \times 2$ chi-square analysis (degrees of freedom $=1)$.

Hypothesis 1 also involved computation of a logistic regression analysis with two categorical variables (history of depression and number of prior losses) in the prediction of a binary outcome (resilient versus non-resilient grief). Prior research has used ANOVA to examine the relationship between history of depression and various grief outcomes, and has revealed a large effect size $(\mathrm{f}=.84)$ for pre-loss depression. Assuming that an absence of depression history and a moderate amount of loss will result in a higher likelihood of having a resilient grief reaction than the $46 \%$ found in previous research, a sample size of 54 would be needed to detect a high odds ratio using logistic regression $($ power $=.80, \alpha=.05)$.

Hypotheses 2 \& 3:

These questions concerned the relationship of resilience with affective complexity, repressive coping and positive emotions. Prior research has suggested medium effect sizes for these relationships using various statistical analyses (tabulated below). 


\begin{tabular}{|l|l|}
\hline & Effect Size \\
\hline $\begin{array}{l}\text { Affective Complexity } \\
\text { (Coifman, Bonanno \& Rafeli, 2007) }\end{array}$ & $\mathrm{d}=.56$ \\
\hline $\begin{array}{l}\text { Positive Emotions } \\
\text { (Ong Fuller-Rowell, \& Bonanno, 2010) }\end{array}$ & $\mathrm{r}=.41$ \\
\hline $\begin{array}{l}\text { Repressive Coping } \\
\text { (Coifman, Bonanno Ray, \& Gross, 2007) }\end{array}$ & $\mathrm{d}=.57$ \\
\hline
\end{tabular}

A logistic regression analysis involving 3 independent variables and one binary outcome variable was required for Hypothesis 2. G*Power analyses suggest a sample size of 66 is needed to detect a medium odds-ratio using two-tailed logistic regression ( $\alpha$ $=.05$, power $=.80)$. Based on all of the above power analyses, a total sample size of 108 was needed in order to detect at least a medium effect size for all statistical analyses proposed in this study (power $=.80$, alpha $=.05$ ). Due to challenges in recruitment, this ideal $\mathrm{N}$ was not attained; thus, the sample size was underpowered for some analyses. 


\section{CHAPTER 3}

\section{RESULTS}

\section{Sample Demographics}

Data were analyzed using IBM SPSS 20.0 (IBM Corp., 2011). Approximately 280 study packets were assembled and distributed to a wide array of recruitment sources in and around the Louisville Area. Of the 280 packets distributed, 74 were returned either in person or by mail, yielding a response rate of $26.43 \%$. Table 1 displays the recruitment sources for the study sample, split between those who completed the study packet 6-12 months after their most recent bereavement $(n=26$; these individuals will be referred to as "Target Subsample") and the entire sample $(\mathrm{N}=74)$, which included individuals in the "Target Subsample" and participants who did not meet the 6-12 postloss time criteria. Of the 26 participants within the Target Subsample, 30.8\% were recruited from local senior centers, $23.1 \%$ were recruited through a local non-profit hospice organization, $19.2 \%$ responded to a study announcement via social media (i.e. university email advertisement and recruitment flyers), 7.7\% were involved in a grief support group, and $7.7 \%$ were referred through a physician's office. Three participants $(11.5 \%)$ did not report their recruitment source. Overall, the majority of the whole sample was recruited through senior centers, the local non-profit hospice organization and social media outlets. 
The demographic characteristics of the participants are presented in Table 2. The average age for all participants was 71.68 years $(S D=8.39)$, and those who were bereaved in the last 6-12 months were on average 70.73 years of age $(S D=6.58)$. The majority of participants that were bereaved within the last 6-12 months of completing the study packet $(\mathrm{n}=26)$ were Caucasian $(88.5 \%)$ and female $(84.6 \%)$, which is a common for bereaved research samples (e.g. Bonanno et al., 2002; van der Howen et al., 2010). The majority of these individuals were also widowed (73.1\%), living alone (53.\%), educated beyond high school (61.5\%), retired (57.7\%), and reported having a yearly income between $\$ 20,000-59,000(50.0 \%)$. There was not a significant difference in mean age between the Target subsample and the 48 participants who did not meet the 612 months bereaved time criteria $[t(72)=.50, p>.05]$. Additionally, these two groups were similar in terms of gender $\left[\chi^{2}(1, \mathrm{~N}=73)=.03, p>.05\right]$, race $\left[\chi^{2}(2, \mathrm{~N}=72)=.62, p\right.$ $>.05]$, marital status $\left[\chi^{2}(4, \mathrm{~N}=73)=4.94, p>.05\right]$, education $\left[\chi^{2}(4, \mathrm{~N}=72)=3.54, p>\right.$ $.05]$, employment status $\left[\chi^{2}(4, \mathrm{~N}=72)=2.33, p>.05\right]$ and yearly income $\left[\chi^{2}(5, \mathrm{~N}=64)\right.$ $=7.54, p>.05]$. These results suggest that the Target Subsample's demographic characteristics are similar to the demographics of remainder of the participants who completed the survey outside the time criteria.

Table 3 summarizes the bereavement-related characteristics of all respondents in the Target Subsample. The participants were bereaved for approximately 9 months across both groups. For the Target Subsample, many of the participants were grieving the loss of a spouse (46.2\%), followed by the loss of another relation, such as friend or neighbor (34.6\%). Chronic illness, acute illness, and natural death were the most frequently reported cause of death $(46.2 \%, 26.9 \%$ and $19.2 \%$, respectively). Nearly half 
of the participants $(\mathrm{n}=12)$ did not seek professional help for bereavement-related issues. Of those that sought such professional help, most engaged in grief counseling $(\mathrm{n}=7)$. These patterns of bereavement-related characteristics were similarly demonstrated across the whole sample $(\mathrm{N}=74)$. However, the total sample included a wider array of types of loss based on relation to the deceased (e.g. grandchildren) and circumstance of the death (e.g. homicide, suicide) than found in the Target Subsample. Over half of the individuals in the whole sample reported their loved one died of chronic illness (56.8\%). Besides the referent deceased person, the Target Subsample reported having experienced an average of $5.46(S D=2.33)$ additional significant bereavements; similarly, across the whole sample, participants reported having experienced an average of $5.18(S D=2.34)$ bereavements in the past.

\section{Descriptive Statistics: Study Variables}

Descriptive statistics for the key study variables for the entire sample and Target Subsample are provided in Tables 4 and 5, respectively. These statistics reflect data that have not been transformed or altered to account for issues related to missing data or nonnormality.

Missing Values

Missing data is an unfortunate, yet common occurrence in aging research, and its occurrence has been shown to relate to various age-related variables, such as increased age, poor health status and cognitive deficits (Chatfield \& Matthews, 2005). Special considerations in addressing missing data in aging research should be made in an effort to minimize the exclusion of available participant data, especially when examining small sample sizes (Hardy, Allore \& Studenski, 2009). This study was at increased risk for 
missing data given the self-report format of the study questionnaire. The following section will discuss how missing data was addressed in both the Target and whole sample.

Out of the 26 individuals who met the time criteria for completing the study packet within 6-12 months post-loss (Target Subsample), 14 participants had complete data across all key study variables. The occurrence of missing data for each participant, either missing sporadically or non-randomly, was not significantly associated with age ( $r$ $=.18, p=.373)$ or education $\left[\chi^{2}(4, \mathrm{~N}=71)=1.47, p>.05\right]$. An exploration of the valid and missing data based on the administration sequence of the measures revealed that although the majority of the missing data occurred towards the end of the study packet, with measures of anxiety (STAI-Y) and social desirability (MC) having the greatest percentage of missing data (26.9\% and $15.4 \%$, respectively), missing data also occurred sporadically in measures administered earlier in the packet (Table 6 lists the percentages of missing cases per variable for the Target Subsample). To account for small rates of missing data, item mean value single imputations were calculated for variables with $\leq 10 \%$ of missing items (Downey \& King, 1998); conversely, participants with missing values comprising greater than $10 \%$ of the observations of a measured variable were excluded from mean value imputations. Table 7 provides the descriptive statistics for the nine key study variables that underwent mean imputations for the Target Subsample. After mean imputations were conducted on variables with small rates of missing data, 25 out of a total of 26 participants within the Target Subsample were without missing data across key study variables. 
As outlined in Table 8, there were missing values across all key study variables for the entire sample, and the occurrence of missing data in the whole sample was not significantly associated with age $(r=.181, p=.125)$ or level of education $\left[\chi^{2}(4, \mathrm{~N}=71)\right.$ $=1.55, p>.05]$. The greatest percentages of missing items occurred on measures of anxiety (STAI; $18.9 \%$ ) and social desirability (MC; $24.3 \%$ ), both of which were administered towards the end of the study packet. Though this pattern of missing data is similar to the pattern found in the Target Subsample, missing data also appeared sporadically throughout measures administered earlier in the study packet (i.e. on the GDS and ITG), suggesting a random spread of missing data across all key study variables. As demonstrated in Tables 8 , the mean single imputation method helped to increase sample size for variables missing small rates of data. After mean imputations were conducted, 59 out of 74 (79.7\%) participants were without missing data across key study variables. Descriptive statistics for all key variables that underwent single mean value imputations are provided in Table 9. Plausible reasons for the occurrence of missing data, and how missing data and imputation influences the interpretation of downstream analyses will be reviewed in the discussion section.

\section{Normality:}

Further exploration of key study variables for the Target Subsample revealed positively skewed and non-normal distributions on measures of depression and present negative affect. Table 10 lists the test of normality for each key study variable. To address issues with non-normal distributions, base 10 logarithmic transformations were used on positively skewed data. Log 10 transformations were computed on both depression and present negative affect scores, with the addition of the constant " 1 " on 
depression scores. After log 10 transformation were completed, the test for normality fell to non-significance on the depression measure $(\mathrm{D}[26]=.17, p=.065)$, whereas the measure for present negative affect remained significantly non-normally distributed $(\mathrm{D}[26]=.17, p=.045)$.

Examination of normality in the whole sample demonstrated positively skewed and non-normal distributions on measures of depression, past and present negative affect, and anxiety (see Table 11). Similar to the method of addressing non-normal distributions, base $10 \log$ transformations were computed on the aforementioned positively skewed variables, with the addition of the constant " 1 " on depression scores. The test of normality fell to non-significance for the anxiety measure $(\mathrm{D}[63]=.11, p>$ $.05)$; however the distributions of past and present negative affect and depression remained significantly non-normal after undergoing log 10 transformations $(D[72]=.11$, $p=.04 ; \mathrm{D}[63]=.16, p=.001 ;$ and $\mathrm{D}[63]=.12, p=.026$, respectively). Visual inspection of the distribution of well-being demonstrated a normal distribution with a single outlier; no transformations were computed for this variable, as regression methods are generally robust to deviations from normality in larger samples (Chatterjee \& Hadi, 2006).

\section{Comparison of Outcome Variables}

Analyses were conducted to compare the Target subsample and those participants who did not meet the study's time criteria of having been bereaved within the last $6-12$ of completing the study packet $(n=48)$. There was not a significant difference in mean depression scores in the Target subsample and the remainder of the sample, $U=573.50, z$ $=-.58, p=.564$. Grief scores were also statistically similar across the two groups $[t(71)=$ $.65, p>.05]$, in addition to well-being $[t(69)=.03, p>.05]$, social functioning $[t(69)=$ 
$.44, p>.05]$, and emotional functioning $[t(71)=-.12, p>.05]$. Together, these results

suggest that the Target subsample is similar to the remainder of the entire sample in terms of bereavement-related psychosocial outcomes.

\section{Research Questions \& Results}

The majority of the participants in this study did not meet the bereavement time criteria proposed for capturing the bereavement outcomes $6-12$ months post-loss $(\mathrm{n}=$ 26). For this reason, the primary analyses were first conducted on the proposed Target Subsample, and then repeated using the whole sample due to the limited size of the Target Subsample. The whole sample's bereavement period ranged from $0-60$ months post-loss $(M=9.25, S D=9.55)$. Eleven participants did not report their bereavement duration, and these were also included in the full sample. Any contrasting results between the two samples for Research Questions 1-3 will be discussed.

Question 1: What is the relationship between number of prior bereavements and resilient and non-resilient grief outcomes following a recent bereavement?

Preliminary analyses examined the relationships between the sample's demographic characteristics (age, gender and race) and the following bereavementrelated variables: total number of reported bereavements, months bereaved since most recent loss, grief (ITG), post-loss depression (GDS), well-being (Ryff), and social and emotional status (COOP Social and Emotional Functioning). Bivariate correlations between age and bereavement-related variables, shown in Table 12, revealed that age was not significantly associated with depression, grief, well-being, social functioning or emotional functioning for the Target Subsample. Age was also not significantly related 
to cumulative lifetime bereavements and total months bereaved since the participant's most recent loss. Age was not associated with these bereavement-related variables for the whole sample, with the exception of the significant relationship between age and grief $(r=-.24, p=.04)$, such that increased age was associated with lower grief scores.

For the Target Subsample, gender was not significantly associated with depression, grief, well-being, social functioning, emotional functioning, or total bereavements reported. There was a significant difference in total months bereaved between men $(M=11.25, S D=.96)$ and women $(M=8.36, S D=2.44) ; t(24)=-2.30, p=$ .030. In the whole sample, males reported significantly higher scores on a measure of social functioning $(M=2.75, S D=14.2)$ compared to females $(M=1.90, S D=1.05)$, indicating females reported less difficulty engaging in social activity, $t(68)=2.40, p=$ .02. Females also reported having experienced significantly more cumulative lifetime bereavements $(M=5.41, S D=2.31)$ compared to males $(M=3.83, S D=2.08), t(71)=$ $2.19, p=.030$. Males and females were similar across measures of depression $(U=$ 298.00, $z=-1.02, p>.05$ ), grief, well-being, emotional functioning, and total months bereaved. These results are summarized in Table 13.

Race was not significantly associated with depression, grief, well-being, emotional functioning, social functioning, months bereaved and total bereavements reported for the Target Sample. Because only one participant identified her race as "Hispanic," within the whole sample, this participant was excluded from mean comparison tests examining mean differences across the bereavement-related variables. The remaining participants in the whole sample identified themselves as either "Caucasian" ( $(\mathrm{n}=62)$ or "African-American" $(\mathrm{n}=8)$. Independent T-test's revealed that 
African-American participants reported significantly more cumulative lifetime bereavements $(M=6.78, S D=1.64)$ compared to Caucasian participants $(M=4.94, S D=$ 2.38), $t(69)=-2.24, p=.03$. However, both race groups in the whole sample scored similarly on a measure of depression $U=249.00, z=-.53, p>.05$ ) and all other bereavement-related variables (see Table 14).

Table 15 summarizes the bivariate correlations among the outcome variables (grief, depression, well-being and social and emotional functioning). There were significant associations between grief, depression, and social and emotional status, such that those who reported higher levels of grief also endorsed higher levels of depression and worse social and emotional functioning. Additionally, depression and social and emotional functioning were highly associated, indicating that higher levels of depression were significantly related to worse social and emotional functioning. Worse emotional functioning was also significantly related to worse social functioning. Well-being as assessed by the Ryff composite score was not significantly related to measures of grief, depression, or social and emotional functioning.

Hypothesis 1 proposed that total number of prior losses reported could differentiate between resilient and non-resilient post-lost outcomes. Specifically, those with "little" and "too much" loss would have non-resilient bereavement outcomes measured at 6-12 months post-loss, as evidenced by greater depression, lower quality of life/well-being, lower social and emotional functioning, and more intense grief symptoms, compared to those with a "moderate" amount of loss. The sample was divided into those with resilient versus non-resilient bereavement outcomes. Based on the findings discussed in the background section, a resilient outcome was described as 
having the following bereavement-related characteristics: absence of post-loss depression, maintained post-loss social and emotional functioning, non-elevated grief scores, and maintained post-loss quality of life/well-being. As a reminder, cases must have met the four following criteria to be coded as "resilient": GDS scores at or below 5, scores of at least 1 SD's above the sample's mean for 1 out of 6 Ryff scales, and scores of 1-2 on both COOP charts (Criteria A, C, and D, respectively). The case also could not meet Criteria A2 and B on the ITG, indicating an uncomplicated level of grief. All cases that did not meet the criteria A - D were coded as "non-resilient." The coding rubric is provided below. A total of seven out of 26 cases met criteria for resilient bereavement outcome in the Target Sample.

\begin{tabular}{|ll|l|}
\hline \multicolumn{2}{|l|}{ Criteria for Resilient Grief: } & \\
\hline E. & Post-Loss Depression & $\leq 5$ on the GDS \\
\hline F. & Grief & $\begin{array}{l}\text { Does not meet Criteria A2 and B on the } \\
\text { ITG }\end{array}$ \\
\hline G. & Well-being & $\begin{array}{l}\text { Scores of at least } 1 S D \text { above the sample's } \\
\text { mean for 1 out of 6 Ryff scales }\end{array}$ \\
\hline H. & Functional Status & Scores of 1-2 on both COOP charts \\
\hline
\end{tabular}

Categorization of number of prior losses was based on the sample's mean of total cumulative losses ( $M=5.46, S D=2.33)$. Similar to Seery et al.'s (2010) categorization method of cumulative lifetime adversity, those with the sample's mean plus one standard deviation $(M+1 S D)$ were coded as having "too much loss" and those with $M-1 S D$ were coded as having "minimal loss". All other cases were coded as having "moderate" amount of loss. Coding the sample based on this method resulted in 15 cases with a "moderate" amount of loss, 3 cases with "minimal loss" and 8 cases with "too much loss" 
relative to the sample's mean of total number of reported bereavements. Table 16 provides the frequency cross-tabulations between the categorical variables of cumulative loss (minimal loss, moderate or too much loss) and bereavement outcome (resilient or non-resilient). A 3 X 2 Chi-Square analysis indicated that varying amounts of cumulative lifetime loss was not significantly associated with type of bereavement outcome $\left[\chi^{2}(2, N\right.$ $=26)=.88, p>.05]$.

Question 1 also involved the differential ability of prior losses to predict bereavement outcome while accounting for pre-bereavement depression. Participants whose responses indicated a history of depression prior to the most recent bereavement were coded as "history of depression" $(\mathrm{n}=15)$. All other cases were coded as "no history of depression." Fisher's Exact Test revealed that the presence or absence of a depression history was not significantly associated with bereavement outcome, $p=.66$.

Eleven out of seventy participants with complete data in the whole sample met criteria for resilient bereavement outcome. Cumulative lifetime bereavements were also stratified into the three categories (minimal, moderate and too much), based on the sample's mean number of total deaths reported, $(M=5.18, S D=2.33)$. This division of the sample resulted in 15 individuals coded as having experienced "minimal" loss, 41 with "moderate" loss, and 18 with "too much" loss relative to the sample's mean. Table 17 provides the frequency cross-tabulations between the categorical variables of cumulative loss (minimal loss, moderate or too much loss) and bereavement outcome (resilient or non-resilient). A 3 X 2 Chi-Square analysis indicated that varying amounts of cumulative lifetime loss was not significantly associated with type of bereavement outcome $\left[\chi^{2}(2, \mathrm{~N}=74)=1.03, p>.05\right]$. 
Thirty-six out of 74 participants were coded as having a depression history. Eight out of 11 resiliently grieving participants did not have a depression history; however, a 2 $\mathrm{X} 2$ chi-square analysis revealed that the presence or absence of a depression history was not significantly associated with bereavement outcome, $\left[\chi^{2}(1, \mathrm{~N}=74)=2.36, p>.05\right]$. However, those with a depression history endorsed significantly greater grief scores $(M=$ 73.69, $S D=24.61)$ compared to those without pre-bereavement depression $(M=54.10$, $S D=19.64), t(71)=-3.77, p>.001$. Similarly, those without a depression history endorsed lower levels of post-loss depression $(M=1.96, S D=2.54)$ compared to participants with a depression history $(M=5.24, S D=3.83), U=311.00, z=-4.07, p<$ .001 .

Question 2: What is the relationship between bereavement-related psychosocial and functioning outcomes and coping and emotion regulation of a recent loss?

This question examines the relationship between resilient versus non-resilient grief outcomes and reports of affective complexity, repressive coping, and amount of positive emotion, as measured by the following coping emotion-regulation variables: retrospective self-reports of positive affect and negative affect (PANAS) one month postlost, anxiety (STAI-Y) and social desirability (MC). Specifically, it was hypothesized that participants' retrospective reports of affective complexity, repressive coping, and amount of positive emotion would be associated with resilient grief outcomes. Bivariate correlations among the coping and emotion regulation variables are presented in Table 18. In both the Target Subsample and whole sample, there were significant relationships between self-reported negative affect and anxiety $\left(r=.60, p=.002\right.$ and $\mathrm{r}_{s}=.52, p>.001$, 
respectively), such that increased anxiety was associated with greater negative affect. A significant correlation between negative affect and social desirability $\left(\mathrm{r}_{s}=-.38, p=.007\right)$ was found in the whole sample, such that those who reported increased negative affect tended to report in a more socially desirable manner. All other relationships were nonsignificant, though the inverse association between self-reported positive and negative affect approached significance, $r=-.36, p=.06$ for the Target Subsample.In the Target Subsample, resiliently grieving participants reported significantly less negative affect compared to non-resiliently grieving individuals, $t(24)=2.94, p=.007$. However, bereavement outcome (resilient and non-resilient) was not significantly associated with self-reported positive affect, anxiety, or social desirability. For the whole sample, there was a significant difference in anxiety scores between resilient and non-resilient grievers, $t(63)=2.18, p=.033$, such that resilient grievers reported significantly less anxiety. Bereavement outcome was not significantly associated with positive affect or social desirability. Negative affect did not significantly vary between resilient and non-resilient grievers in the whole sample, $(U=200.00, z=-1.95, p=.051)$, though the difference in means approached significance. Tables 19 and 20 present the descriptive statistics for these variables for the Target Subsample and whole sample, respectively.

Affective complexity involves the degree of association between positive and negative affect, in which less severe inverse associations indicates greater affective complexity. The relative difference between each participant's self-reported positive and negative affect subscale score (PA and NA, respectively) was calculated to provide a scaled ratio between PA and NA scores for the Target Subsample $(M=.47, S D=.38$, range $=0-1.13)$ and whole sample $(M=.45, S D=.38$, range $=0-1.25)$. Affective 
complexity scores closer to zero indicated less relative distance between PA and NA scores, suggesting less of a bipolar relationship between positive and negative affect and greater affective complexity. An independent t-test showed that resilient grievers did not report a statistically greater amount of affective complexity $(M=.55, S D=.46)$ compared to non-resilient grievers $(M=.44, S D=.36), t(24)=-.65, p>.05$, suggesting the two groups experienced similar amounts of affective complexity. This result was similar in the whole sample, $t(64)=-49, p>.05)$.

The quartile-split method was used to identify repressive coping (Boden \& Baumeister, 1997; Erskine et al., 2007; Weinberg et al., 1979), such that participants whose scores were above the subsample's upper quartile on a measure of social desirability (MC; score of 24) and below the subsample's lower quartile on a measure of anxiety (STAI - Y; score of 27) were coded as having engaged in current "repressive coping." This method identified three participants as repressive copers, and only one of these was also considered a resilient griever. As expected given the small cell counts, Fisher's Exact test revealed that the presence or absence of resilient coping was not significantly associated with engagement in repressive coping, $p=.66$. A similar pattern of results was revealed in the whole sample, in that 3 participants were coded as repressive copers using the quartile split method, and only once of which was also considered to have a resilient bereavement outcome. Not surprisingly, Fisher's Exact test indicated a non-significant relationship between repressive coping and type of bereavement outcome, $p=.41$. 
Question 3: What are the relationships between number of prior losses, resilient and nonresilient grief outcomes, and coping/emotion regulation during the most recent bereavement?

Question 3 involves the hypothesis that the relationship between number of prior losses and bereavement outcomes (resilient and non-resilient grief) would be mediated by the following coping/emotion regulation variables during the most recent bereavement: affective complexity, engagement in repressive coping, and amount of positive emotion experience. That is, the benefit of experiencing prior losses is hypothesized to be related to the development of better emotional coping skills, which then lead to better outcomes. This last question examines the relationship between number of prior losses (independent variable; IV) and grief outcome (dependent variable; DV), with the addition of the following mediating variables (M): affective complexity, repressive coping, and positive emotions, analyzed using separate mediation models. As discussed in Baron \& Kenny (1986), the following series of regressions is required to test mediation: (1) regression between the IV and DV; (2) regression of the IV predicting M; (3) regression of M predicting DV and (4) regression of IV and M predicting the DV. Mediation is established when Steps 1-3 result in significant relationships, and that the relationship between the IV and DV reduces to zero-order non-significance after controlling for the relationship between the mediator and DV.

However, results related to Question 1 (presented above) indicated non-significant relationships between bereavements experienced and resilient outcomes, in addition to non-significant relationships between the hypothesized mediating variables and resilient outcomes, which were presented in Question 2. Even when total number of 
bereavements was not stratified into the three subgroups (minimal, moderate and too much loss) and was instead treated as a continuous variable, the IV-DV relationship remained non-significant in the Target Subsample, $\left[\chi^{2}(1, \mathrm{~N}=26)=.06, p=.81\right]$ and whole sample $\left[\chi^{2}(1, N=74)=.81 p=.37\right]$. The results from these logistic regressions are presented in Tables 21 and 22.

Given that Steps 1 and 3 did not meet the requirements for testing the proposed mediating effect of the emotion/coping variables on bereavement outcome, other analyses were performed to explore the relationships between (A) total bereavements reported and the emotion-regulation/coping variables; and (B) the emotion-regulation/coping variables and bereavement-related outcomes, using the whole scales of each outcome variable.

\section{(A) Cumulative Lifetime Loss and Emotion-Regulation/Coping Variables}

One-way between-groups analyses of variance were conducted to explore the relationships between level of cumulative lifetime loss (minimal, moderate, and too much) and affective complexity and self-reported positive emotion. In the Target Subsample, the assumption of homogeneity of variance was violated for affective complexity; therefore, the Welch $F$-ratio is reported. There was a significant effect of cumulative lifetime loss level on affective complexity, $F(2,13.40)=38.52, p<.001$. Post-hoc comparisons using the Tukey HSD test indicated that the mean score for participants with "minimal" total bereavements $(M=.02, S D=.03)$ was significantly lower from that of participants with "too much" loss $(M=.69, S D=.22)$. Those with a “moderate' amount of loss $(M=.44, S D=.41)$ did not differ significantly from those with "minimal" or "too much" loss. When this analysis was extended to the whole sample, there was no significant difference in affect complexity across levels of 
cumulative loss, $F(2,69)=.28, p>.05$, suggesting that the three groups of cumulative loss experienced similar levels of affective complexity. Additionally, there was not a significant effect of total bereavements on self-reported positive emotions in either the Target Subsample $[F(2,23)=2.25, p>.05]$ or the whole sample $[\mathrm{F}(2,69)=1.92, p>$ .05]. Chi-square tests for independence also indicated a non-significant association between total bereavements and repressive coping for the Target Subsample $\left[\chi^{2}(2, N=\right.$ $26)=1.58, p>.05]$ and whole sample $\left[\chi^{2}(2, \mathrm{~N}=70)=.74 p>.05\right]$.

When analyzed as a continuous variable, total number of bereavements in the Target Subsample correlated significantly with affective complexity $(r=.47, p=.02)$, suggesting grievers experience less complex affect as the number of losses increases. Total number of bereavements was not significantly related to self-reported positive affect $(r=.32, p>.05)$ in the Target Subsample; however, this relationship was found to be significant in the whole sample $(r=.25, p=.04)$, indicating that experiencing more bereavements was associated with greater positive affect.

\section{(B) Emotion-Regulation/Coping Variables and Bereavement-Related Outcomes}

Question 2 addressed the relationships between the hypothesized mediating variables and bereavement outcome (resilient vs. non resilient), all of which were found to be non-significant. Exploration of the relationships between the continuous emotionregulation/coping variables (affective complexity and positive emotions) and outcome variables (depression, grief, well-being and social and emotional functioning), using their whole-scale scores, revealed significant relationships between affective complexity and emotional functioning, and between self-reported positive affect and social functioning. Similarly, in the whole sample, there were significant correlations between affective 
complexity and with emotional functioning. Additionally, positive affect was significantly and negatively associated with depression, and positively associated with well-being. Greater self-reported positive affect was also significantly related to better emotional and social functioning. All other relationships were non-significant (see Tables 23 and 24). Repressive coping was not significantly related to any of the outcome variables [depression, $t(22)=1.14, p>.05$; grief, $t(22)=1.07, p>.05$; well-being, $t(22)$ $=.652, p>.05$, emotional functioning $t(22)=.92, p>.05$, and social functioning, $t(21)=$ $.41, p>.05]$.

\section{Secondary Analyses}

As displayed in Tables 15 and 23, well-being did not significantly correlate with other bereavement outcomes (depression, grief, and social and emotional functioning), affective complexity, or self-reported positive affect in the Target Subsample. This pattern of non-significant associations was also found in the whole sample, with the exception of a significant relationship between well-being and positive affect $(r=.25, p=$ .04). Because no specific cut-off points have been established to distinguish between individuals with high and low well-being (Ryff \& Keyes, 1995), the quartile-split method was used to define participants whose scores reflect high well-being (upper quartile) and low well-being (lower quartile) based on the sample's spread of scores. A 3 x 2 ChiSquare analyses revealed that having high or low well-being was not significantly related to resilient or non-resilient bereavement outcomes in the Target Subsample $\left[\chi^{2}(2, N=26)\right.$ $=.47, p>.05]$ or whole sample $\left[\chi^{2}(2, \mathrm{~N}=26)=.33, p>.05\right]$. Together, these results suggest that overall well-being, as captured by Ryff's Psychological Well-Being Scale, 
may not necessarily be related to the bereavement outcomes within this sample. Possible explanations for this finding will be explored in the discussion section.

The number of resilient grievers increased from 11 to 34 in the whole sample when well-being was excluded as a criterion for defining a resilient bereavement outcome. Given this increase, secondary analyses were performed on the whole sample to examine if the removal of the well-being criterion would lead to different results compared to the originally proposed categorization. Excluding the well-being criterion, bereavement outcome remained unrelated to level of cumulative lifetime loss (too little, moderate, too much), $\left[\chi^{2}(2, \mathrm{~N}=71)=2.23, p>.05\right]$ and total number of bereavements reported, $t(69)=-.47, p>.05$. However, unlike the original analyses, depression history was significantly related to bereavement outcome in the whole sample, $\chi^{2}(1, N=71)=$ $5.12, p=.02$, such that those without a depression history were more likely to be resiliently grieving (see Table 25 for the crosstabulations).

Removal of the well-being criterion demonstrated differential results across the emotion-regulation/coping variables, compared to the findings from the original analyses. Resilient grievers reported experiencing significantly more positive affect $[t(65)=2.76, p$ $=.008]$ and significantly less anxiety $[t(64)=5.59, p<.001]$ and negative affect $(U=$ 293.00, $z=-3.62, p<.001)$. Surprisingly, resilient grievers also engaged in a lesser degree of affective complexity compared to non-grievers, $t(65)=-3.69, p<.001]$. The relationship between bereavement outcome and social desirability remained nonsignificant. Table 26 displays the descriptive statistics for these variables.

Given these significant relationships, a logistic regression was preformed to assess the impact of affective complexity on the likelihood that participants would be 
coded as resiliently grieving. The full model containing affective complexity was statistically significant, $\chi^{2}(1, \mathrm{~N}=67)=11.62 p=.001$, indicating that the model was able to distinguish between participants with or without resilient bereavement outcomes based on affective complexity scores. The model as a whole explained between 15.9\% (Cox \& Snell R square) and $64.2 \%$ (Nagelkerke R square) of the variance in bereavement outcome, and correctly classified $78.5 \%$ of the cases. Affective complexity proved to be the stronger predictor of bereavement outcome, recording an odds ratio of 11.08, suggesting that for every increased unit of change in affective complexity, participants were over 6 times more likely to be resiliently grieving. Please note that affective complexity scores deviating from zero are indicative of greater relative distance between positive and negative affect scores, suggesting less affective complexity.

A second logistic regression was performed to determine which affective response, either positive or negative, contributed more strongly to predicting differences in bereavement outcome. The full model containing both positive and negative affect was statistically significant, $\chi^{2}(1, N=67)=21 . .73 p<.001$, suggesting that it was able to distinguish between resilient and non-resilient grievers, and explain 27.7\% (Cox \& Snell $\mathrm{R}$ square) and 36.9\% (Nagelkerke R square) of the variance in type of bereavement outcome. $74.6 \%$ of the cases were correctly identified. As shown in Table 28, both positive and negative affect were significant predictors of bereavement outcome, suggesting that participants who reported either greater positive affect or less negative affect were 1.01 and .002 times more likely, respectively, to be resilient grievers. 


\section{CHAPTER 4}

\section{DISCUSSION}

Broadly, this study explored the relationships among pre-loss variables (i.e. cumulative lifetime loss and depression history), coping/emotion regulation variables, and post-loss outcomes within the context of late-life bereavement. Three main research questions and related hypotheses were addressed with the main aim of expanding our knowledge of late-life bereavement by examining how cumulative lifetime loss is related to resilient versus non-resilient bereavement outcomes. Overall findings from this study provide limited support that merely accounting for cumulative losses experienced over a lifetime can differentiate between resilient and non-resilient grievers; rather, as will be discussed, other variables, such as depression history, and positive and negative affect, may be stronger factors in the prediction of bereavement outcome.

Research Question 1: What is the relationship between number of prior bereavements and resilient and non-resilient grief outcome following a recent bereavement?

Seery and colleagues (2010) demonstrated that experiencing a moderate amount of cumulative lifetime adversity was related to more favorable psychosocial outcomes, in terms of lower global distress, functional impairment, post-traumatic stress symptoms, and better life satisfaction, compared to those with either low or high lifetime adversity. They concluded that experience gleaned from enduring a moderate amount of lifetime adversity might facilitate more resilient coping in the face of current stressors. Applying 
this concept to bereavement, it was hypothesized that accounting for the total number of prior bereavements could predict between resilient $v s$. non-resilient bereavement outcomes as determined by scores on self-reports of depression, grief, social, and emotional functioning and well-being. More specifically, it was hypothesized that recently bereaved individuals with "minimal" and "too much" prior loss would have nonresilient post-loss outcomes, and those with a moderate amount of loss would endorse more resilient bereavement outcomes. Findings from the current study failed to support this hypothesis, as there was no significant relationship between cumulative lifetime loss and bereavement outcome. Though cell-counts were low in the resilient category, which likely contributed to the non-significant finding due to lack of power, the majority of participants in the non-resilient category experienced a "moderate" amount of cumulative lifetime adversity, countering the assumption that most non-resilient grievers would have fallen into the "minimal" or "too much" loss categories similar to what Seery and colleagues (2010) found.

Also embedded within Question 1 was the hypothesis that the absence of prebereavement depression would be related to resilient bereavement outcomes. Similar to cumulative lifetime loss, this hypothesis was unsupported in the current study, in that those with or without a depression history did not show significantly different bereavement outcomes when the dichotomous resilience/non-resilience categorization was used. However, consistent with previously established research demonstrating that depression history is an important factor in predicting more complicated grief courses, namely those with elevated depression and grief up to 18 months post-loss (Bonanno et al., 2002), participants with a depression history in the current sample endorsed 
significantly greater amounts of depression and grief compared to those without depression histories, and vice versa for those without a history of depression.

Although data from this study failed to support hypotheses from Question 1, the current bereaved sample replicated past research demonstrating the overlap between depression and grief scores (e.g. Boelen, van den Bout \& de Keijser, 2003; Bonanno, 2006; Horowitz et al., 1993; Prigerson et al., 1995a; Prigerson et al., 1996; Prigerson \& Maciejewski, 2005-2006, Stroebe et al., 2008; Thompson et al., 2007), given the high correlations between these two variables. Higher post-loss depression and grief were also significantly related to greater impairments in social and emotional functioning, which is also similar to extant research demonstrating functional impairment following a significant loss is related to more complicated bereavement outcomes (Boelen \& van den Bout, 2008; Mancini \& Bonanno, 2009; Prigerson \& Maciejewski, 2005-2006; Ott, 2003). The inverse interpretation of these relationships suggests that individuals who did not endorse elevated depression or grief experienced minimal disruptions in their lives, despite having endured a recent bereavement.

Together, the results from Question 1 suggest that the resilient and non-resilient grievers cannot be differentiated from each other solely based on cumulative lifetime loss or depression history. As will be discussed later, these non-significant relationships may be due in part to the small sample size and/or method of categorizing bereavement outcome. Despite this, the findings replicate existing research examining the overlap of depression and grief symptoms in bereaved samples, in addition to social and emotional functional difficulties experienced when grief and depression symptoms are elevated. Moreover, when examined individually, grief and depression scores were significantly 
higher in individuals with depression history, indicating that pre-bereavement depression may be a strong factor in predicting those with more symptomatic grief courses.

Research Question 2: What is the relationship between bereavement-related psychosocial and functioning outcomes and coping and emotion regulation of a recent loss?

Pulling from the resilience and coping literatures, favorable bereavement-related psychosocial functioning (lower depression and anxiety, higher quality of life/well-being, maintained social/emotional functioning, and lowered grief symptoms) was hypothesized to be associated with affective complexity, engagement in repressive coping, and maintenance of positive emotions during the grieving process, as these emotionregulation and coping variables have been related to resilient or adaptive outcomes following a stressor (e.g. Coifman, Bonanno \& Rafeaeli, 2007, Coifman, Bonanno, Ray \& Gross, 2007, Ong et al., 2004, respectively). Across both the Target Subsample and the whole sample, affective complexity and positive emotions were not significantly related to resilient versus non-resilient bereavement outcome, though resilient grievers reported significantly less negative affect than non-resilient grievers in the Target Subsample. These results suggest that both resilient and non-resilient grievers demonstrated similar degrees of affective heterogeneity and positive emotions, which is inconsistent with previous research demonstrating that affective complexity or higher levels of positive affect are linked to resilient outcomes. In terms of repressive coping, only 3 subjects in both the Target Subsample and whole sample were identified as "repressive copers" using the quartile-split method on measures of trait anxiety and social desirability, as employed by Boden \& Baumeister, 1997, Erskine et al., 2007, Weinberg 
et al., 1979. Not surprisingly, repressive coping was unrelated to bereavement outcome. However, resilient grievers reported significantly less anxiety than non-resilient grievers, which is consistent with the notion that resilient post-loss outcomes would also include lower levels of anxiety.

Overall, the results from this study failed to support the hypothesis that resilient post-loss outcomes would be related to affective complexity, positive emotions and repressive coping. Again, and as will be discussed later, these findings may be due to the strict categorization method for categorizing resilient and non-resilient grievers, small sample size, or inaccurate reporting of retrospective affect. Moreover, while affective complexity was determined using the relative distance between positive and negative affect scores measured at one time point, it is typically measured across multiple assessment periods and based on inter-affect correlations, capturing a more comprehensive assessment of affect across time. However, the relationship between positive and negative affect was non-significant in the current sample, suggesting that as a whole, participants may have experienced affective heterogeneity or a more restricted range of affect. Additionally, participants also reported more positive affect than negative affect, which is also consistent with other bereaved research samples (e.g. Stewart, Craig, MacPherson \& Alexander, 2001) and what is typically found in the aging literature (e.g. Carstensen et al., 2000 and Gross et al., 1997).

Research Question 3: What are the relationships between number of prior losses, resilient and non-resilient grief outcomes, and coping/emotion regulation during the most recent bereavement? 
Integrating Questions 1 and 2, Question 3 involved the hypothesis that the relationship between cumulative lifetime loss and resilient versus non-resilient bereavement outcome would be mediated by the measured emotion-regulation/coping variables. However, as evidenced in Question 1, there was a non-significant relationship between number of prior bereavements and bereavement outcome, in addition to nonsignificant relationships between the emotion regulation/coping variables and bereavement outcome. Because these relationships failed to meet the requirements to test mediation (Baron \& Kenney, 1986), supplementary analyses were conducted to explore the nature of emotion-regulation/coping variables as they relate to cumulative lifetime loss and whole-scale outcome variables. In the Target Subsample (but not the whole sample), affective complexity was related to the three levels of cumulative lifetime loss, such that those with "minimal" loss reported greater affective complexity than those with "too much" loss. Likewise, when cumulative lifetime loss was analyzed as a continuous variable, it was also significantly related to affective complexity, indicating that as number of bereavements increased, self-reported affect became more disparate. These findings appear to be consistent with past research demonstrating that increased stress is related to the experience of less complex affect as cognitive resources to cope with heightened stress narrows (Zautra et al., 2002). Experiencing additive stress specifically related to enduring multiple significant bereavements over a lifetime might affect affective heterogeneity, resulting in a more bipolar experience of affect. Although the concept of "bereavement overload," (Kastenbaum, 1969, as cited in Hansson \& Stroebe, 2007), or the psychosocial impact of experiencing multiple losses, is occasionally discussed within the bereavement literature, it has yet to undergo empirical examination. 
Further exploratory analyses of the relationship between the self-reported positive affect and whole-scale outcome variables revealed several significant associations. Higher self-reported positive affect was related to lower depression, greater well-being, and better emotional and social function across the whole sample, which is similar to previous research indicating that ratings of positive emotions in recently bereaved participants are associated with reports of reduced post-loss anxiety and depression (Ong et al., 2004). Given these associations and the observation that the sample reported greater positive affect than negative affect, positive affect may play an important role in buffering against the negative effects of experiencing a recent bereavement as indicated by more favorable/adaptive psychosocial bereavement outcomes (Folkman \& Moskowitz, 2006, Ong et al., 2004, Tugade \& Fredrickson). Psychological Well-Being

Interestingly, well-being, as measured by Ryff's Scales of Psychological WellBeing, was unrelated to post-loss depression, grief, and social-emotional functioning in the current sample. Additional analyses also indicated that those participants with "high" or "low" well-being, as defined by the quartile-split method, were not significantly different with regard to resilient versus non-resilient bereavement outcome as defined by the original criteria for coding a resilient outcome. These findings appear to contradict previous research demonstrating that greater well-being following a significant bereavement is associated with a resilient grief trajectory (e.g. Ott et al., 2007), and that elevations in grief symptomology are associated with lower levels of well-being (Ott, 2003). Given the lack of association between well-being and other bereavement-related psychosocial outcomes, it may be the case that the Ryff scales failed to adequately 
capture well-being in the current bereaved sample. Though the Ryff scales are theoretically derived, perhaps other, more existential, facets of well-being not measured by the Ryff scales, such as adaptation to role transitions, physical health, optimism, religiosity and spirituality are more indicative of well-being within the context of late-life bereavement (Fry, 2001). Moreover, although the measure has been utilized in a variety populations, it was originally validated on a sample of younger adults whose mean age was 45.6 years (Ryff \& Keyes, 1995); thus, the nature of psychological well-being in older adulthood may be comprised of different aspects compared to those more salient in early adulthood (Guindon, O’Rourke \& Cappeliez, 2004).

A review of past studies measuring well-being in bereaved samples revealed that the methodology of assessing well-being is variable, yet result in some similar findings. For example, in Ott et al.'s (2007) study examining various grief trajectories in a sample of 141 conjugally bereaved older adults, well-being/quality of life was measured using the SF - 12 Health Survey (Ware, Kosinski \& Keller, 1996), a generic health measure commonly used in medical outcomes research. Similarly, Prigerson et al. (2009) measured quality of life/well-being in a sample of 291 bereaved participants using a longer version of the SF - 12 Health Survey. Both studies demonstrated that elevations in grief scores were related to lower levels of well-being as measured by these questionnaires. In contrast, Richardson \& Balaswamy (2001) utilized Bradburn's (1969) Affect Balance Scale, in which negative affect scores were subtracted from positive affect scores to arrive at an indirect measurement of well-being in a sample of 200 older widowers. Thus, while the Ryff scales are a broad measure of psychological well-being, they have not been commonly utilized in bereavement research. Perhaps use of a 
measure that is more tailored to capture well-being within the contexts of bereavement and/or older adulthood could have resulted in findings that aligned with what has been documented in the bereavement literature.

\section{Secondary Analyses}

Given that well-being was unrelated to other outcome variables, secondary analyses were conducted to determine if removing the well-being criterion for categorizing resilient and non-resilient bereavement outcomes would produce different results in the whole sample compared to what was found in the original analyses. Doing so, the number of participants coded as "resilient" increased from 11 to 34, resulting in a more even split between resilient and non-resilient grievers. As with the original analyses, cumulative lifetime loss, when measured as either a categorical or continuous variable, remained unrelated to bereavement outcome. However, as hypothesized in Questions 1 and 2 and consistent with past research, resilient grievers were more likely to lack a depression history, and report greater positive affect and less negative affect. Affective complexity also varied significantly between resilient and non-resilient grievers; those with less affective complexity were approximately 11 times more likely to be coded as resilient grievers. This finding appears to be inconsistent with previous research demonstrating that affective complexity suggests resilient coping during times of stress, however, additional analyses indicated that both positive and negative affect were strong predictors of bereavement outcome. A closer look at these relationships showed a stronger effect size for positive affect (as indicated by a higher odds ratio), suggesting that positive affect was a stronger predictor of bereavement outcome compared to 
negative affect. Similar to what was found in the original analyses, these secondary analyses suggest that positive affect contributes significantly to resilient coping during bereavement, or that resilient grievers have a tendency to report higher levels of positive affect and may minimize experiences of negative affect, which may explain why resilient grievers experienced less complex emotions compared to non-resilient grievers.

\section{Limitations \& Suggestions for Future Research}

Although the information gleaned from this study shed some valuable light onto the nature of late-life bereavement, several limitations should be considered when interpreting these results. Great efforts were made to recruit participants with a wider variety of sociocultural backgrounds, however, the current sample was comprised of mostly Caucasian, widowed, well-educated females. Sample homogeneity is a frequent occurrence in bereavement research and could be a result of sample selection bias and recruitment methodology, as women may be more likely to respond to recruitment materials (Stroebe \& Stroebe, 1989; Stroebe, Stroebe \& Schut, 2004). Therefore, generalizing these findings to more diverse groups should be done with caution, because the degree to which we can infer that various cultures share aspects of grief is unclear given the lack of bereavement research examining such multicultural issues. Recruitment of participants from a broader array of ethnic and sociodemographic backgrounds might have been improved by developing culturally sensitive and appealing recruitment materials, more face-to-face recruitment, and developing stronger rapport with community leaders and gate-keepers to which older ethnic minorities defer (Areán, Alvidrez, Nery, Estes \& Linkins, 2003). 
Participation in this study was voluntary, thus, individuals who self-selected into the study could differ on several demographic and psychological dimensions from those who met the study's inclusion criteria yet chose to forego participation (e.g. health status, gender bias, familiarity with research procedures). Moreover, nearly half of the sample reported having sought some type of grief-related professional help, most of which was grief counseling. This proportion of individuals seeking grief-related professional help may be higher than what is typically found in the general population. For example, Currow and colleagues (2008) found that out of nearly 2,000 South Australians who had experienced a death of a loved one within the last 5 years, only $13 \%$ sought grief-related help from friends, family, grief counselors, spiritual advisors, nurses/doctors. Therefore, the participants in this sample may be an overrepresentation of grieved individuals who have sought grief-related services, possibly leading to response bias, as those who received professional help may have had increased comfort in sharing their experience and/or may have been more or less symptomatic at the time of completing the survey. In addition to issues with sample selection and homogeneity, there were also several methodological issues that likely limit interpretation of results in the current sample. First, all data collected was based on the participant's self-report, and some measures required retrospective recall of past affective experiences and previous coping methods, which may be subject to retrospective reappraisals of how well or poorly one has coped since the time of loss and/or overestimation or underestimation of previous grief-related affective states. Moreover, retrospective recall of grief-related thoughts, behaviors and emotions may be influenced by the participant's current emotional state. For example, Safer and colleagues (2001) demonstrated that bereaved individuals who 
endorsed high levels of grief at 6-months and 5-years post-loss tended to overestimate their initial grief state, whereas those whose grief subsided overtime tended to underestimate their initial grief state. Hence, the accuracy with which the participants responded to study questions could be questioned, and future research could incorporate collection of collateral or objective data from which to compare the self-report data.

Additionally, although participants had the option of completing the study packet alongside a trained researcher, most opted to complete the questionnaires on their own. This led to a higher frequency of missing data as researchers were unable to accurately monitor written responses, which is a frequent issue in research using postal surveys or non face-to-face interviews (Bowling, 2005). As mentioned earlier, the occurrence of missing data in aging research is common, likely related to various demographic and health-related factors, such as increased age, health status, cognitive deficits and lower education (Chatfield \& Matthews, 2005), in addition to possible methodological issues. Although the study packet was comprehensive, its numerous questions may have been burdensome to participants, especially to those with physical limitations (since it required writing), causing an increased likelihood of missing data. Given the already small sample size, efforts were made to account for missing data. The mean imputation method was used on variables with $\leq 10 \%$ of missing items. Though this method was employed to remedy the occurrence of missing data, there are issues that may have influenced downstream analyses. Mean imputation does not add new information and creates more "noise" in the dataset as it increases sample size and power, which may lead to distortions in the distributions of variables and underestimations of error or standard deviation. 
Thus, mean imputation may have distorted relationships between variables by making them appear more similar than distinct (Howell, 2007).

Sample size also proved to be an issue in the current study. Despite efforts to recruit from a variety of resources, only 74 out of a total of 280 distributed packets were returned. Reasons to forego participation or non-completion of the study packet were not tracked, which might have yielded valuable data on methods to improve recruitment. The current sample size fell below the calculated sample size to detect a medium effect for all proposed analyses $(n=108)$ and possibly compromised statistical power. Moreover, only 26 out of the 74 participants met the $6-12$ months post-loss time criterion, which was set in place to capture outcomes as demonstrated by various studies examining the course of grief-related symptoms over time (Prigerson et al., 2009). Although all proposed analyses were performed on this subsample, adequate power to detect differences was lacking, and conclusions drawn from results using the Target Subsample should be interpreted with caution. For this reason, the proposed analyses were extended to the whole sample, and comparative analyses revealed that these two samples appeared to be similar in terms of their psychosocial outcomes despite varying widely in terms of time since the most recent bereavement $(0-60$ months $)$. Future research should examine the impact of time since loss, as findings within the bereavement literature suggest that bereavement-related distress generally decreases over time (e.g. Bonanno et al, 2002; Ott et al., 2007), even after more traumatic death circumstances, such as suicide (Feigelman, Jordon \& Gorman, 2008-2009).

Related to small sample size, the method for which participants were categorized as "resilient" based on the five proposed criteria (low depression and grief scores, 
elevated well-being, and no impairment in social and emotional functioning) may have been too strict, though such outcomes have been linked to resilient bereavement-related coping (e.g. Bonanno et al., 2002, Ott et al., 2007). As discussed previously, removing the well-being criterion increased inclusion into the resilient category, and future research could explore other criterion combinations (i.e. grief and depression, or grief and social and emotional functioning) to examine differential results based on various inclusion criteria. Additionally, the method for categorizing repressive coping was also highly exclusionary, as only 3 participants scored within the upper quartile on the social desirability measure and below the lower quartile on the anxiety measure (Boden \& Baumeister, 1997; Erskine et al., 2007; Weinberg et al., 1979). This appears lower than what has been published in existing coping literature; for example, in a sample of 65 community-dwelling older adults, 26 were classified as repressive copers based on the quartile-spilt method presented above (Erskine et al., 2007). A review of the frequency distributions of trait anxiety scores revealed that most participants in the current sample tended to score at the lower end of the scale, suggesting that the majority of the sample were experiencing minimal anxiety and making categorization more difficult. A recent measure of repressive coping involves the comparison of stress-related physiological data, such as heart rate and skin conductance to self-reported negative affect (Coifman et al., 2007), such that those who are considered to be engaged in repressive coping would endorse low levels of negative affect but demonstrate elevated physiological arousal. Future research examining repressive coping in bereaved samples should aim to utilize such methods to yield richer data that may be less prone to item-response bias or possible underreporting of anxiety symptoms. 
Given these methodological concerns, perhaps different study designs for future research endeavors could help address some of the issues presented above and improve the quality of data collection. More recently, there has been a push to conduct large prospective and longitudinal studies that allow researchers to track participants pre- and post-loss (i.e. Bonanno et al., 2002 and 2004, Carr et al., 2006). Such study designs capture the complex nature of various grief trajectories as they unfold, along with a means of evaluating the relationships between pre-loss factors and outcomes, and allow researchers to account more strongly for the effects of time and potential confounds to the grieving process (i.e. a subsequent loss, co-occurring stressful life events, or engagement in grief-related interventions). Tracking participants on a monthly basis or use of other methods that monitor participants' responses to study questions, such as a daily or weekly diary, could also yield richer data on the ebb and flow of bereavement-related experiences over time and a more accurate assessment of variables that may be more difficult to report retrospectively and subject to response bias (i.e. affect).

What does this study reveal about resilience in late-life bereavement?

While much of the recent bereavement literature has focused on examining the course and correlates of complicated grief in both younger and older populations, the aim of this study was to expand our knowledge of resilient grief, given that the boundary between uncomplicated and complicated grief has yet to be empirically solidified (Hogan, Worden \& Schmidt, 2003-2004) and most older bereaved individuals endure a pattern of resilient grief (Bonanno et al., 2002, Ott et al., 2007). Drawing from the bereavement and resilience literatures and the proposed Late-Life Comprehensive 
Bereavement Outcome Framework (Shah \& Meeks, 2012), it was hypothesized that accounting for certain pre-bereavement factors (e.g. cumulative lifetime loss and depression history) and emotion-regulation/coping variables (e.g. affective complexity, positive emotions and repressive coping) could shed light on the boundary between resilient and non-resilient grievers, thereby allowing for a more accurate prediction of bereavement outcome.

For the current bereaved older population, resilient bereavement outcomes were robustly associated with higher self-reported positive affect. This finding is consistent with previous literature examining the function of positive emotions during times of stress (e.g. Folkman \& Moskowitz, 2000; Kelter \& Bonanno, 1997; Kuiper et al., 1993; Ong et al., 2004), and suggests that positive emotions play an important, and perhaps adaptive, buffering, and/or restorative, role in the bereavement coping process (Folkman, 2008; Ong et al., 2004). Resilient grievers in the current sample also reported having experienced co-occuring negative affect, although to a significantly lesser degree than positive affect. The co-occurrence of positive and negative emotions during times of stress (affective complexity) has been linked to an ability to self-regulate emotions, especially in older adulthood (Carstensen, 2000; Charles, 2005) and those that are able to experience affective complexity during heightened stress also demonstrate more resilient outcomes (e.g. Ong et al., 2004). Given that resilient grievers in the current sample reported less complex emotions compared to non-resilient grievers and that positive emotions were strongly related to bereavement outcome, it may be the case that the resilient grievers either minimized their negative emotional experience during their bereavement, or that they were able to better control their negative emotions and sustain 
positive emotions to a greater degree than non-resilient grievers (Carstensen, 2000). Although causal inferences between the coping/emotion regulation and bereavement outcomes cannot be determined based on the results of this study, it appears that the resilient griever's ability to regulate emotions via affective complexity, in addition to his or her ability to maintain positive affect during the grief process , are possible indicators of an effective coping strategy and signs of resilience following a late-life bereavement (Davis et al., 2007; Hanson \& Stroebe, 2007). The results therefore support the notion that accounting for the ability to regulate positive affect during the grief process is an important variable that deserves consideration in the prediction of late-life bereavement outcome.

Another noteworthy finding comes from the secondary analyses, which were conducted after removing the well-being criterion for defining a resilient bereavement outcome. Using the revised criteria, the relationship between depression history and bereavement outcome was significant, in that those without a depression history were more likely to be coded as resilient. This finding supports the hypothesis and replicates previous findings that the absence of pre-loss depression would be associated with more resilient outcomes (Bonanno et al., 2002), and provides further validation that considering the pre-loss context is important to predicting bereavement outcome (Bonanno et al., 2002, Shah \& Meeks, 2012). In regards to this particular finding, the absence of pre-loss depression suggests that resiliently grieving individuals may have engaged coping styles that facilitate quicker assimilation, adaptation and/or recuperation following previously experienced stressful events, given the likelihood of having experienced numerous stressful events over their lifetimes without great disruptions in 
their emotional well-being. Thus, resilient grievers in the current sample may have engaged in similar coping styles that have been effective in handling past stressors, including previous bereavements.

An area in which this study failed to delineate the boundary between resilient and non-resilient grief is the relationship between cumulative lifetime loss and bereavement outcome. Accounting for number of previous bereavements was unrelated to bereavement outcome, suggesting that those with minimal, moderate or too much loss reported similar amounts of post-loss depression, grief, well-being, and social and emotional functioning. Therefore, perhaps distinguishing between resilient and nonresilient outcomes goes beyond merely accounting for cumulative lifetime loss. Because having prior experience with coping with adverse events, such as bereavement, may lessen the negative impact of current, similar stressors (Norris \& Murrell, 1988), it may be fruitful for future research to examine the subjective impact of previous bereavements, their cumulative effect on current mental health well-being and functioning, lessons learned/wisdom gained from having endured difficult bereavements in the past, and appraisals regarding one's ability to cope with future losses based on previous experience. Along with examining the relative impact of experiencing multiple bereavements, future research could also assess how the individual has made meaning of the loss (i.e. timeliness of the loss or how the loss integrates in one's broader life story), in an effort to arrive at a better understanding of the assimilation/accommodation cognitive coping processes possibly occurring in a resilient grief response (meaning reconstruction theory; Gilles \& Neiymeyer, 2006). Use of a measure that assesses for the impact of a stressful event, such as bereavement, on the individuals self and world-view, 
such as the Integration of Stressful Life Experiences Scale (ISLES; Holland, Currier, Coleman \& Neimeyer, 2010) could also reveal how the event also influenced the person's self and worldviews. Similarly, it is also worthwhile for future research to examine the effects of experiencing multiple bereavements across various time frames, as those with an inadequate amount of time to "recover" between losses may experience different outcomes compared to those whose losses are spaced so as to allow time for recovery to baseline functioning.

\section{Implications \& Summary}

Although grief counseling seems to be a common and intuitive intervention given the possible emotional disturbance of having experienced a significant loss, its efficacy has been called into question by many prominent grief researchers (e.g. Currier, Neimeyer, \& Berman, 2008; Jordan \& Neimeyer, 2003; Lindstrom, 2002; Stroebe et al., 2005), and some posit that universal grief interventions can do more harm than good for some bereaved individuals, especially for individuals who are not distressed by the loss (Bonanno \& Lilienfield, 2008). In light of these critiques, efforts have been made to strengthen the efficacy of grief interventions by tailoring them to treat symptoms specific to complicated grief (e.g. Complicated Grief Treatment by Shear and Frank, 2006), rather

than grief experiences that are more general or universal. A comprehensive understanding of grief, including the more adaptive coping mechanisms, can inform and strengthen such interventions; thus, an accurate assessment of grief is required to help determine which grievers may optimally benefit from such interventions and tailor treatment as necessary. This study revealed that considering information about a 
person's psychiatric history and emotion regulation/coping style, in addition to current grief symptoms and how much they influence daily functioning, may help determine which bereaved individuals might benefit the most from grief-related interventions, though these factors are not exhaustive.

Overall, the results from this study support the notion that examining the pre-loss context, such as psychiatric history and emotional regulation skills (especially engagement in positive affect) during bereavement are important factors in distinguishing between resilient and non-resilient outcomes. These findings also uphold previous research examining the overlap in correlates of various bereavement outcomes, such as grief and depression (e.g. Boelen, et al., 2003; Bonanno, 2006; Horowitz et al., 1993; Prigerson et al., 1995a; Prigerson et al., 1996; Prigerson \& Maciejewski, 2005-2006, Stroebe et al., 2008; Thompson, et al., 2007), given the high correlations between these two variables. The results also emphasize the importance of considering the prebereavement context, as illustrated in the Proposed Late-Life Comprehensive Bereavement Outcome Framework, in the prediction of various bereavement outcomes. While depression history, affective complexity, and engagement in positive emotions are just a few of many bereavement-related variables to consider, they shed valuable light on the complex nature of late-life bereavement and enrich our current conceptualization of processes involved in coping with loss. 


\section{REFERENCES}

Aartsen, M .J., Van Tilburg, T., Smits, C. H., Comijs, H. C., \& Knipscheer, K. P. (2005). Does widowhood affect memory performance of older adults? Psychological Medicine: A Journal of Research in Psychiatry and the Allied Sciences , 35(2), 217-226.

Abbot, R. A., Ploubidis, G. B., Huppert, F. A., Kuh, D., Wadsworth, M. E., \& Croudace, T. J. (2006). Psychometric evaluation and predictive utility of Ryff's psychological well-being items in a UK birth cohort sample of women. Health and Quality of Life Outcomes, 4, 76.

Aldwin, C. M. (1991). Does age affect the stress and coping process? Implication of age differences in perceived control. Journal of Gerontology: Psychological Sciences, 46(4), P174-180.

Aldwin, C. M., Sutton, K. J., Chiara, G., \& Sprio, A. (1996). Age differences in stress, coping, and appraisal: Findings from the Normative Aging Study. Journal of Gerontology: Psychological Sciences, 51B(4), P179-P188.

Almeida, O. P., \& Almeida, S. A. (1999). Short versions of the Geriatric Depression Scale: A study of their validity for the diagnosis of major depressive episode according to ICD-10 and DSM-IV. International Journal of Geriatric Psychiatry, $14,858-856$. 
American Psychiatric Association. (2000). Diagnostic and statistical manual of mental disorders $\left(4^{\text {th }}\right.$ ed., Text Revision). Washington, DC: Author.

Amirkhan, J., \& Auyeung, B. (2007). Coping with stress across the lifespan: Absolute vs. relative changes strategy. Journal of Applied Developmental Psychology, 28, 298317.

Areán, P. A., Alvidrez, J., Nery, R., Estes, C., \& Linkins, K. (2003). Recruitment and retention of older minorities in mental health services research. The Gerontologist, 43(1), 36-44.

Asendorpf, J. B., \& Scherer, K. R. (1983). The discrepant repressor: Differentiation between low anxiety, high anxiety, and repression by autonomic-facial-verbal patterns of behavior. Journal of Personality and Social Psychology, 45(6), 13341346.

Averill, J.R. (1968). Grief: It’s nature and significance. Psychological Bulletin, 70(6), $721-748$.

Barger, S. D., Kircher, J. C., \& Croyle, R. T. (1997). The effects of social context and defensiveness on the physiological responses of repressive copers. Journal of Personality and Social Psychology, 73(5), 1118-1128.

Beaufait, D. W., Nelson, E. C., Langraf, J. M., Hays, R. D., Kirk, J. W., Wasson, J. H., \& Keller, A. (1992). Coop Measures of Functional Status. In M. Stewart, F. Tudiver, M. J. Bass, E. V. Dunn \& P. G. Norton (Eds.), Tools for Primary Care Research, Volume 2 (pp. 151-157). Newbury Park, California: Sage Publications.

Beck, J. G., Novy, D. M., Dienfenbach, G. J., Stanley, M. A., Averill, P. M., \& Swann, 
A. C. (2003). Differentiating anxiety and depression in older adults with generalized anxiety disorder. Psychological Assessment, 15(2), 184-192.

Boden, J. M., \& Baumeister, R. F. (1997). Repressive coping: Distraction using pleasant thoughts and memories. Journal of Personality and Social Psychology, 73(1), 4562.

Boelen, P. A., \& Prigerson, G. G. (2007). The influence of symptoms of prolonged grief disorder, depression, and anxiety on quality of life among bereaved adults: A prospective study. European Archives of Psychiatry and Clinical Neuroscience, $257,444-452$.

Boelen, P. A., \& van den Bout, J. (2005). Complicated grief, depression, and anxiety as distinct postloss syndromes: A confirmatory factor analysis study. American Journal of Psychiatry, 162(11), 2175-2177.

Boelen, P. A., \& van den Bout, J. (2008). Complicated grief and uncomplicated grief are distinguishable constructs. Psychiatry Research, 157, 311-314.

Boelen, P. A., van den Bout, J., \& de Keijser, J. (2003). Traumatic grief as disorder distinct from bereavement-related depression and anxiety: A replication study with bereaved mental health care patients. American Journal of Psychiatry, 160 (7), 1339-1341.

Boelen, P. A., van den Bout, J., de Keijser, J., \& Hoijtink, H. (2003). Reliability and validity of the Dutch version of the Inventory of Traumatic Grief (ITG). Death Studies , 27, 227-247.

Bonanno, G. A. (2004). Loss, trauma, and human resilience: Have we understood the 
human capacity to thrive after extremely aversive events? American Psychologist, 59(1), 20-28.

Bonanno, G. A. (2006). Is complicated grief a valid construct? Clinical Psychology: Science and Practice, 13, 129-134.

Bonanno, G. A., Goorin, L., \& Coifman, K. G. (2008). Sadness and Grief. In Lewis, M., Haviland-Jones, J. M., \& Barrett, L. F. (Eds.) Handbook of Emotions ( ${ }^{\text {rd }}$ Ed., pp. 797-810). New York, New York: Guildford Press.

Bonanno, G. A., \& Kaltman, S. (1999). Toward an integrative perspective on bereavement. Psychological Bulletin, 125(6), 760-776.

Bonanno, G. A., Keltner, D., Holen, A. \& Horowitz, M J. (1995). When avoiding unpleasant emotions might not be such a bad thing: Verbal-autonomic response dissociation and midlife conjugal bereavement. Journal of Personality and Social Psychology, 69(5), 975-989.

Bonanno, G. A., \& Lilienfeld, S. O. (2008). Lets be realistic: When grief counseling is effective and when it's not. Professional Psychology: Research and Practice , 39 (3), 377-380.

Bonanno, G. A., Neria, Y., Mancini, A., Coifman, K. G., Litz, B., \& Insel, B. (2007). Is there more to complicated grief than depression and posttraumatic stress disorder? A test of incremental validity. Journal of Abnormal Psychology, 116 (2), 342351.

Bonanno, G. A., Nesse, R. M., \& Wortman, C. B. (2004). Prospective patterns of resilience and maladjustment during widowhood. Psychology and Aging , 19 (2), 260-271. 
Bonanno, G. A., Wortman, C. B., Lehman, D. R., Tweed, R. G., Haring, M., Sonnega, J., et al. (2002). Resilience to loss and chronic grief: A prospective study from preloss to 18-months postloss. Journal of Personality and Social Psychology , 83 (5), 1150-1164.

Bowling, A. (2005). Mode of questionnaire administration can serious effects on data quality. Journal of Public Health, 27(3), 281-291.

Bradburn, N. M. (1969). The structure of psychological well-being. Chicago: Aldine.

Breen, L. J., \& O'Connor, M. (2007). The fundamental paradox in the grief literature: A critical reflection. Omega: The Journal of Death and Dying , 55 (3), 199-218.

Brink, T., Yesavage, L., Lum., Heersema, P., Addey, M., Rose, T. (1982). Screening tests for geriatric depression. Clinical Gerontologist, 1, 37-41

Brodman, K., Erdmann, A. J. Jr., \& Wolff, H. G. (1949). Cornell Medical Index Health Questionnaire Manual. Ithaca, NY: Cornell University Medical College.

Carr, D., House, J. S., Kessler, R. C., Nesse, R. M., Sonnega, J., \& Wortman, C. (2000). Marital quality and psychological adjustment to widowhood among older adults: A longitudinal analysis. The Journals of Gerontology: Series B: Psychological Sciences and Social Sciences, 55B (4), S197-S207.

Carr, D., Nesse, R. M., \& Wortman, C. B. (Eds.). (2006). Spousal bereavement in late life. New York, New York: Springer Publishing Company.

Carstensen, L. L. (1995). Evidence for a life span theory of socioemotional selectivity. Current Directions in Psychological Science, 4(5), 151-156.

Carstensen, L. L., Gross, J. J., \& Fung, H. H. (1997). The social context of emotional 
experience. In M. P. Lawton \& K. W. Schaie (Eds.), Annual Review of Gerontology \& Geriatrics (pp. 325-352). New York: Springer.

Carstensen, L. L., Pasupathi, M., Mayr, U., \& Nesselroade, J. R. (2000). Emotional experience in everyday life across the adult life span. Journal of Personality and Social Psychology, 79(4), 644-655.

Charles, S. T. (2005). Viewing injustice: Greater emotion heterogeneity with age. Psychology and Aging, 20(1), 159-164.

Charles, S. T., \& Carstensen, L. L. (2010). Social and emotional aging. Annual Review of Psychology, 61, 383-409.

Coifman, K. G., Bonanno, G. A., \& Rafaeli, E. (2007). Affect dynamics, bereavement, and resilience to loss. Journal of Happiness Studies, 8, 371-392.

Coifman, K. G., Bonanno, G. A., Ray, R. D., \& Gross, J. J. (2007). Does repressive coping promote resilience? Affective-autonomic response discrepancy during bereavement. Journal of Personality and Social Psychology, 92(4), 745-758.

Crowne, D. P., \& Marlowe, D. (1960). A new scale of social desirability independent of psychopathology. Journal of Consulting Psychology, 24(4), 349-354.

Currier, J. M., Neimeyer, R. A., \& Berman, J. S. (2008). The effectiveness of psychotherapeutic interventions for bereaved persons: A comprehensive quantitative review. Psychological Bulletin, 134(5), 648-661.

Currow, D. C., Allen, K., Plummer, J., Aoun, S., \& Abernethy, A. P. (2008). Bereavement-help seeking following an 'expected' death: a cross-sectional randomized face-to-face population survey. BMC Palliative care, 7(19).

Davis, M.C., Zautra, A.J., Johnson, L.M., Murray, K.E., \& Okvat, H.A. (2007). 
Psychosocial stress, emotion regulation, and resilience among older adults. In C.M. Aldwin, C.L. Park, \& A. Spiro, III (Eds.), Handbook of health psychology and aging (pp. 250-266). New York: Guilford Press.

Derakshan, N., \& Eysenck, M. W. (2001). Manipulation of focus of attention and its effects on anxiety in high-anxious individuals and repressors. Anxiety, Stress, and Coping, 14, 173-191.

Elder, M. A. (1995). Theory and present thinking in bereavement. Issues in Psychoanalytic Psychology, 17(1), 67-83.

Erlangsen, A., Jeune, B., Bille-Brahe, U., \& Vaupel, J. W. (2004). Loss of partner and suicide risks among oldest old: A population-based register study. Age and Ageing , 33 (4), 378-383.

Erskine, J. A. K., Kvavilashvili, L., Conway, M. A., \& Myers, L. (2007). The effects of age on psychopathology, well-being, and repressive coping. Aging and Mental Health, 11(4), 394-404.

Federal Interagency Forum on Age-Related Statistics. (2008). Older Americans 2008: Key indicators of well-being. Washington, DC: U.S. Government Printing Office. Feigelman, W., Jordon, J. R., \& Gorman, B. S. (2008-2009). How they died, time since loss, and bereavement outcomes. OMEGA: Journal of Death and Dying, 58(4), 251-273.

First, M. B., Spitzer, R. L., Gibbon M., and Williams, J. B.W. (2002). Structured Clinical Interview for DSM-IV-TR Axis I Disorders, Research Version, Non-patient Edition. (SCID-I/NP). New York: Biometrics Research, New York State Psychiatric Institute. 
Folkman, S. (2008). The case for positive emotions in the stress process. Anxiety, Stress, and Coping, 21(1), 3-14.

Folkman, S., \& Lazarus, R. S. (1998). Coping as a mediator of emotion. Journal of Personality and Social Psychology, 54(3), 466-475.

Folkman, S., \& Moskowitz, J. T. (2000). Positive affect and the other side of coping. American Psychologist, 55(6), 647-654.

Folstein, M. F., Folsten, S. E., \& McHugh P. R. (1975). 'Mini-mental state’' a practical method for grading the cognitive state of patients for the clinician. Journal of Psychiatric Research, 12, 189-198.

Freud, S. (1963). Mourning and melancholia. (Johan Riviere, Trans.). In General psychology theory. New York: Collier. (Original work published 1917).

Fry, P. S. (2001). The unique contribution of key existential factors to the prediction of psychological well-being of older adults following spousal loss. The Gerontologist, 41(1), 69-81.

Granek, L. (2010). Grief as pathology: The evolution of grief theory in psychology from Freud to the Present. History of Psychology, 13(1), 46-71.

Gilewski, M. J., Farberow, N. L., Gallager, D. E., \& Thompson, L. W. (1991). Interaction of depression and bereavement on mental health in the elderly. Psychology and Aging, 6(1), 67-75.

Gilles, J., \& Neimeyer, R. A. (2006). Loss, grief, and the search for significance: Toward a model of meaning reconstruction in bereavement. Journal of Constructivist Psychology, 19, 31-65.

Gray, M. J., Prigerson, H. G., \& Litz, B. T. (2004). Conceptual and definitional issues in 
complicated grief. In Litz, B. T (Ed). Early Interventions for Trauma and Traumatic Loss (pp. 85-84). New York, New York: Guildford Press.

Greve, W. P. \& Staudinger, U. M. (2006). Resilience in later adulthood and old age: Resources and potentials for successful aging. In D.Cicchetti \& D. J. Cohen (Eds.), Developmental Psychopathology (2nd ed., pp. 796-840). Hoboken, NJ.

Gross, J. J., Carstensen, L. L., Skorpen, C. G., Tsai, J., \& Hsu, A. Y. C. (1997). Emotion and aging: Expression, experience, and control. Psychology and Aging, 12(4), 590-599.

Guindon, S., O’Rourke, N., \& Cappeliez, P. (2004). Factor structure and invariance of responses by older men and women to an abridged version of the Ryff Scale of Psychological Well-Being. Journal of Mental Health and Aging, 10(3), 301-310.

Hamarat, E., Thompson, D., Steele, D., Matheny, K., \& Simons, C. (2002). Age differences in coping resources and satisfaction with life among middle-aged, young-old, and oldest-old adults. Journal of Genetic Psychology, 163(3), 360367.

Hamilton, M. (1960). A rating scale for depression. Journal of Neurology, Neurosurgery and Psychiatry, 23, 56-62.

Hansson, R. O., Hayslip, B., \& Stroebe, M. S. (2007). Grief and Bereavement. In J. A. Blackburn, \& C. N. Dulmus (Eds.), Handbook of Gerontology: Evidence-Based Approaches to Therpay, Practice, and Policy (pp. 367-394). Hoboken, NJ: John Wiley \& Sons, Inc.

Hansson, R. O., \& Stroebe, M. S. (Eds.). (2007). Bereavement in Late Life: Coping, Adaptation, and Developmental Influences. Washington, DC: American 
Psychological Association.

Hardy, S. E., Concato, J., \& Gill, T. M. (2002). Stressful life events among communityliving older persons. Journal of General Internal Medicine, 17, 841-847.

Hardy, S. E., Concato, J., \& Gill, T. M. (2004). Resilience of community-dwelling older persons. Journal of the American Geriatric Society, 52, 257-262.

Haywood, K. L., Garratt, A. M., Fitzpatrick, R. (2005). Quality of life in older people: A structured review of generic self-assessed health instruments. Quality of Life Research 14, 1651-1668.

Hildon, Z., Montgomery, S. M, Blane, D., Wiggins, R. D., \& Netuveli, G. (2009). Examining resilience of quality of life in the face of health-related and psychosocial adversity in older adults: What is "right" about the way we age? The Gerontologist, 50(1), 36-47.

Himmelfarb, S., \& Murrell, S. A. (1983). Reliability and validity of five mental health scales in older persons, Journal of Gerontology, 38, 333-339.

Holland, J. M., Currier, J. M., Coleman, R. A., \& Neimeyer, R. A. (2010). The Integration of Stressful Life Experiences Scale (ISLES): Development and initial validation of a new measure. International Journal of Stress Management, 17(4), 325-352.

Holland, J. M., \& Neimeyer, R. A. (2010). A examination of stage theory of grief among individuals bereaved by natural and violent causes: A meaning-oriented contribution. Omega: The Journal of Death and Dying, 61(2), 103-120.

Horowitz, M. J., Bonanno, G. A., \& Holen, A. (1993). Pathological grief: Diagnosis and explanation. Psychosomatic Medicine , 55, 260-273. 
Howell, D. C. (2007). The analsis of missing data. In W. Outhwaite \& S. Turner. (Eds.), Handbook of Social Methodology. London: Sage.

IBM Corp. (Released 2011). IBM SPSS Statistics for Windows, Version 20.0. Armonk, NY: IBM Corp.

Impens, A. (2005). Bereavment related mortaliity among older adults. Dissertation Abstracts International: Section B: The Sciences and Engineering , 66 (2-B), 846.

Jacobs, S. (1993). Pathological grief: Maladaptation to loss. Washington, DC: American Psychiatric Press.

John, O. P., Donahue, E. M., \& Kentle, R. L. (1991). The Big Five Inventory: Versions 4a and 54 [Technical Report]. Berkeley: University of California, Institute of Personality and Social Research.

Jordan, J. R., \& Neimeyer, R. A. (2003). Does grief counseling work? Death Studies, 27, 765-786.

Kabacoff, R. I., Segal, D. L., Hersen, M., \& Van Hasselt, V. B. (1997). Psychometric properties and diagnostic utility of the Beck Anxiety Inventory and the State-Trait Anxiety Inventory with older adult psychiatric outpatients. Journal of Anxiety Disorders, 11(1), 33-47.

Keltner, D. \& Bonanno, G. A. (1997). Study of laugher and dissociation: Distinct correlates of laughter and smiling during bereavement. Journal of Personality and Social Psychology, 73(4), 687-702.

Kohout, F. J., Berkman, L. F., Evans, D. A., et al. (1993). Two shorter forms of the CESD depression symptom index. Journal of Aging and Health, 5, 179-193.

Kubler-Ross, E. (1969). On Death and Dying. New York, New York: Scribner. 
Kuiper, N. A., Martin, R. A., \& Olinger, L. J. (1993). Coping humour, stress, and cognitive appraisals. Canadian Journal of Behavioral Sciences, 25(1), 81-96.

Labouvie-Vief, G. \& Medler, M. (2002). Affect optimization and affect complexity: Modes and styles of regulation in adulthood. Psychology \& Aging, 17(4), 571588.

Lang, F. R., \& Carstensen, L. L. (1994). Close emotional relationships in late life: Further support for proactive aging in the social domain. Psychology \& Aging, 9(2), 315324.

Langner, R., \& Maercker, A. (2005). Complicated grief as a stress response disorder: evaluating diagnostic criteria in a German sample. Journal of Psychosomatic Research, 58 235-242

Lawton, M. P., Kleban, M. H., Rajagopal, D., \& Dean, J. (1992). Dimensions of affective experience in three age groups. Psychology and Aging, 7(2), 171-184.

Lazarus, R., \& Folkman, S. (1984). Stress, appraisal, and coping. New York: Springer Publishing Company.

Lee, M., \& Carr, D. (2007). Does the context of spousal loss affect the physical functioning of older widowed persons? A longitudinal analysis. Research on Aging , 29(5), 454-487.

Lesher, E. L., \& Berryhill, J. S. (1994). Validation of the geriatric depression scale-short form among inpatients. Journal of Clinical Psychology, 50(2), 256-260.

Lichtenthal, W. G., Cruess, D. G., \& Prigerson, H. G. (2004). A case for establishing complicated grief as a distinct mental disorder in DSM-V. Clinical Psychology Review, 24, 637-662. 
Lindstrom, T. C. (2002). "It ain't necessarily so..." Challenging mainstream thinking about bereavement. Family and Community Health, 25, 11-21.

Lloyd, D. A., \& Tuner, R. J. (2008). Cumulative lifetime adversities and alcohol dependence in adolescence and young adulthood. Drug and Alcohol Dependence, $92,217-226$.

Lockenhoff, C. E., \& Carstensen, L. L. (2004). Socioemotional Selectivity Theory, Aging, and Health: The increasing delicate balance between regulating emotions and making tough choices. Journal of Personality, 72(6), 1396-1424.

Maciejewski, P. K., Zhang, B., Block, S. D., \& Prigerson, H. (2007). An empirical examination of the stage theory of grief. Journal of the American Medical Association, 297(7), 716-723.

Mancini, A. D. \& Bonanno, G. A. (2009). Predictors and parameters of resilience to loss: Toward an individual differences model. Journal of Personality, 77(6), 18051831.

Martin, P., Kliegel, M., Rott, C., Poon, L., \& Johnson, M. A. (2008). Age differences and changes of coping behavior in three age groups: Findings from the Georgia Centenarian Study. International Journal of Aging and Human Development, $66(2), 97-114$

Meeks, S., Carstensen, L. L., Tamsky, B., Wright, T. L., \& Pellegrini, D. (1989). Age differences in coping: Does less mean worse? International Journal of Aging and Human Development, 28(2), 127-140.

Moos, R. H., Brennan, P. L., Schutte, K. K., \& Moos, B. S. (2006). Older adults' coping 
with negative life events: Common processes of managing health, interpersonal, and financial/work stressors. International Journal of Aging and Human Development, 62(2), 39-59.

Myers, L. B. (2000). Identifying repressors: A methodological issue for health psychology. Psychology \& Health, 15, 205-214.

Murrell, S. A., Norris, F. H., \& Hutchins, G. L. (1984). Distribution and desirability of life events in older adults: Population and policy implications. Journal of Community Psychology, 12, 301-311.

Nelson, E. C., Wasson, J., Kirk, J., Keller, A., Clark, D., Deitrich, A.,...Zubkoff, M. (1987). Assessment of function in routine clinical practice: Description of the COOP chart method and preliminary findings. Journal of Chronic Diseases, 40, 55S-63S.

Newton, T. L., \& Contrada, R. J. (1992). Repressive coping and verbal-autonomic response dissociation: The influence of social context. Journal of Personality and Social Psychology, 62(1), 159-167.

Norris, F. H., \& Murrell, S. A. (1988). Prior experience as a moderator of disaster impact on anxiety symptoms in older adults. American Journal of Community Psychology, 16(5), 665-683.

Norris, F. H., \& Murrell, S. A. (1990). Social support, life events, and stress as modifiers of adjustment to bereavement by older adults. Psychology and Aging , 5 (3), 429436.

Onrust, S. A., \& Cuijpers, P. (2006). Mood and anxiety disorders in widowhood: A 
systematic review. Aging and Mental Health, 10(4), 327-334.

Ong, A. D., Bergeman, Bisconti, T. L. (2004). The role of daily positive emotions during conjugal bereavement. Journal of Gerontology: Series B: Psychological Sciences and Social Sciences, 59B(4), P168-P174.

Ong, A. D., Bergeman, C. S., \& Boker, S. M. (2009). Resilience comes with age: Defining feaures in later adulthood. Journal of Personality, 77(6), 1777-1804.

Ott, C. H. (2003). The impact of complicated grief on mental and physical health at various points in the bereavement process. Death Studies, 27, 249-272.

Ott, C. H., Lueger, R. J., Kelber, S. T., \& Prigerson, H. G. (2007). Spousal bereavement in older adults: Common, resilient, and chronic grief with defining characteristics. Journal of Nervous and Mental Disease, 332-341.

Parkes, C. M., \& Prigerson, H.G. (2010). Bereavement: Studies of grief in adult life $\left(4^{\text {th }}\right.$ ed.). New York, New York: Routledge.

Phillips, L. H., Henry, D. J., Hosie, J. A., \& Milne, A. B. (2008). Effective regulation of the experience and expression of negative affect in old age. Journals of Gerontology:

Psychological Sciences, 63B, P138-P145.

Prigerson, H. G., Bierhals, A. J., Kasl, S. V., Reynolds, Charles F. III, Shear, M. K., Newsom, J. T., \& Jacobs, S. (1996). Complicated grief as disorder distinct from bereavement-related depression and anxiety: A replication study. American Journal of Psychiatry, 153(11), 1484-1486.

Prigerson, H. G., Frank, E., Kasl, S. V., Reynolds, C. F., Andersen, B., Zubenko, G. S., et 
al. (1995a). Complicated grief and bereavement-related depression as distinct disorders: Preliminary empirical validation in elderly bereaved spouses. American Journal of Psychiatry, 152 (1), 22-30.

Prigerson, H.G., Horowitz, M. J., Jacobs, S. C., Parkes, C. M., Aslan, M., Goodkin, K., et al. (2009). Prolonged grief disorder: Psychometric validation of criteria proposed for DSM-V and ICD- 11. PloS Med, 6(8), 1-12.

Prigerson, H. G., \& Jacobs, S. C. (2001). Traumatic grief as a distinct disorder: A rationale, consensus criteria, and a preliminary empirical test. In M. S. Stroebe, R. O. Hansson, W. Stroebe, and H. A. W Schut (Eds.), Handbook of bereavement research. Consequences, coping and care (pp. 613-647). Washington, DC: American Psychological Association Press.

Prigerson, H. G., \& Maciejewski, P. K. (2005-2006). A call for sound empirical testing and evaluation of criteria for complicated grief proposed for DSM-V. OMEGA: Journal of Death \& Dying, 52(1), 9-19.

Prigerson, H. G., Maciejewski, P. K., Reynolds III, C. F., Bierhals, A. J., Newsom, J. T., Fasiczka, A., et al. (1995b). Inventory of complicated grief: A scale to measure maladaptive symptoms of loss. Psychiatry Research, 59, 65-79.

Prigerson, H. G., Shear, K., Jacobs, S. C., Reynolds, C. F., Maciejewski, P. K., Davidson, J. R., et al. (1999). Consenus criteria for traumatic grief: A preliminary empirical test. British Journal of Psychiatry, 174 (1), 67-73.

Radolff, L. (1977). The CES-D scale: A self-repot depression scale for research in the general population. Applied Psychological Measurement, 1, 381-401.

Richardson, V. E., \& Balaswamy, S. (2001). Coping with bereavement among elderly 
widowers. Omega: Journal of Death and Dying, 43(2), 129-144.

Ryff, C. D., Keyes, C. L. M. (1995). The structure of psychological well-being revisited. Journal of Personality and Social Psychology, 69(4), 719-727.

Ryff, C. D., Lee, Y. H., Essex, M. J., Schmutte, P. S. (1994). My children and me: Midlife evaluations of grown children and of self. Psychology and Aging, 9(2), $195-205$.

Ryff, C. D., \& Singer, B. (2003). Flourishing under fire: Resilience as a prototype of challenged thriving. In C.L.M. Keyes \& J. Haidt (Eds.), Positive psychology and the life well-lived (pp. 15-36). Washington, DC: American Psychological Association.

Safer, M. A., Bonanno, G. A., \& Field, N. P. (2001). "It was never that bad": Bias recall of grief and long-term adjustment to the death of a spouse. Memory, 9(3), 195204.

Sandler, I. N., Wolchick, S. A., \& Ayers, R. S. (2008). Resilience rather than recovery: A contextual framework on adaptation following bereavement. Death Studies, 32, $59-73$.

Seery, M D., Holman, E. A., \& Silver, R. C. (2010). Whatever does not kill us: Cumulative lifetime adversity, vulnerability, and resilience. Journal of Personality and Social Psychology, 99(6), 1025-1041.

Segal, D. L., June, A., Payne, M., Coolidge, F. L., \& Yochim, B. (2010). Development and initial validation of self-report assessment tool for anxiety among older adults: The Geriatric Anxiety Scale. Journal of Anxiety Disorders, 24, 709-714.

Shah, S. N., \& Meeks, S. (2012). Late-life bereavement and complicated grief: A 
proposed comprehensive framework. Aging and Mental Health, 16(1), 39-56.

Shear, M. K., \& Frank, E. (2006). Treatment of Complicated Grief: Integrating Cognitive-Behavioral Methods with Other Treatment Approaches. Cognitivebehavioral therapies for trauma (2nd ed.) (pp. 290-320). New York, NY US: Guilford Press.

Sheikh J., Yesavage J. A. (1986). Geriatric Depression Scale (GDS): recent evidence and development of a shorter version. Clinical Gerontologist, 5, 165-173.

Singh, B., \& Raphael, B. (1981). Postdisaster morbidity of the bereaved: A possible role of preventive psychiatry? The Journal of Nervous and Mental Disease, 169, 203212.

Soubelet, A., \& Salthouse, T. A. (2011). Influence of social desirability on age differences in self-reports of mood and personality. Journal of Personality, 79(4), $741-762$.

Spielberger C. D., Gorsuch R. L., Lushene P. R., Vagg P. R., Jacobs A. G. (1983). Manual for the State-Trait Anxiety Inventory (Form Y). Consulting Psychologists Press, Inc.: Palo Alto.

Stewart, M., Craig, D., MacPherson, K., \& Alexander, S. (2001). Promoting positive affect and diminishing loneliness of widowed seniors through a support intervention. Public Health Nursing, 18(1), 54-63.

Stanely, M. A., Beck, J. G., \& Zebb, B. J. (1996). Psychometric properties of four anxiety measures in older adults. Behaviour, Research and Therapy, 34(10), 827-838.

Stanely, M. A., Novy, D. M., Bourland, S. L., Beck, J. G., \& Averill, P. M. (2001). 
Assessing older with generalized anxiety: a replication and extension. Behaviour Research and Therapy, 38, 221-235.

Stroebe, M. S., Folkman, S., Hansson, R. O., \& Schut, H. (2006). The prediction of bereavement outcome: Development of an integrative risk framework. Social Science \& Medicine, 63, 2440-2451.

Stroebe, M. S., Hansson, R. O., Schut, H., \& W. Stroebe, W. (Eds.). (2008). Handbook of Bereavement Research and Science: Advances in Theory and Intervention. Washington, DC: American Psychological Association.

Stroebe, M .S., \& Schut, H. (1999). The dual process model of coping with bereavement: Rationale and description. Death Studies, 23, 197-224.

Stroebe, M. S., \& Schut, H. (2010). The dual process model of coping with bereavement: A decade on. Omega: The Journal of Death and Dying, 61(4), 273-289.

Stroebe, M. S., Schut, H., \& Stroebe, W. (2007). Health outcomes of bereavement. Lancet, 370, 1960-1973.

Stroebe, M. S., \& Stroebe, W. (1989). Who participates in bereavement research? A review and empirical study. Journal of Death and Dying, 20(1), 1- 20.

Stroebe, M. S., Stroebe, W., \& Schut, H. (2003). Bereavement researh: methological issues and ethical concerns. Palliative Medicine, 17, 235-240.

Stroebe, W., \& Schut, H. (2001). Risk factors in bereavement outcome: A methodolgoical and emprical review. In M. S. Stroebe, R. O. Hansson, W. Stroebe, and H. A. W Schut (Eds.), Handbook of bereavement research. Consequences, coping and care (pp. 349-371). Washington, DC: American Psychological Association Press. 
Stroebe, W., Schut, H., \& Stroebe, M. S. (2005). Grief work, disclosure and counseling: Do they help the bereaved? Clinical Psychology Review, 25, 395-414.

Thompson, L. W., Tang, P. C., di Mario, J., Cusing, M., \& Gallagher-Thomspon, D. (2007). Bereavement and adjustment disorders. In D. G. Blazer, D. C. Steffens, \& E. W. Busse (Eds.), Essentials of Geriatric Psychiatry (pp. 219-239). Arlington, VA: American Psychiatric Publishing.

Tugade, M. M., \& Fredrickson, B. L. (2004). Resilient indivuals use postive emotions to bounce back from negative emotional experiences. Journal of Personality and Social Psychology, 86(2), 320-333.

Turner, R. J., \& Lloyd, D. A. (1995). Lifetime traumas and mental health: The signficance of cumulative adversity. Journal of Health and Social Behavior, 36, 360-376.

U.S. Deparment of Health and Human Services. (2010). Health, United States, 2009, With Special Feature on Medical Technology. Hyattsville, MD: Centers for Disease Control and Prevention, National Center for Health Statistics.

Vahia, I.V., Meeks, T.W., Thompson, W.K., Depp, C.A., Zisook, S., Allison, M. et al. (2010). Subthreshold depression and successful aging in older women, American Journal of Geriatric Psychiatry, 18, 212-220.

Van Baarsen, B., van Duijn, M. A., Smit, J. H., Snijders, T. A., \& Knipscheer, K. P. (2001-2002). Patterns of adjustment to partner loss in old age: The widowhood adaptation longitudinal study. Omega: The Journal of Death and Dying , 44(1), 536.

Van der Houwen, K., Stroebe, M., Stroebe, W., Schut, H., van den Bout, J., \& 
Winjgaards-De Meij, L. (2010). Risk factors for bereavement outcome: A multivariate approach. Death Studies, 34, 195-220.

Walter, C. A., \& McCoyd, J. L. M. (2009). Grief and loss across the lifespan: A biopsychosocial perspective. New York, New York: Spring Publishing Company, LLC.

Wancata, J., Alexandrowicz, R., Marquart, B., Weiss, M., \& Friedrich, F. (2006) Acta Psychiatrica Scaninavica, 114, 398-410.

Ware, J. E., Kosinksi, M., \& Keller, S. D. (1996). A 12-item short-form health survey: Construction of scales and preliminary tests of reliability of validity. Medical Care, 34(3), 220-233.

Watson, D., Clark, L., \& Tellegan, A. (1988). Development and validation of brief measures of positive and negative affect: The PANAS scales. Journal of Personality and Social Psychology, 54, 1063-1070.

Whitbourne, S. K., \& Meeks, S. (2010). Psychopathology, bereavement and aging. In K. W. Shaie, \& S. L. Willis (Eds.), Handbook on the Psychology of Aging (7th ed.). Elsevier.

Wortman, C. B., \& Silver, R. C. (1989). The myths of coping with loss. Journal of Consulting and Clinical Psychology, 57, 349-357.

Weinberger, D. A., Schwartz, G. E., \& Davidson, R. J. (1979). Low-anxious, highanxious, and repressive coping styles: Psychometric patterns and behavioral and physiological response to stress. Journal of Abnormal Psychology, 88(4), 369380.

Werner, E. E. (1993). Risk, resilience, and recovery: Perspectives from the Kauai 
Longitudinal Study. Development and Psychopathology, 5(4), 503-515.

Yesavage, J. A., Brink, T. L., Rose, T. L., Lum, O., Huang, V., Adey, M. et al. (1982). Development and validation of a geriatric depression screening scale: preliminary report. Journal of Psychiatric Research, 17, 37-49.

Yochim, B. P., Mueller, A. E., June, A., Segal, D. L. (2011). Psychometric properties of the Geriatric Anxiety Scale: Comparison of the Beck Anxiety Inventory and the Geriatric Anxiety Inventory. Clinical Gerontologist, 34, 21-33.

Zautra, A. J., Arewasikporn, A., \& Davis, M. C. (2010). Resilience: Promoting wellbeing through recovery, sustainability, and growth. Research in Human Development, 7(3), 221-238.

Zautra, A. J., Berkhof, J., \& Nicolson, N. A. (2002). Changes in affect intercorrelation as a function of stressful events. Cognition and Emotion, 16(2), 309-318.

Zisook, S., DeVaul, R. A., \& Click, Jr. M. A. (1982). Measuring symptoms of grief and bereavement. American Journal of Psychiatry, 139, 1590-1593. 
Table 1

Recruitment Sources for Study Participants - no. (\%)

\begin{tabular}{lcc} 
Recruitment Source & $\begin{array}{c}\text { Target Subsample } \\
(\mathrm{n}=26)\end{array}$ & Total $(\mathrm{N}=74)$ \\
\hline Senior Center & $8(30.8 \%)$ & $29(39.2 \%)$ \\
Physician's Office & $2(7.7 \%)$ & $4(5.4 \%)$ \\
Senior Housing Unit & - & $3(4.1 \%)$ \\
Non-Profit Hospice Organization & $6(23.1 \%)$ & $16(21.6 \%)$ \\
Grief Support Group & $2(7.7 \%)$ & $5(6.8 \%)$ \\
Social Media & $5(19.2 \%)$ & $8(10.8 \%)$ \\
YMCA & - & $2(2.7 \%)$ \\
Festival & - & $1(1.4 \%)$ \\
No response & $3(11.5 \%)$ & $6(8.1 \%)$ \\
\hline
\end{tabular}

${ }^{+}$Target Subsample represents those individuals whose most recent bereavement occurred within 6-12 months of completing the study packet. 
Table 2

Characteristics of Study Participants

\begin{tabular}{|c|c|c|}
\hline Characteristic & $\begin{array}{c}\text { Target } \\
\text { Subsample } \\
(\mathrm{n}=26)\end{array}$ & $\begin{array}{c}\text { Total } \\
(\mathrm{N}=74)\end{array}$ \\
\hline Age (years) & $70.73(6.58)$ & $71.68(8.39)$ \\
\hline \multicolumn{3}{|l|}{ Gender - no. $(\%)$} \\
\hline Female & $22(84.6 \%)$ & $61(82.4 \%)$ \\
\hline Male & $4(15.4 \%)$ & $12(16.2 \%)$ \\
\hline No response & - & $1(1.4 \%)$ \\
\hline \multicolumn{3}{|l|}{ Ethnicity - no. (\%) } \\
\hline Caucasian & $23(88.5 \%)$ & $62(83.8 \%)$ \\
\hline African-American & $3(11.5 \%$ & $9(12.2 \%)$ \\
\hline Hispanic & - & $1(1.4 \%)$ \\
\hline No response & - & $2(2.7 \%)$ \\
\hline \multicolumn{3}{|c|}{ Current Marital Status - no. (\%) } \\
\hline Married & $2(7.7 \%)$ & $13(17.6 \%)$ \\
\hline Widowed & $19(73.1 \%)$ & $49(66.2 \%)$ \\
\hline Separated & - & $1(1.4 \%)$ \\
\hline Never married & $1(3.8 \%)$ & $1(1.4 \%)$ \\
\hline Divorced & $3(11.5 \%)$ & $9(12.2 \%)$ \\
\hline No response & $1(3.8 \%$ & $1(1.4 \%)$ \\
\hline \multicolumn{3}{|c|}{ Current Living Situation - no. $(\%)$} \\
\hline Living alone & $14(53.8 \%)$ & $45(60.8 \%)$ \\
\hline With spouse/partner & $2(7.7 \%)$ & $9(12.2 \%)$ \\
\hline $\begin{array}{l}\text { With spouse/partner \& } \\
\text { children }\end{array}$ & & $3(4.1 \%)$ \\
\hline With children only & $5(19.2 \%)$ & $9(12.2 \%)$ \\
\hline Other & $5(19.2 \%)$ & $8(10.8 \%)$ \\
\hline \multicolumn{3}{|l|}{ Education - no. $(\%)$} \\
\hline Less than $12^{\text {th }}$ grade & $1(3.8 \%)$ & $6(8.1 \%)$ \\
\hline High school or GED & $8(30.8 \%)$ & $17(23.0 \%)$ \\
\hline More than high school & $16(61.5 \%)$ & $49(66.2 \%)$ \\
\hline No response & - & $2(2.7 \%)$ \\
\hline \multicolumn{3}{|l|}{ Employment Status - no. (\%) } \\
\hline Full time & $3(11.5 \%)$ & $9(12.2 \%)$ \\
\hline Part time & $2(11.5 \%)$ & $6(8.1 \%)$ \\
\hline Homemaker & $4(15.4 \%)$ & $7(9.5 \%)$ \\
\hline Disabled & $1(3.8 \%)$ & $4(5.4 \%$ \\
\hline Retired & $15(57.7 \%)$ & $46(62.2 \%)$ \\
\hline No response & - & $2(2.7 \%)$ \\
\hline \multicolumn{3}{|l|}{ Yearly Income - no. (\%) } \\
\hline$<\$ 20,000$ & $8(30.8 \%)$ & $24(32.4 \%)$ \\
\hline$\$ 20,000-59,999$ & $13(50.0 \%)$ & $31(41.9 \%)$ \\
\hline$>\$ 60,000$ & $1(3.8 \%)$ & $9(12.2 \%)$ \\
\hline No response & $4(15.4 \%$ & $10(13.5 \%)$ \\
\hline
\end{tabular}

${ }^{+}$Target Subsample represents those individuals whose most recent bereavement occurred within 6-12 months of completing the study packet. 
Table 3

Bereavement Characteristics of Study Participants

\begin{tabular}{|c|c|c|}
\hline Characteristic & $\begin{array}{l}\text { Target Subsample } \\
\qquad(\mathrm{n}=26)^{+}\end{array}$ & $\begin{array}{c}\text { Total } \\
(\mathrm{N}=74)\end{array}$ \\
\hline Months bereaved & $8.81(2.50)$ & $9.25(9.55)$ \\
\hline \multicolumn{3}{|l|}{ Relation to the Deceased } \\
\hline Spouse & $12(46.2 \%)$ & $29(39.2 \%)$ \\
\hline Son & $2(7.7 \%)$ & $4(5.4 \%)$ \\
\hline Parent & $1(3.8 \%)$ & $3(4.1 \%)$ \\
\hline Daughter & $1(3.8 \%)$ & $3(4.1 \%)$ \\
\hline Extended family & $1(3.8 \%)$ & $8(10.8 \%)$ \\
\hline Grandchild & - & $2(2.7 \%)$ \\
\hline Other & $9(34.6 \%)$ & $23(31.1 \%)$ \\
\hline No response & - & $2(2.7 \%)$ \\
\hline \multicolumn{3}{|l|}{ Circumstances of Death } \\
\hline Chronic illness & $12(46.2 \%)$ & $41(56.8 \%)$ \\
\hline Acute illness & $7(26.9 \%)$ & $10(13.5 \%)$ \\
\hline Car accident & $1(3.8 \%)$ & $2(2.7 \%)$ \\
\hline Homicide & - & $2(2.7 \%)$ \\
\hline Suicide & - & $3(4.1 . \%)$ \\
\hline Natural death & $5(19.2 \%)$ & $11(14.9 \%)$ \\
\hline Overdose & $1(3.8 \%)$ & $1(1.4 \%)$ \\
\hline No response & - & $3(4.1 \%)$ \\
\hline \multicolumn{3}{|l|}{ Professional Help Sought } \\
\hline Grief counseling & $7(26.9 \%)$ & $20(27.0 \%)$ \\
\hline Support group & $4(15.4 \%)$ & $9(12.2 \%)$ \\
\hline Religious/Spiritual support & - & $1(1.4 \%)$ \\
\hline Psychiatry & $1(3.8 \%)$ & $3(4.1 \%)$ \\
\hline Psychotherapy & $2(7.1 \%)$ & $2(2.7 \%)$ \\
\hline None & $12(46.2 \%)$ & $36(48.6 \%)$ \\
\hline No response & - & $3(4.1 \%)$ \\
\hline
\end{tabular}

${ }^{+}$Subsample represents those individuals whose most recent bereavement occurred within 6-12 months of completing the study packet. 
Table 4

Descriptive Statistics for Key Study Variables for the Whole Sample $(N=74)$

$\underline{N}$

Mean (SD)

Pre-Bereavement Variables: no. (\%)

History of Depression

$36(48.6 \%)$

Coping \& Emotion Regulation Variables

$\begin{array}{lll}\text { STAI-Y } & 60 & 38.00(9.47) \\ \text { MC } & 56 & 20.02(5.49)\end{array}$

Affect Complexity \& Positive Emotions Variables

PANAS Positive (past month)

65

$26.98(13.82)$

PANAS Negative (past month)

PANAS Positive (present)

$30.66(12.87)$

PANAS Negative (present)

70

$16.39(7.51)$

Outcome Variables

Grief

ITG

$64.79(24.77)$

Depression

$$
\text { GDS - } 15
$$

66

Psychological Well-Being

$\begin{array}{lll}\text { Ryff Autonomy } & 70 & 12.81(2.29) \\ \text { Ryff Environmental Mastery } & 70 & 13.14(2.57) \\ \text { Ryff Purpose in Life } & 73 & 10.38(3.02) \\ \text { Ryff Positive Relations with Others } & 73 & 10.23(2.60) \\ \text { Ryff Personal Growth } & 73 & 13.10(2.48) \\ \text { Ryff Self-Acceptance } & 72 & 11.86(2.70) \\ \text { Ryff Composite Score } & 69 & 71.81(9.07)\end{array}$

Social and Emotional Functioning

COOP Emotional Status $\quad 73$

COOP Social Activities/Social Support

71

$2.04(1.15)$

Note: STAI-Y = Speilberger State-Trait Anxiety Inventory, Form Y-2; MC = Marlow

Crowne Social Desirability Scale; PANAS = Positive and Negative Affect Schedule; ITG

$=$ Inventory of Traumatic Grief; GDS $-15=$ Geriatric Depression Scale- 15; Ryff = Ryff's Scale of Psychological Well-Being; COOP = Dartmouth COOP Scales of Functioning 
Table 5

Descriptive Statistics for Key Variables for Target Subsample $(n=26)^{+}$

$\underline{N}$

Mean (SD)

Pre-Bereavement Variables: no. (\%)

History of Depression

Coping \& Emotion Regulation Variables

STAI-Y

$\mathrm{MC}$

Affect Complexity \& Positive Emotions Variables

PANAS Positive (past month)

PANAS Negative (past month)

PANAS Positive (present)

PANAS Negative (present)
19

22

24

25

25

26

25

Grief

ITG

Depression

GDS - 15

24

$3.08(3.54)$

Psychological Well-Being

Ryff Autonomy

26

Ryff Environmental Mastery

26

Ryff Purpose in Life

Ryff Positive Relations with Others

Ryff Personal Growth

Ryff Self-Acceptance

Ryff Composite Score
26

26

26

26

26
$35.58(8.88)$

$20.18(5.16)$

$25.25(8.33)$

$19.56(7.59)$

$28.12(9.82)$

$15.19(6.03)$

$63.48(22.79)$

$12.57(1.77)$

$12.92(2.42)$

$10.35(2.87)$

$10.42(2.16)$

$12.92(2.61)$

$12.31(1.74)$

$71.50(1.26)$

Social and Emotional Functioning

COOP Emotional Status

26

$2.27(1.04)$

COOP Social Activities/Social Support

25

${ }^{+}$Target Subsample represents those individuals whose most recent bereavement occurred within 6-12 months of completing the study packet. 
Table 6

Missing Data for Key Study Variables: Target Subsample $(n=26)^{+}$

\section{Missing Cases Per Measure}

Before Mean Imputation After Mean Imputation

\begin{tabular}{|c|c|c|c|c|}
\hline Measure & $\underline{\mathrm{N}}$ & Percent & $\underline{\mathrm{N}}$ & $\underline{\text { Percent }}$ \\
\hline GDS & 2 & $7.7 \%$ & 0 & $0 \%$ \\
\hline ITG & 1 & $3.8 \%$ & 0 & $0 \%$ \\
\hline PANAS Positive (Past Month) & 2 & $7.7 \%$ & 0 & $0 \%$ \\
\hline PANAS Negative (Past Month) & 1 & $3.8 \%$ & 0 & $0 \%$ \\
\hline PANAS Positive (Present) & 1 & $3.8 \%$ & 1 & $3.8 \%$ \\
\hline PANAS Negative (Present) & 1 & $3.8 \%$ & 0 & $0 \%$ \\
\hline COOP Social Activities & 1 & $3.8 \%$ & 1 & $3.8 \%$ \\
\hline STAI & 7 & $26.9 \%$ & 3 & $11.5 \%$ \\
\hline $\mathrm{MC}$ & 4 & $15.4 \%$ & 0 & $0 \%$ \\
\hline
\end{tabular}

${ }^{+}$Target Subsample represents those individuals whose most recent bereavement occurred within 6-12 months of completing the study packet. 
Table 7

Descriptive Statistics for Imputed Variables: Target Subsample $(n=26)^{+}$

\section{$\underline{\text { Before Mean Imputation }}$}

Measure

GDS

ITG

PANAS Positive (Past Month)

PANAS Negative (Past Month)

PANAS Positive (Present)

PANAS Negative (Present)

COOP Social Activities

STAI-Y

$\mathrm{MC}$

Target Subsample represents those individuals whose most within 6-12 months of completing the study packet. $\underline{\text { After Mean Imputation }}$

$\begin{array}{llll}\underline{\mathrm{N}} & \underline{\text { Mean }(S D)} & \underline{\mathrm{N}} & \underline{\text { Mean }(S D)} \\ 24 & 3.08(3.54) & 26 & 3.40(3.67) \\ 25 & 63.48(22.79) & 26 & 62.67(22.71) \\ 24 & 25.25(8.33) & 26 & 24.67(8.27) \\ 25 & 19.56(7.59) & 26 & 19.61(7.44) \\ 25 & 28.12(9.82) & 25 & 28.12(9.82) \\ 26 & 15.19(6.03) & 26 & 14.91(5.56) \\ 25 & 1.96(1.27) & 25 & 1.96(1.27) \\ 19 & 35.58(8.88) & 26 & 34.34(8.29) \\ 22 & 20.18(5.16) & 26 & 19.75(5.59)\end{array}$

$19.75(5.59)$ 
Table 8

Missing Data for Key Study Variables: Whole Sample $(N=74)$

Missing Cases Per Measure

$\underline{\text { Before Mean Imputation } \quad \text { After Mean Imputation }}$

\begin{tabular}{|c|c|c|c|c|}
\hline Measure & $\underline{\mathrm{N}}$ & Percent & $\underline{\mathrm{N}}$ & $\underline{\text { Percent }}$ \\
\hline GDS & 8 & $10.8 \%$ & 0 & $0 \%$ \\
\hline ITG & 11 & $14.9 \%$ & 1 & $1.4 \%$ \\
\hline PANAS Positive (Past Month) & 9 & $12.2 \%$ & 4 & $5.4 \%$ \\
\hline PANAS Negative (Past Month) & 8 & $10.8 \%$ & 2 & $2.7 \%$ \\
\hline PANAS Positive (Present) & 4 & $5.4 \%$ & 3 & $4.1 \%$ \\
\hline PANAS Negative (Present) & 2 & $2.7 \%$ & 1 & $1.4 \%$ \\
\hline COOP Emotional Status & 1 & $1.4 \%$ & 1 & $1.4 \%$ \\
\hline COOP Social Activities & 3 & $4.1 \%$ & 3 & $4.1 \%$ \\
\hline Ryff Composite Score & 5 & $6.8 \%$ & 3 & $4.1 \%$ \\
\hline STAI-Y & 14 & $18.9 \%$ & 7 & $9.5 \%$ \\
\hline $\mathrm{MC}$ & 18 & $24.3 \%$ & 4 & $5.4 \%$ \\
\hline
\end{tabular}


Table 9

Descriptive Statistics for Imputed Variables: Whole Sample $(N=74)$

\section{Before Mean}

Imputation

\begin{tabular}{lllll} 
Measure & $\underline{\mathrm{N}}$ & $\underline{\mathrm{M}(S D)}$ & $\underline{\mathrm{N}}$ & $\underline{\mathrm{M}(S D)}$ \\
GDS & 66 & $3.36(3.58)$ & 74 & $3.55(3.61)$ \\
ITG & 63 & $64.79(24.77)$ & 73 & $63.7624 .18)$ \\
PANAS Positive (Past Month) & 65 & $26.98(13.82)$ & 70 & $25.54(9.62)$ \\
PANAS Negative (Past Month) & 66 & $21.41(8.89)$ & 72 & $21.11(8.94)$ \\
PANAS Positive (Present) & 70 & $30.66(12.87)$ & 71 & $29.12(9.60)$ \\
PANAS Negative (Present) & 71 & $16.39(7.51)$ & 73 & $16.33(7.30)$ \\
COOP Emotional Status & 73 & $2.25(1.16)$ & 73 & $2.25(1.16)$ \\
COOP Social Activities & 71 & $2.04(1.15)$ & 71 & $2.04(1.15)$ \\
Ryff Composite Score & 69 & $71.81(9.07)$ & 71 & $71.53(9.10)$ \\
STAI-Y & 60 & $38.00(9.47)$ & 67 & $37.55(9.55)$ \\
MC & 56 & $20.02(5.49)$ & 70 & $20.19(5.56)$ \\
\hline
\end{tabular}

After Mean

Imputation

$\mathrm{M}(S D)$

$3.55(3.61)$

(3.76 24.18$)$

$1.11(8.94)$

$9.12(9.60)$

$16.33(7.30)$

$.25(1.16)$

$04(1.15)$

$37.55(9.55)$ 
Table 10

Kolmogorov-Smirnov Test of Normality: Target Subsample $(n=26)^{+}$

\begin{tabular}{lccc} 
Measure & $D$ & $d f$ & $p$ \\
\hline GDS & .205 & 26 & $.006^{*}$ \\
ITG & .141 & 26 & .200 \\
PANAS Positive (past month) & .131 & 26 & .200 \\
PANAS Negative (past month) & .109 & 26 & .200 \\
PANAS Positive (present) & .069 & 25 & .200 \\
PANAS Negative (present) & .219 & 26 & $.002^{*}$ \\
Ryff Composite & .126 & 26 & .200 \\
STAI-Y & .118 & 24 & .200 \\
MC & .104 & 26 & .200 \\
\hline
\end{tabular}

${ }^{+}$Target Subsample represents those individuals whose most recent bereavement occurred within 6-12 months of completing the study packet.

$* p<.05$ level 
Table 11

Kolmogorov-Smirnov Test of Normality: Whole Sample $(N=74)$

\begin{tabular}{lccl}
\hline Measure & $D$ & $d f$ & $p$ \\
\hline GDS & .193 & 74 & $.000^{* * *}$ \\
ITG & .085 & 73 & .200 \\
PANAS Positive (past month) & .054 & 73 & .200 \\
PANAS Negative (past month) & .107 & 72 & $.040^{*}$ \\
PANAS Positive (present) & .060 & 71 & .200 \\
PANAS Negative (present) & .193 & 73 & $.000^{* * *}$ \\
Ryff Composite & .140 & 71 & $.001^{* *}$ \\
STAI-Y & .123 & 67 & $.014^{*}$ \\
MC & .094 & 70 & .200 \\
\hline
\end{tabular}

$* \mathrm{p}<.05, * * \mathrm{p}<.01, * * * \mathrm{p}<.001$ 
Table 12

Bivariate Correlations between Age and Bereavement Outcomes and Characteristics

\begin{tabular}{lcc} 
Variable & $\begin{array}{c}\text { Target Subsample } \\
(\mathrm{n}=26)\end{array}$ & $\begin{array}{c}\text { Whole Sample } \\
(\mathrm{N}=74)\end{array}$ \\
\hline GDS & -.23 & $r_{s}=-.26$ \\
ITG & -.24 & $-.24^{*}$ \\
Ryff Composite & -.02 & -.07 \\
COOP Emotional Status & -.26 & -.17 \\
COOP Social Activities & -.10 & -.23 \\
Total Months Bereaved & .01 & .165 \\
Cumulative Lifetime Loss & -.33 & .05
\end{tabular}

${ }^{+}$Target Subsample represents the 26 individuals whose most recent bereavement occurred within 6-12 months of completing the study packet.

$* p<.05$ 
Table 13

Bereavement-Related Variable Means for Males and Females

\begin{tabular}{|c|c|c|c|c|}
\hline \multirow{3}{*}{$\begin{array}{l} \\
\text { Variables: Target Sample } \\
(\mathrm{n}=26)\end{array}$} & \multicolumn{2}{|c|}{ Gender } & \multirow[b]{2}{*}{$t$} & \multirow[b]{2}{*}{$d f$} \\
\hline & Males & Females & & \\
\hline & & & & \\
\hline GDS & $\begin{array}{c}3.05 \\
(2.48)\end{array}$ & $\begin{array}{c}3.46 \\
(3.89)\end{array}$ & .30 & 24 \\
\hline ITG & $\begin{array}{c}67.75 \\
(12.42)\end{array}$ & $\begin{array}{c}61.74 \\
(24.31)\end{array}$ & .48 & 24 \\
\hline Ryff Composite & $\begin{array}{c}7.02 \\
(3.51)\end{array}$ & $\begin{array}{c}6.36 \\
(1.36)\end{array}$ & .84 & 24 \\
\hline COOP Emotional Status & $\begin{array}{l}2.25 \\
(.96)\end{array}$ & $\begin{array}{c}2.27 \\
(1.08)\end{array}$ & -.04 & 24 \\
\hline COOP Social Activities & $\begin{array}{l}2.75 \\
(1.26)\end{array}$ & $\begin{array}{c}1.81 \\
(1.25)\end{array}$ & .64 & 24 \\
\hline Total Months Bereaved & $\begin{array}{l}11.25 \\
(.96)\end{array}$ & $\begin{array}{l}8.36 \\
(2.44)\end{array}$ & $-2.30^{*}$ & 24 \\
\hline Cumulative Lifetime Loss & $\begin{array}{l}3.50 \\
(1.30)\end{array}$ & $\begin{array}{l}5.81 \\
(2.32)\end{array}$ & -1.92 & 24 \\
\hline \multicolumn{5}{|l|}{$\begin{array}{l}\text { Variables: Whole Sample } \\
(\mathrm{N}=74)\end{array}$} \\
\hline ITG & $\begin{array}{c}76.15 \\
(32.90)\end{array}$ & $\begin{array}{c}61.67 \\
(21.59)\end{array}$ & 1.93 & 70 \\
\hline Ryff Composite & $\begin{array}{c}70.91 \\
(16.63)\end{array}$ & $\begin{array}{l}71.44 \\
(7.04)\end{array}$ & -.18 & 68 \\
\hline COOP Emotional Status & $\begin{array}{l}2.17 \\
1.34\end{array}$ & $\begin{array}{c}2.25 \\
(1.14)\end{array}$ & -.22 & 70 \\
\hline COOP Social Activities & $\begin{array}{c}2.75 \\
(1.42)\end{array}$ & $\begin{array}{l}1.90 \\
(1.05)\end{array}$ & $2.40 *$ & 68 \\
\hline Total Months Bereaved & $\begin{array}{c}9.18 \\
(9.85)\end{array}$ & $\begin{array}{c}9.37 \\
(9.65)\end{array}$ & -.06 & 60 \\
\hline Cumulative Lifetime Loss & $\begin{array}{c}3.83 \\
(2.08)\end{array}$ & $\begin{array}{c}5.41 \\
(2.31)\end{array}$ & $-2.19^{*}$ & 71 \\
\hline
\end{tabular}

${ }^{+}$Target Subsample represents the 26 individuals whose most recent bereavement occurred within 6-12 months of completing the study packet.

Note: Standard Deviations appear in parentheses below means.

$* p<.05$ 
Table 14

Bereavement-Related Variable Means for Caucasian and African-American Participants Race

Caucasia

$\mathrm{n}$

Variables: Target Sample

$(\mathrm{n}=26)$

GDS

ITG

Ryff Composite

COOP Emotional Status

COOP Social Activities

Total Months Bereaved

Cumulative Lifetime Loss
African-

American $d f$

$t \quad d f$

1.67

(2.08)

49.45

(10.90)

75.33

$(5.51)$

2.00

(1.73)

2.00

$(1.00)$

(1.33)

8.91

$(2.43)$

5.40

(2.43)
8.00

(3.46)

6.00

(1.73)
24

24

24

24

23

34

24

Variables: Whole Sample

$(\mathrm{n}=74)$

ITG

65.13

(25.38)

Ryff Composite

COOP Emotional Status

COOP Social Activities

Total Months Bereaved

Cumulative Lifetime Loss
70.57

(9.38)

2.26

(1.17)

2.05

(1.22)

9.38

(9.92)

4.94

(2.38)
53.88

(11.56)

77.13

(5.49)

2.33

(1.22)

1.89

(.78)

11.38

$(7.61)$

6.78

(1.64)
$-1.11$

.47

$-.06$

.59

$-.42$

${ }^{+}$Target Subsample represents the 26 individuals whose most recent bereavement occurred within 6-12 months of completing the study packet.

Note: Standard Deviations appear in parentheses below means.

$* p<.05$ 
Table 15

Pearson Correlational Matrix of Outcome Variables: Target Subsample ${ }^{+}$and Whole Sample

\begin{tabular}{lllllll}
\hline & Measure & 1 & 2 & 3 & 4 & 5 \\
\hline 1 & GDS - 15 & - & $.81 * * *$ & .25 & $.57 * * *$ & $.78 * *$ \\
2 & ITG & $.76^{* * *}$ & - & .12 & $.58 * *$ & $.77 * *$ \\
3 & Ryff Composite & .22 & .21 & - & .25 & .21 \\
4 & $\begin{array}{l}\text { COOP } \\
\text { Emotional Status }\end{array}$ & $.57^{* * *}$ & $.60 * * *$ & .17 & - & $.63 * * *$ \\
5 & $\begin{array}{l}\text { COOP Social } \\
\text { Activities }\end{array}$ & $.56^{* * *}$ & $.53 * * *$ & -.03 & $.41 * *$ & - \\
\hline
\end{tabular}

${ }^{+}$Target Subsample represents the 26 individuals whose most recent bereavement occurred within 6-12 months of completing the study packet.

Note: Spearman's rho correlations were performed for all GDS - 15 comparisons for the whole sample. All other comparisons reflect Pearson correlations. Correlations for the whole sample are located in the shaded area.

$* \mathrm{p}<.05, * * \mathrm{p}<.01, * * * \mathrm{p}<.001$ 
Table 16

Cross Tabulations of Number of Reported Bereavements (Too Little, Moderate, Too Much) and Bereavement Outcome (Resilient and Non-Resilient) for the Target Subsample

\begin{tabular}{lccc} 
& & Bereavement Outcome & \\
\cline { 2 - 3 } Bereavements & Non-Resilient & Resilient & Total \\
Minimal loss & 2 & 1 & 3 \\
Moderate & 12 & 3 & 15 \\
Too much loss & 5 & 3 & 8 \\
Total & 19 & 7 & 26 \\
${ }^{+}$Target Subsample represents those individuals whose most recent bereavement \\
occurred within 6-12 months of completing the study packet.
\end{tabular}


Table 17

Cross Tabulations of Number of Reported Bereavements (Too Little, Moderate, Too Much) and Bereavement Outcome (Resilient and Non-Resilient) for the Whole Sample $(N=74)$

\begin{tabular}{lccc} 
Bereavements & \multicolumn{2}{c}{ Bereavement Outcome } & \\
\cline { 1 - 2 } Minimal loss & $\begin{array}{c}\text { Non- } \\
\text { Resilient }\end{array}$ & Resilient & Total \\
Moderate & 13 & 2 & 15 \\
Too much loss & 34 & 5 & 39 \\
Total & 12 & 4 & 16 \\
\hline
\end{tabular}


Table 18

Correlational Matrix of Emotion Regulation Variables: Target Subsample ${ }^{+}$and Whole Sample

\begin{tabular}{|c|c|c|c|c|c|}
\hline \multicolumn{2}{|c|}{ Measure } & 1 & 2 & 3 & 4 \\
\hline 1 & PANAS Positive & - &.-.36 & -.16 & -.06 \\
\hline 2 & PANAS Negative & -.16 & - & $.60 * *$ & -.06 \\
\hline 3 & STAI - Y & -.21 & $.52 * * *$ & - & -.27 \\
\hline 4 & $\mathrm{MC}$ & -.08 & $-.38 * *$ & -.10 & - \\
\hline
\end{tabular}

${ }^{+}$Target Subsample represents the 26 individuals whose most recent bereavement occurred within 6-12 months of completing the study packet.

Note: Spearman's rho correlations were performed for all PANAS Negative comparisons for the whole sample. All other comparisons reflect Pearson correlations. Correlations for the whole sample are located in the shaded area.

$* \mathrm{p}<.05, * * \mathrm{p}<.01, * * * \mathrm{p}<.001$ 
Table 19

Means of Emotional Regulation and Coping Variables between Resilient $(n=7)$ and Non-Resilient Grievers $(n=19)$ for the Target Subsample ${ }^{+}(n=26)$

\begin{tabular}{lcccc}
\hline & Resilient & $\begin{array}{c}\text { Non- } \\
\text { Resilient }\end{array}$ & & \\
\cline { 2 - 3 } & $M(S D)$ & $M(S D)$ & & \\
\hline & & & & \\
PANAS Positive & $25.42(9.20)$ & $24.39(8.15)$ & -.28 & 24 \\
PANAS Negative & $13.42(3.95)$ & $21.88(7.17)$ & $2.94 * *$ & 24 \\
STAI - Y & $30.96(5.94)$ & $35.73(8.86)$ & 1.30 & 22 \\
MC & $18.04(6.96)$ & $20.38(5.07)$ & .95 & 24 \\
\hline
\end{tabular}

${ }^{+}$Target Subsample represents those individuals whose most recent bereavement occurred within 6-12 months of completing the study packet.

$* * \mathrm{p}<.01$ 
Table 20

Means of Emotional Regulation and Coping Variables between Resilient

$(n=11)$ and Non-Resilient Grievers $(n=59)$ for the Whole Sample $(N=74)$

\begin{tabular}{lcccc}
\hline & Resilient & $\begin{array}{c}\text { Non- } \\
\text { Resilient }\end{array}$ & & \\
\cline { 2 - 3 } & $M(S D)$ & $M(S D)$ & $t$ & $d f$ \\
\hline PANAS Positive & $28.62(9.66)$ & $25.22(9.65)$ & -1.07 & 65 \\
PANAS Negative & $16.27(6.05)$ & $21.92(9.19)$ & - & - \\
STAI - Y & $31.98(9.43)$ & $38.70(9.34)$ & $2.17 *$ & 63 \\
MC & $22.15(4.87)$ & $19.69(5.69)$ & -1.33 & 64 \\
\hline$* \mathrm{p}<.05$ & & &
\end{tabular}


Table 21

Logistic Regression Predicting Likelihood of Bereavement Outcome (Resilient or NonResilient: Target Subsample ${ }^{+}(n=26)$

\begin{tabular}{|c|c|c|c|c|c|c|c|c|}
\hline & \multirow[t]{2}{*}{$B$} & \multirow[t]{2}{*}{ S.E. } & \multirow[t]{2}{*}{ Wald } & \multirow[t]{2}{*}{$d f$} & \multirow[t]{2}{*}{$p$} & \multirow[t]{2}{*}{$\operatorname{Exp}(B)$} & \multicolumn{2}{|c|}{$\begin{array}{c}95 \% \text { CI for Odds } \\
\text { Ratio }\end{array}$} \\
\hline & & & & & & & Lower & Upper \\
\hline $\begin{array}{l}\text { Total } \\
\text { Deaths }\end{array}$ & -.05 & .19 & .06 & 1 & .81 & .96 & .66 & 1.39 \\
\hline Constant & -.75 & 1.12 & .46 & 1 & .50 & .47 & & \\
\hline
\end{tabular}


Table 22

Logistic Regression Predicting Likelihood of Bereavement Outcome (Resilient or NonResilient: Whole Sample $(N=74)$

\begin{tabular}{lcccccccc} 
& $B$ & S.E. & Wald & $d f$ & $p$ & $\operatorname{Exp}(\mathrm{B})$ & $\begin{array}{c}95 \% \text { CI for Odds } \\
\text { Ratio } \\
\text { Lower }\end{array}$ & Upper \\
\hline $\begin{array}{l}\text { Total } \\
\text { Deaths }\end{array}$ & -.23 & .26 & .79 & 1 & .38 & .80 & .48 & 1.32 \\
Constant & 2.04 & 1.21 & 2.86 & 1 & .09 & .13 & & \\
\hline
\end{tabular}


Table 23

Pearson Correlations between Emotion Regulation and Outcome Variables: Target Subsample

\begin{tabular}{lccccc}
\hline Variable & GDS - 15 & ITG & $\begin{array}{c}\text { Ryff } \\
\text { Composite }\end{array}$ & $\begin{array}{c}\text { COOP } \\
\text { Emotional } \\
\text { Status }\end{array}$ & $\begin{array}{c}\text { COOP } \\
\text { Social } \\
\text { Activities }\end{array}$ \\
Affective Complexity & -.12 & -.15 & -.04 & $-.41^{*}$ & -.32 \\
Positive Emotions & -.33 & -.37 & .07 & -.38 & $-.41^{*}$ \\
\hline
\end{tabular}

${ }^{+}$Target Subsample represents those individuals whose most recent bereavement occurred within 6-12 months of completing the study packet.

$* \mathrm{p}<.05$ 
Table 24

Bivariate Correlations between Emotion Regulation and Outcome Variables: Whole Sample

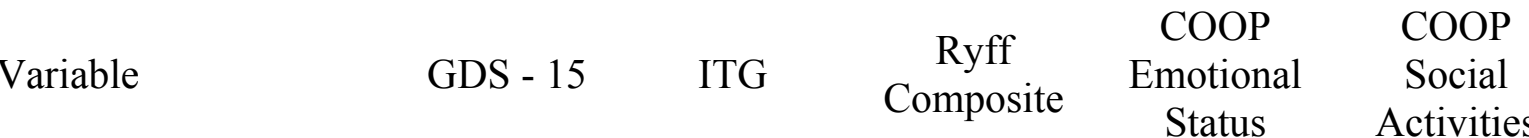

$\begin{array}{llllll}\text { Affective Complexity } & -.22 & -.15 & .11 & -.28^{*} & -.12\end{array}$

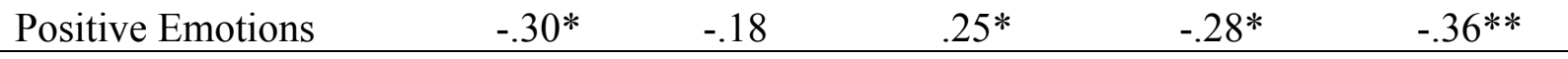

Note: Spearman's rho correlations were performed for all GDS - 15 comparisons. All other comparisons reflect Pearson correlations.

$$
* \mathrm{p}<.05, * * \mathrm{p}<.01
$$


Table 25

Cross Tabulations of Depression History and Bereavement Outcome (Resilient and NonResilient) for the Whole Sample $(N=74)$

\begin{tabular}{cccc}
\hline & & Bereavement Outcome & \\
Depression History & Non-Resilient & Resilient & Total \\
Absent & 14 & 22 & 36 \\
Present & 23 & 12 & 35 \\
Total & 37 & 34 & 71 \\
\hline
\end{tabular}


Table 26

Means of Emotional Regulation and Coping Variables between Resilient $(n=11)$ and Non-Resilient Grievers $(n=59)$ for the Whole Sample $(N=74)$

\begin{tabular}{cccc} 
Resilient & Non-Resilient & & \\
\hline$M(S D)$ & $M(S D)$ & $t$ & $d f$ \\
\hline
\end{tabular}

$\begin{array}{lllll}\text { PANAS Positive (PA) } & 28.93(9.23) & 22.73(9.19) & -2.76^{* *} & 65\end{array}$

PANAS Negative (NA) $17.30(7.44) \quad 24.91(8.96) \quad$ -

STAI - Y

$32.05(7.33) \quad 42.94(8.43)$

$5.59 * * *$

64

$\mathrm{MC}$

$20.79(5.51)$

$19.66(5.72)$

$-.83$

66

Affective Complexity

$.62(.38)$

$.31(.32)$

$-3.58 * * *$

65 
Table 27

Logistic Regression Predicting Likelihood of Bereavement Outcome (Resilient or NonResilient) based on Affective Complexity: Whole Sample $(N=74)$

\begin{tabular}{lcccccccc}
\hline & $B$ & S.E. Wald & $d f$ & $p$ & $\operatorname{Exp}(\mathrm{B})$ & $\begin{array}{c}95 \% \text { CI for Odds } \\
\text { Ratio }\end{array}$ \\
& & & & & & & Lower & Upper \\
\hline $\begin{array}{l}\text { Affective } \\
\text { Complexity }\end{array}$ & 2.41 & .77 & 9.88 & 1 & .002 & 11.08 & 2.48 & 49.69 \\
Constant & -1.15 & .44 & 6.8 & 1 & .09 & .318 & & \\
\hline
\end{tabular}


Table 28

Logistic Regression Predicting Likelihood of Bereavement Outcome (Resilient or NonResilient) based on Positive and Negative Affect: Whole Sample $(N=74)$

\begin{tabular}{lccccccccc}
\hline & $B$ & S.E. & Wald & $d f$ & $p$ & Exp(B) & $\begin{array}{c}95 \% \text { CI for Odds } \\
\text { Ratio } \\
\text { Lower }\end{array}$ & Upper \\
\hline PANAS Positive (PA) & .08 & .03 & 5.74 & 1 & .017 & 1.08 & 1.01 & 1.15 \\
PANAS Negative (NA) & -6.24 & 1.88 & 11.02 & 1 & .001 & .002 & .00 & .08 \\
Constant & 6.00 & 2.39 & 6.32 & 1 & .012 & 404.10 & & \\
\hline
\end{tabular}




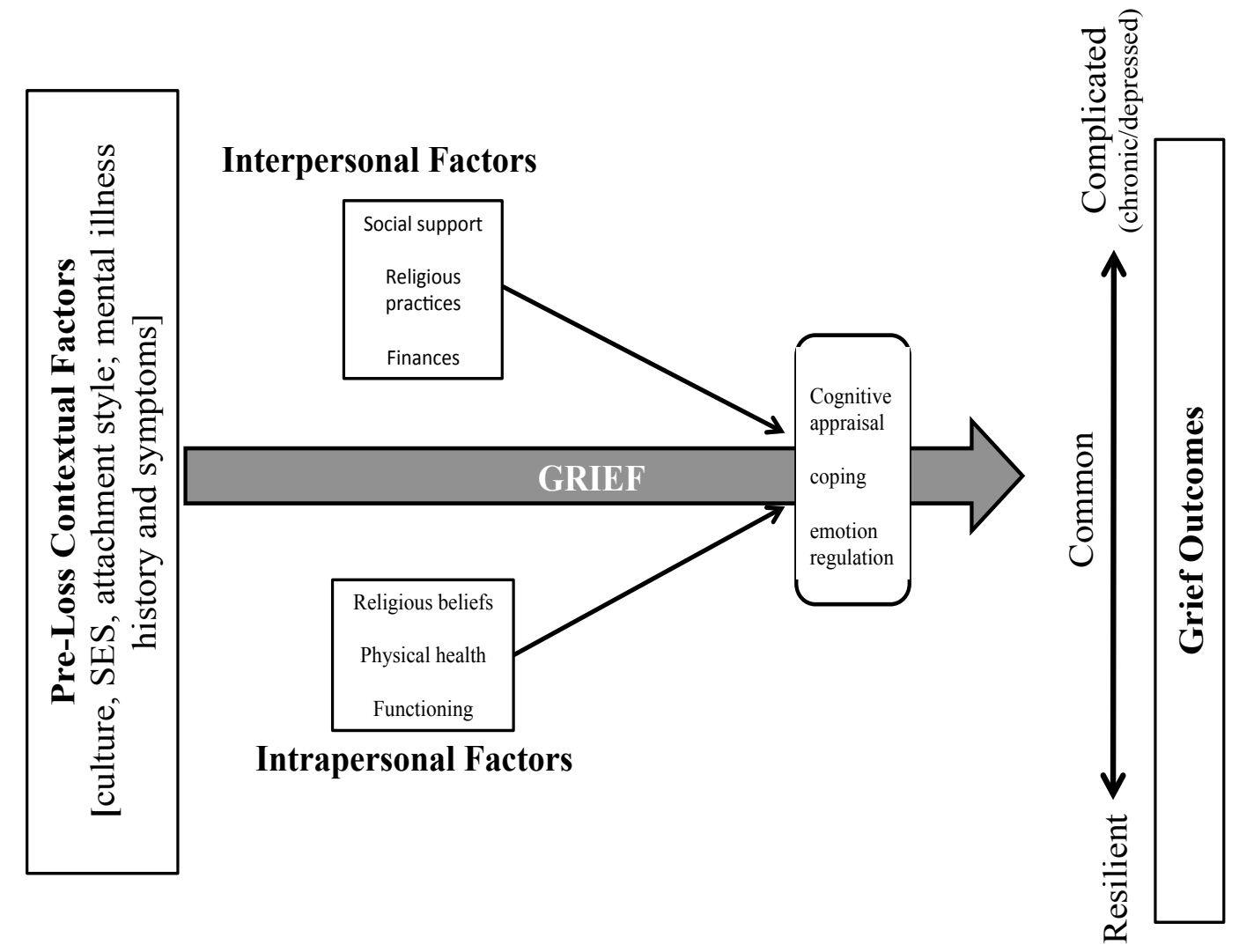

Figure 1. Proposed Late-Life Comprehensive Bereavement Outcome Framework. From "Late-Life Bereavement and Complicated Grief: A Proposed Comprehensive Framework," by S. N. Shah and S. Meeks (2012), Aging and Mental Health, 16(1), 3956. 


\section{Appendix A}

\section{DEMOGRAPHIC INFORMATION}

TODAY'S DATE: (month/day/year)

AGE:

GENDER: Female Male (Circle one)

RACE: (check one)

$\begin{array}{lll}\square \quad \text { White (Non-Hispanic) } & \square \text { Hispanic } \\ \square \quad \text { African - American (Non-Hispanic) } & \square \quad \text { Asian } \\ \square \quad \text { Other (specify) }\end{array}$

CURRENT MARITIAL STATUS: (check one)

$\begin{array}{lll}\square & \text { Married } & \square \quad \text { Never Married } \\ \square & \text { Separated } & \text { Divorced } \\ \square & \text { Widowed } & \end{array}$

CURRENT LIVING SITUATION: (check one)
Living Alone
Living with spouse/partner
Living with spouse/partner and children
Live with children only
Other (specify):

EDUCATION: (check highest level completed)

$\begin{array}{lll}\square & \text { Less than } 12^{\text {th }} \text { grade } & \square \quad \text { College Degree } \\ \square & \text { High School Graduate/GED } & \square \quad \text { Graduate Degree } \\ \square & \text { Some College }\end{array}$


EMPLOYMENT: (check all that apply)
Full-time job
Disabled
Part-time job
Retired
Homemaker

Please specify your occupation if you are currently employed:

HOUSEHOLD INCOME:

$\begin{array}{lll}\square<\$ 10,000 & \square \quad \$ 40,000-\$ 59,999 \\ \square \quad \$ 10,000-\$ 19,999 & \square \quad \$ 60,000-\$ 100,000 \\ \square \quad \$ 20,000-\$ 39,000 & \square>\$ 100,000\end{array}$

\section{Questions about your most recent loss:}

1. When were you last bereaved?

2. What is your relationship to your lost loved one? (check one)

$\begin{array}{lll}\square \text { Spouse } & \square \text { Daughter } \\ \square \text { Son } & \square \text { Extended family (cousin, aunt, uncle, etc.) } \\ \square \text { Parent } & \square \text { Grandchild } \\ \square \text { Other (specify): } & & \end{array}$

3. How did your loved one pass away (e.g. illness, car accident, natural death)? 


\section{APPENDIX B}

\section{BEREAVEMENT HISTORY}

Adapted from the Grief Evaluation Measure Jordan, Baker, Matteis, Rosenthal \& Ware, 2005

Please list below all the loved ones in your life who have died. DO NOT INCLUDE THE PERSON WHOM YOU ARE CURRENTLY GRIEVING. Please also rate from "none" to "very great" the impact the death had on you. If there has been more than eight losses, please continue on the other side of this page.

\begin{tabular}{|c|c|c|c|c|c|c|c|}
\hline \multirow{2}{*}{$\begin{array}{l}\text { CATEGORY } \\
\text { (e.g., parent, } \\
\text { child, } \\
\text { grandparent, } \\
\text { sibling, friend, } \\
\text { spouse/partner) }\end{array}$} & $\begin{array}{l}\text { Year of } \\
\text { Death }\end{array}$ & \multicolumn{6}{|c|}{ IMPACT OF DEATH } \\
\hline & & None & $\begin{array}{l}\text { Very } \\
\text { Slight }\end{array}$ & Slight & $\begin{array}{l}\text { Slightly } \\
\text { Great }\end{array}$ & Great & $\begin{array}{l}\text { Very } \\
\text { Great }\end{array}$ \\
\hline & & None & $\begin{array}{l}\text { Very } \\
\text { Slight }\end{array}$ & Slight & $\begin{array}{l}\text { Slightly } \\
\text { Great }\end{array}$ & Great & $\begin{array}{l}\text { Very } \\
\text { Great }\end{array}$ \\
\hline & & None & $\begin{array}{l}\text { Very } \\
\text { Slight }\end{array}$ & Slight & $\begin{array}{l}\text { Slightly } \\
\text { Great }\end{array}$ & Great & $\begin{array}{l}\text { Very } \\
\text { Great }\end{array}$ \\
\hline & & None & $\begin{array}{l}\text { Very } \\
\text { Slight }\end{array}$ & Slight & $\begin{array}{l}\text { Slightly } \\
\text { Great }\end{array}$ & Great & $\begin{array}{l}\text { Very } \\
\text { Great }\end{array}$ \\
\hline & & None & $\begin{array}{l}\text { Very } \\
\text { Slight }\end{array}$ & Slight & $\begin{array}{l}\text { Slightly } \\
\text { Great }\end{array}$ & Great & $\begin{array}{l}\text { Very } \\
\text { Great }\end{array}$ \\
\hline & & None & $\begin{array}{l}\text { Very } \\
\text { Slight }\end{array}$ & Slight & $\begin{array}{l}\text { Slightly } \\
\text { Great }\end{array}$ & Great & $\begin{array}{l}\text { Very } \\
\text { Great }\end{array}$ \\
\hline & & None & $\begin{array}{l}\text { Very } \\
\text { Slight }\end{array}$ & Slight & $\begin{array}{l}\text { Slightly } \\
\text { Great }\end{array}$ & Great & $\begin{array}{l}\text { Very } \\
\text { Great }\end{array}$ \\
\hline & & None & $\begin{array}{l}\text { Very } \\
\text { Slight }\end{array}$ & Slight & $\begin{array}{l}\text { Slightly } \\
\text { Great }\end{array}$ & Great & $\begin{array}{l}\text { Very } \\
\text { Great }\end{array}$ \\
\hline
\end{tabular}




\section{APPENDIX C}

\section{HISTORY OF EMOTIONAL PROBLEMS}

\section{Please answer the following questions about your past emotional well-being: (circle Yes or NO)}

Have you ever been....

\begin{tabular}{|c|c|c|}
\hline $\begin{array}{l}\text {...diagnosed with a mental or emotional } \\
\text { problem? }\end{array}$ & YES & $\mathrm{NO}$ \\
\hline $\begin{array}{l}\ldots \text { in treatment with a mental health } \\
\text { professional?.................................. }\end{array}$ & YES & $\mathrm{NO}$ \\
\hline $\begin{array}{l}\text {...prescribed medication for a mental or } \\
\text { emotional problem? }\end{array}$ & YES & $\mathrm{NO}$ \\
\hline $\begin{array}{l}\ldots \text { been hospitalized for such a } \\
\text { problem? }\end{array}$ & YES & $\mathrm{NO}$ \\
\hline
\end{tabular}

1. Have you ever had a period when you were feeling depressed or down most of the day nearly everyday? YES or NO? (circle one)

2. Have you ever had a time when you lost interest or pleasure in things you usually enjoyed? YES or NO (circle one)

**If you answered NO to Questions 1 AND 2, you may stop here and go on to the next questionnaire.

**If you answered YES to Questions 1 or 2, please proceed with the following questions:

3. During that time, did you lose interest or pleasure in things you usually enjoyed? YES or NO? (circle one) 
4. If you've had more than one time like that, focus on the worse two weeks you felt when answering the following questions. Circle YES or NO.

\begin{tabular}{|r|l|l|l|}
\hline a. & Did you have weight loss or a decreased appetite? & YES & NO \\
\hline b. & Did you have weight gain or an increase in appetite? & YES & NO \\
\hline c. & Did you sleep less than normal, nearly everyday? & YES & NO \\
\hline d. & Did you sleep more than normal, nearly everyday? & YES & NO \\
\hline e. & $\begin{array}{l}\text { Did you feel markedly restless and fidgety, nearly } \\
\text { everyday? }\end{array}$ & YES & NO \\
\hline f. & $\begin{array}{l}\text { Did you find yourself moving markedly slower than } \\
\text { usual, nearly everyday? }\end{array}$ & YES & NO \\
\hline g. & Did you feel fatigued/low energy, nearly everyday? & YES & NO \\
\hline h. & $\begin{array}{l}\text { Did you have trouble concentrating or making } \\
\text { decisions, nearly everyday day? }\end{array}$ & YES & NO \\
\hline & Did you have thoughts of death or hurting yourself? & YES & NO \\
\hline
\end{tabular}




\title{
CURRICULUM VITAE
}

\author{
SHRUTI N. SHAH \\ 502.550.4741 • shrutishah128@gmail.com • 1000 Escalon Ave, Apt. E-2035 \\ Sunnyvale, CA 94085
}

\section{EDUCATION}

Ph.D. in Clinical Psychology

2007 - Present

Area of Concentration: Gerontology

University of Louisville, Louisville, KY

Dissertation: Resilience in Late-Life Bereavement: Disentangling the

Relationship between Resilience and Cumulative Lifetime Loss

Estimated Defense: July 2013

Chair: Suzanne Meeks, Ph.D.

\section{M.A. in Clinical Psychology}

2010

University of Louisville, Louisville, KY

\section{B.A. in Psychology}

2006

Area of Concentration: Natural Sciences

University of Louisville, Louisville, KY

Summa Cum Laude

\section{AREAS OF INTEREST}

- Late-Life Bereavement Outcomes

- Grief Trajectories; Complicated Grief; Anticipatory Grief

- Aging and Mental Health; Mood and Chronic Illness

- Non-pharmacological Interventions for Late-Life Mood Disorders 


\section{AWARDS}

Stanley A. Murrell Scientist-Practitioner Award, Recipient, Noble H. 2012

Kelley Psychological Services Center, University of Louisville

Stanley A. Murrell Scientist-Practitioner Award, Nominee, Noble H. 2011

Kelley Psychological Services Center, University of Louisville

University Graduate Fellowship, Dept. of Psychological \& Brain 2007 - 2009

Sciences, University of Louisville

Amber Huerman Undergraduate Honors Research Fund, University of 2006

Louisville

National Dean's List 2006

Woodcock Honor Society, Arts \& Sciences Award, University of 2004

Louisville

Dean's List, College of Arts \& Sciences, University of Louisville 2002,2004-

\section{CLINICAL EXPERIENCE}

Veteran's Affairs Palo Alto Health Care System,

2013 - Present

Palo Alto, CA

APA Accredited Postdoctoral Clinical Psychology Fellowship

Area of Emphasis: Clinical Geropsychology

Clinical Rotations:

- Geriatric Research, Education and Clinical Center

- Memory Clinic

- Geropsychology Community Living Center

- Spinal Cord Injury Service

Veteran's Affairs Palo Alto Health Care System,

Palo Alto, CA

APA Accredited Pre-doctoral Clinical Psychology Internship

Clinical Rotations:

- Hospice and Palliative Care Center/Sub-Acute Medicine Unit

- Women's Trauma Recovery Program

- Home-Based Primary Care Program

- Intensive Treatment Unit (Impatient Psychiatry)

BE-ACTIV: Treating Depression in Nursing Homes,

University of Louisville, Louisville, KY

Principal Investigator: Suzanne Meeks, Ph.D.

Delivered a 10-week behavioral intervention to depressed nursing home residents. 
Noble H. Kelley Psychological Services Center, University of

Louisville, Louisville, KY

Graduate student therapist on the following clinical teams:

Geropsychology Assessment and Intervention Team $2009-2011$

Interpersonal Psychotherapy Clinical Team $\quad 2007-2009$

Psychological Assessment

$2008-2011$

Wedgewood Healthcare Center, Clarksville, IN

$2007-2008$

Graduate student therapist; delivered psychological services (brief cognitive assessments and psychotherapy) to depressed or anxious nursing home residents, with or without co-occurring cognitive impairment.

\section{WORK-RELATED EXPERIENCE}

Central State Hospital, Louisville, KY

Mental Health Technician

Worked in an adult impatient psychiatric hospital for patients with acute psychiatric disorders. Responsibilities included facilitating and maintaining a safe and comfortable environment for patients and staff, conducting routine checks with patients, alerting staff members of disruptive or dangerous behaviors, and providing one-on-one supervision with suicidal patients. Attended daily meetings with nursing staff and psychiatrics to determine patient treatment and discharge status.

\section{RESEARCH EXPERIENCE}

Dissertation: Resilience in Late-Life Bereavement: 2011 - Present Disentangling the Relationship Between Resilience and Cumulative Lifetime Loss

Project Director

Supervisor: Suzanne Meeks, Ph.D.

The purpose of this study is to examine the relationship between cumulative lifetime loss and late-life grief outcome, with an emphasis on understanding how bereavement-related coping and emotion regulation variables mediate the relationship between cumulative lifetime loss and resilient bereavement outcomes. Recently bereaved older individuals in and around the Louisville metropolitan area were asked to complete a series of questionnaires regarding their demographics, bereavement history, history of depression, coping and emotional functioning during their most recent bereavement, and post-loss psychosocial functioning.

BE-ACTIV: Treating Depression in Nursing Homes, $2008-2012$

\section{University of Louisville}

Graduate Research Assistant

Principal Investigator: Suzanne Meeks, Ph.D.

BE-ACTIV is an NIMH RO1 funded intervention study designed to treat depression in nursing home residents. The purpose of this study is to examine the effectiveness of a ten- 
week behavioral activation intervention for depressed nursing home residents. Responsibilities include conducting individual intervention with residents which involves discussing the study rationale, scheduling pleasant events, discussing barriers for successful engagement in pleasant events, and reinforcing progress. Data is collected from residents, activities staff, and CNAs, which include assessments of mood, pleasant events, working alliance, and memory and behavior problems. Random chart reviews are conducted to evaluate the quality of documentation pertaining to depression diagnoses and antidepressant use. Data entry is also routinely entered into SPSS and Filemaker databases.

Understanding Anxiety in Older Adults with Dementia Residing $\quad 2008-2009$ in Nursing Home Homes, University of Louisville

Project Director: Lauren Hess, Ph.D.

Assisted fellow graduate student with recruitment and data collection for a pilot study whose purpose was to better understand anxiety in older adults with dementia residing in nursing homes and to examine the psychometric properties of the Rating Anxiety in Dementia scale for this population. Responsibilities included recruiting nursing homes in and around the Louisville Area for participation in the study, completing psychodiagnostic and neuropsychological assessments with residents and informants, gathering data from residents' nursing home charts, and entering and tracking data. Additional duties included assisting with data analysis, submitting abstracts, and presenting results at a conference.

Validation of The Pleasant Event Schedule, Nursing Home Version, University of Louisville

Undergraduate Research Assistant

Principle Investigator: Suzanne Meeks, Ph.D.

Assisted in the data collection of a study whose purpose was validate the use of the Pleasant Event Schedule for a nursing home population. Responsibilities included conducting neuropsychological, psychodiagnostic, and pleasant events assessments with consented nursing home residents; gathering information from residents medical charts; and entering data in SPSS databases. Additional responsibilities included assisting the principle investigator with data analyses and preparation for a manuscript.

Organizational Culture in Nursing Homes Dissertation Study, 2005-2006 University of Louisville

Undergraduate Research Assistant

Project Director: Brandy Chaneb, Ph.D.

Assisted in the recruitment of nursing homes and data collection for a dissertation study focusing on the relationships between the organizational culture of the nursing home, staff satisfaction, and resident psychosocial outcomes. Responsibilities included calling and recruiting nursing homes in and around the Louisville area for study participation; conducting neuropsychological and psychodiagnostic assessment with nursing home residents, administering questionnaires to nursing home staff; entering data into an SPSS database; assisting graduate students in the preparation of a poster presentation; and analyzing data and presenting results in an undergraduate senior honors thesis and at a conference. 


\section{GRANTS}

'Resiliency in Late-Life Bereavement: Disentangling the Relationship between Resilience and Cumulative Lifetime Loss'. University of Louisville Intramural Research Initiation Grant, \$3,034. Time Period: 01/01/2012 - 12/31/2012.

\section{PUBLICATIONS}

Gerstenecker, A., Mast, B. T., Shah, S., \& Meeks, S. (in press). Tracking the cognition of nursing home residents. Clinical Gerontologist.

Shah, S. N. Meeks, S. (2012). Late-Life Bereavement and Complicated Grief: A Proposed Comprehensive Framework. Aging \& Mental Health, 16(1), 39-56.

Shah, S. N., Shoenbachler, B., Streim, J. \& Meeks, S. (2011). Antidepressant prescribing in nursing homes: Second-generation issues revisited. Journal of the American Medical Directors Association, available online.

Meeks, S., Shah, S., \& Ramsey, S. (2009). The Pleasant Events Scale- Nursing Home Versions: A Useful Tool for Behavioral Interventions in Long Term Care. Aging \& Mental Health, 13(3), 445-455.

\section{PRESENTATIONS}

Imel, J., Shah, S., \& Meeks, S. (2013, November). Comparing Resiliency in Early and LateLife Bereavement. Poster accepted to the Gerontological Society of America's $66^{\text {th }}$ Annual Scientific Meeting, New Orleans, LA.

Getz, B. G., Kostiwa, I., Shah, S.N., Ludwin, B., \& Meeks, S. (2012, November). Employee perception of employer expectation and its relation to job satisfaction in the nursing home. Poster presented at the Gerontological Society of America's $65^{\text {th }}$ Annual Scientific Meeting, San Diego, CA.

Shah, S. N., Getz, B., Ludwin, B., Kostiwa, I., \& Meeks, S. (2012, November). An examination of the utility of the Revised Memory and Behavior Problems Checklist- Nursing Home version $(R M B P C-N H)$ in a depressed long-term care resident sample. Poster presented at the Gerontological Society of America's $65^{\text {th }}$ Annual Scientific Meeting, San Diego, CA.

Imel, J., Shah, S., \& Meeks, S. (2012, August). Comparing Early and Late-Life Bereavement. Poster presented at the University of Louisville Summer Research Opportunity Program Research Day, Louisville, KY

Gerstenecker, A., Shah, S., Meeks, S., \& Mast, B. (2011, November). Tracking the 
performance of nursing home residents on the MMSE: Can variability be used to predict a dementia diagnosis? Paper presented at the Gerontological Society of America's $64^{\text {th }}$ Annual Scientific Meeting, Boston, MA.

Shah, S., Meeks, S., Schoenbachler, B., \& Streim, J. (2010, November). Antidepressants prescribing in the nursing home: Second-generation issues revisited. Poster presented at the Gerontological Society of America's $63^{\text {rd }}$ Annual Scientific Meeting, New Orleans, LA.

Hess, L.S., Shah, S., \& Meeks, S. (2009, November). Assessing anxiety and agitation in nursing home residents with dementia. Poster presented at the Gerontological Society of America's $62^{\text {nd }}$ Annual Scientific Meeting, Atlanta, GA.

Hess, L.S., Shah, S., \& Meeks, S. (2008, July). Assessing anxiety and agitation among nursing home residents with Alzheimer's disease. Paper Presented at the International Conference on Alzheimer's Disease 2008, Chicago, IL.

Rodgers, J.R., Chaneb, B.J., Kostiwa, I.M., Shah, S. N., \& Meeks, S. (2006, April). Organizational culture and resident outcomes in nursing homes. Paper presented at the Seventeenth Annual Southeastern Regional Student Mentoring. Conference in Gerontology and Geriatrics, Lexington, KY.

Shah, S., Chaneb, B., Kostiwa, I., Rodgers, J., \& Meeks, S. (2006, April). An Evaluation of Depression and Quality of Life for Nursing Home Residents in Relation to Staff-Resident Relationships, Social Interaction and Organizational Culture. Paper presented at the Seventeenth Annual Southeastern Regional Student Mentoring Conference in Gerontology and Geriatrics, Lexington, KY.

\section{TEACHING EXPERIENCE}

Resources for Academic Achievement (REACH), 2006 University of Louisville

Tutor \& Teaching Assistant

Course: Abnormal Psychology

Assisted undergraduate students who were enrolled in a summer Abnormal Psychology course. Conducted group and individual tutoring, provided students with handouts and notes, and attended weekly class meetings. Lectured one class on panic disorders.

Depression During the Holiday's,

Arthur S. Kling Senior Health \& Wellness Center, Louisville, KY

Presented tips and methods of coping with depression during holiday seasons to a group of community-dwelling older individuals at the Kling Senior Center. 


\title{
PROFESSIONAL SERVICES
}

\author{
Graduate Student Peer Mentor, University of Louisville
}

Act as a mentor and confidant for first and second year clinical psychology

graduate students.

Clinical Psychology Alternate Student Representative,

Dept. of Psychological \& Brain Sciences, University of Louisville

Fulfilled the roles and responsibilities as Clinical Psychology Student Representative

if the current student representative was unable to do so.

Clinical Psychology Student Representative,

Dept. of Psychological \& Brain Sciences, University of Louisville

Functioned as a liaison between the clinical psychology student body and clinical psychology faculty members. Attended clinical psychology faculty meetings, presented issues and/or concerns brought forth by the study body, and assisted the program's Director of Clinical Training with applicant interviews and preparation for APA site visits.

\section{VOLUNTEER SERVICES}

Kentucky Regional Science Fair, University of Louisville

Social Sciences Judge

Evaluated the quality and content of high school students' social sciences projects in at the Kentucky Regional Science Fair. Presented evaluations with other judges to determine winners within the social sciences group.

Kentucky Refugee Ministries, Louisville, KY

Volunteer for Elder Refugee Program

Visited with elder refugees from various countries. Had routine one-on-one visits with an elder Afghani refugee during which we discussed cultural differences and the process of adjusting to American culture.

Kentucky Psychological Association, Spring Academic Conference, Lexington, $\mathrm{KY}$

Psych Bowl Judge

Worked at a conference judging the KPA Psych Bowl. Read questions and evaluated responses to determine winner of the bowl.

Clinical Psychology Doctoral Program, University of Louisville

Applicant Interview Coordinator

Worked the clinical psychology student body and program director to prepare for

applicant interviews. Scheduled applicant interview dates and coordinated interviews between applicants, current graduate students and faculty. 
Home of the Innocents, Louisville, KY

Adolescent Girls Gheen's House Volunteer

Worked with at-risk or abused and/or neglected teenage girls. Focused on behavior modification, appropriate social interaction, manner/etiquette, and ways of seeking role models.

Kentucky Psychological Association, Kentucky State Fair, Louisville, KY 2005

Volunteer for the Heads Up Kentucky Booth

Promoted healthy mind-body awareness and provided information about the Kentucky

Psychological Association and psychological services around the Louisville area.

\section{PROFESSIONAL MEMBERSHIPS}

Kentucky Psychological Association

Gerontological Society of America

American Psychological Association

Clinical Geropsychology, 12/II
$2006-2012$

2007 - Present

2011 - Present 